\title{
Persistent Organic Nanopores Amenable to Structural and Functional Tuning
}

Xiaoxi Wei, ${ }^{\dagger \ddagger}$ Guoqing Zhang, ${ }^{\dagger \dagger}$ Yi Shen, ${ }^{\| \star}$ Yulong Zhong, ${ }^{\dagger}$ Rui Liu, ${ }^{\dagger \oplus}$ Na Yang, ${ }^{\dagger}$ Fayez Y. Al-mkhaizim, ${ }^{\natural}$ Mark Kline, ${ }^{\natural}$ Lan He, ${ }^{\S}$ Minfeng Li, ${ }^{\dagger}$ Zhong-Lin Lu, ${ }^{\dagger *}$ Zhifeng Shao, ${ }^{\| *}$ and Bing Gong I†** $^{*}$

${ }^{\dagger}$ College of Chemistry, Beijing Normal University, Beijing 100875, China

" Department of Chemistry, The State University of New York at Buffalo, Buffalo, New York 14260, United States

" School of Biomedical Engineering, Shanghai Jiao Tong University, Shanghai 200240, China

$\S$ National Institute for Food and Drug Control, Beijing 100050, China

\section{Supporting Information}

I. General Information $\quad$ S2

II. Synthesis and Characterization of Macrocycles 2 S3

III. $\quad{ }^{1} \mathrm{H}$ and ${ }^{13} \mathrm{C}$ NMR Spectra of Macrocycles $2 \quad$ S6

IV. High-Resolution MALDI-FT-ICR Spectra of Macrocycles 2 S10

V. Synthesis and Characterization of Precursors $\quad$ S14

VI. $\quad{ }^{1} \mathrm{H}$ and ${ }^{13} \mathrm{C}$ NMR Spectra of Precursors $\quad$ S24

VII. $\quad{ }^{1}$ H NMR Comparison of 2 in Different Solvents $\quad$ S29

$\begin{array}{ll}\text { VIII. Fluorescence Spectra } & \text { S37 }\end{array}$

IX. CD spectra $\quad$ S39

$\begin{array}{ll}\text { X. Atomic Force Microscopy } & \mathbf{S 4 0}\end{array}$

XI. Stopped-Flow Kinetic Assays $\quad$ S44

XII. Liposome-Based Assays on Chloride Transport $\quad$ S45

XIII. Single Channel Electrophysiology $\quad$ S46 


\section{General Information}

Chemicals were purchased from commercial sources and used as received. Reactions requiring an inert gas were all under nitrogen. Silica gel for analytical thin layer chromatography (TLC) and column chromatography (200 300 mesh) were purchased from Qingdao Haiyang Chemical Co. Ltd. \& Special Silica Gel Factory.

Melting points were measured on a microscope hot stage melting point apparatus and are uncorrected. ${ }^{1} \mathrm{H}$ NMR spectra were recorded at $400 \mathrm{MHz}$ on Bruker AV400 spectrometers at ambient temperature using $\mathrm{CDCl}_{3}$ or DMSO- $\mathrm{d}_{6}$, unless otherwise noted. ${ }^{13} \mathrm{C}$ NMR spectra were measured at $101 \mathrm{MHz}$ as above. Chemical shifts ( $\delta$ ) are reported in ppm values downfield of TMS (tetramethylsilane) or solvent residual signals. Coupling constants in 1H NMR spectra are expressed in Hertz. Mass spectra were acquired on a Waters Quattro Mocro spectrometer and high resolution mass spectra were acquired on a Waters LCT Premier XE spectrometer. MS (MALDI-TOF) spectra were performed with an Autoflex III instrument. Scanning electron microscope imaging was performed on Hitachi S-800 scanning electron microscope. Circular dichroism spectra were measured on ChirascanTM from Applied Photophysics Ltd. Fluorescence spectra were measured on a Varian Cary Eclipse spectrometer. UV-Vis spectra were measured on a Varian Cary $300 \mathrm{UV}$-Vis spectrophotometer using solutions in $1.0 \mathrm{~cm}$ quartz cuvettes. 


\section{Synthesis and Characterization of Macrocycles 2}

Scheme S1. Synthesis of macrocycles 2.

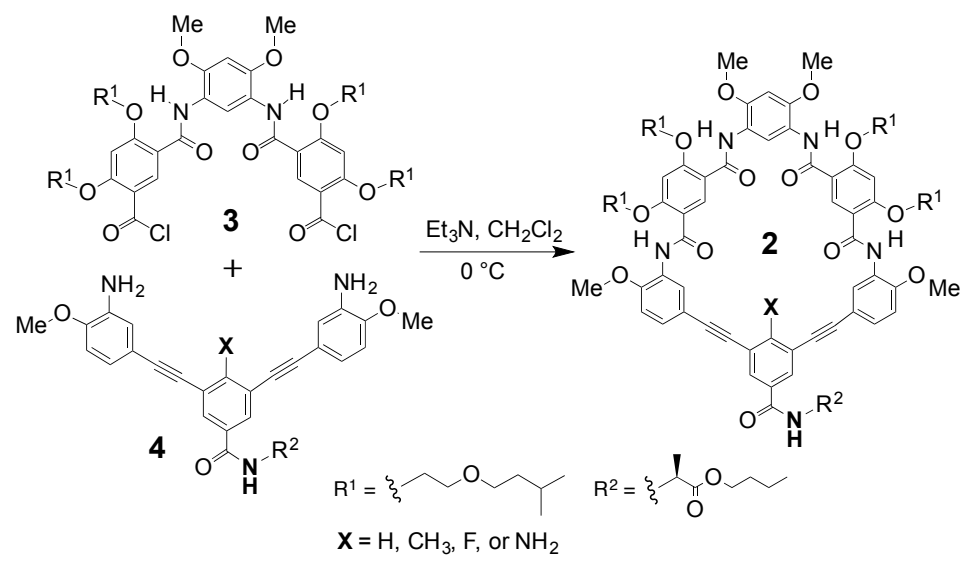

Macrocycle 2-H: A solution of compound $1.5(368 \mathrm{mg}, 0.37 \mathrm{mmol})$ and $\mathrm{SOCl}_{2}(0.5 \mathrm{~mL})$ in $\mathrm{CH}_{2} \mathrm{Cl}_{2}(50 \mathrm{~mL})$ was heated under reflux for $2 \mathrm{hrs}$ with stirring. Concentrating the reaction mixture in vacuo left 3 as a yellow solid that was re-dissolved in dry $\mathrm{CH}_{2} \mathrm{Cl}_{2}(50 \mathrm{~mL})$. The solution of 3 was added dropwise to a solution of compound 4-H (164 mg, $0.304 \mathrm{mmol}$ ) and $\mathrm{Et}_{3} \mathrm{~N}(0.5 \mathrm{~mL})$ in $\mathrm{CH}_{2} \mathrm{Cl}_{2}(50 \mathrm{~mL})$ at $0{ }^{\circ} \mathrm{C}$. The mixture was stirred for $3 \mathrm{hrs}$, followed by washing with water and saturated brine. The organic layer was dried with anhydrous sodium sulfate and then concentrated in vacuo. The remaining solid residue was purified with column chromatography (chloroform/methanol $=10 / 1$, silica gel) to give $\mathbf{2}-\mathbf{H}$ as a white solid (185 mg, 41\%). mp: $255.8-256.9^{\circ} \mathrm{C} .{ }^{1} \mathrm{H}$ NMR (400 MHz, DMSO-d $)$ ) 810.03 (s, 2H), 9.56 (s, 2H), 9.36 (s, 1H), 9.01 (s, 3H), 8.79 (s, 2H), 8.00-7.99 (m, 3H), 7.36 (d, J=8.12 Hz, 2H), 7.16 (d, J=8.12 Hz, 2H), $6.99(\mathrm{~s}, 2 \mathrm{H}), 6.83(\mathrm{~s}, 1 \mathrm{H}), 4.58-4.52(\mathrm{~m}, 9 \mathrm{H}), 4.10-4.09(\mathrm{~m}, 2 \mathrm{H}), 3.98-3.91(\mathrm{~m}, 20 \mathrm{H})$, $3.53-3.50(\mathrm{~m}, 8 \mathrm{H}), 1.59-1.45(\mathrm{~m}, 6 \mathrm{H}), 1.44(\mathrm{~d}, J=7.32 \mathrm{~Hz}, 3 \mathrm{H}), 1.35-1.28(\mathrm{~m}, 10 \mathrm{H}), 0.89(\mathrm{t}, J=$ $7.40 \mathrm{~Hz}, 3 \mathrm{H}), 0.77-0.72(\mathrm{~m}, 24 \mathrm{H}) ;{ }^{13} \mathrm{C}$ NMR $\left(101 \mathrm{MHz}, \mathrm{CDCl}_{3}\right) \delta 173.26,165.66,162.40,162.25$, $159.93,159.51,148.94,145.46,138.65,137.12,134.42,128.99,128.54,126.35,125.03,124.35$, $120.65,115.93,114.80,109.62$, 97.12, 94.33, 92.04, 86.28, 69.68, 69.39, 68.82, 68.66, 65.55, $55.79,55.67,48.76,38.53,30.59,25.00,24.96,22.56,22.51,19.07,18.73,13.66$; HRMS (MALDI-FTICR) m/z Calcd. for $\mathrm{C}_{84} \mathrm{H}_{105} \mathrm{~N}_{5} \mathrm{O}_{19}: 1510.7296\left(\mathrm{M}+\mathrm{Na}^{+}\right)$, Found: $1510.7306(\mathrm{M}+$ $\mathrm{Na}^{+}$). 
Macrocycle 2-Me: A solution of compound $1.5(302 \mathrm{mg}, 0.306 \mathrm{mmol})$ and $\mathrm{SOCl}_{2}(0.5 \mathrm{~mL})$ in $\mathrm{CH}_{2} \mathrm{Cl}_{2}(50.0 \mathrm{~mL})$ was heated under reflux for $2 \mathrm{hrs}$ with stirring. Concentrating the reaction mixture in vacuo left $\mathbf{3}$ as a yellow solid that was re-dissolved in dry $\mathrm{CH}_{2} \mathrm{Cl}_{2}(50.0 \mathrm{~mL})$. The solution of $\mathbf{3}$ was added dropwise to a solution of compound 4-Me (170 mg, $0.307 \mathrm{mmol})$ and $\mathrm{Et}_{3} \mathrm{~N}(0.5 \mathrm{~mL})$ in $\mathrm{CH}_{2} \mathrm{Cl}_{2}(50.0 \mathrm{~mL})$ at $0{ }^{\circ} \mathrm{C}$. The mixture was stirred for $3 \mathrm{hrs}$, followed by washing with water and saturated brine. The organic layer was dried with anhydrous sodium sulfate and then concentrated in vacuo. The remaining solid residue was purified with column chromatography (chloroform/methanol=10/1, silica gel) to give 2-Me as a white solid (67 mg, 15\%). mp: $114.3-115.9^{\circ} \mathrm{C} .{ }^{1} \mathrm{H}$ NMR (400 MHz, DMSO-d 6 ) $\delta 10.05$ (s, 2H), 9.57 (s, 2H), 9.33 (s, 1H), $9.00(\mathrm{~s}, 3 \mathrm{H}), 8.82(\mathrm{~d}, J=1.64 \mathrm{~Hz}, 2 \mathrm{H}), 8.00(\mathrm{~s}, 2 \mathrm{H}), 7.35(\mathrm{~d}, J=8.04 \mathrm{~Hz}, 2 \mathrm{H}), 7.17(\mathrm{~d}, J=$ $8.04 \mathrm{~Hz}, 2 \mathrm{H}), 6.99(\mathrm{~s}, 2 \mathrm{H}), 6.83(\mathrm{~s}, 1 \mathrm{H}), 4.58-4.49(\mathrm{~m}, 9 \mathrm{H}), 4.09-4.08$ (m, 2H), 3.99-3.91 (m, $20 \mathrm{H}), 3.52-3.47$ (m, 8H), $2.83(\mathrm{~s}, 3 \mathrm{H}), 1.58-1.50(\mathrm{~m}, 6 \mathrm{H}), 1.44(\mathrm{~d}, J=7.28 \mathrm{~Hz}, 3 \mathrm{H}), 1.35-1.28$ (m,10H), 0.89 (t, $J=7.35 \mathrm{~Hz}, 3 \mathrm{H}), 0.77-0.73(\mathrm{~m}, 24 \mathrm{H}) .{ }^{13} \mathrm{C} \mathrm{NMR}\left(101 \mathrm{MHz}, \mathrm{CDCl}_{3}\right) \delta 173.19$, $166.48,162.15,161.42,159.15,147.81,145.57,138.53,131.41,130.51,128.97,128.38,125.43$, $124.04,118.48,115.55,114.61,113.40,109.18,95.44,94.20,85.77,69.91,68.69,64.99,62.65$, $55.46,49.21,38.66,38.43,30.70,29.69,25.04,22.68,22.66,22.57,22.53$, 19.13, 13.75; HRMS $\left(\right.$ MALDI-FTICR) m/z Calcd. For $\mathrm{C}_{85} \mathrm{H}_{107} \mathrm{~N}_{5} \mathrm{O}_{19}$ : $1524.7425\left(\mathrm{M}+\mathrm{Na}^{+}\right)$, Found: $1524.7445(\mathrm{M}+$ $\left.\mathrm{Na}^{+}\right)$.

Macrocycle 2-F: A solution of compound $1.5(250 \mathrm{mg}, 0.25 \mathrm{mmol})$ and $\mathrm{SOCl}_{2}(0.5 \mathrm{~mL})$ in $\mathrm{CH}_{2} \mathrm{Cl}_{2}(50.0 \mathrm{~mL})$ was heated under reflux for $2 \mathrm{hrs}$ with stirring. Concentrating the reaction mixture in vacuo left 3 as a yellow solid that was re-dissolved in dry $\mathrm{CH}_{2} \mathrm{Cl}_{2}(50.0 \mathrm{~mL})$. The solution of 3 was added dropwise to a solution of compound 4-F (140 mg, $0.307 \mathrm{mmol}$ ) and $\mathrm{Et}_{3} \mathrm{~N}(0.5 \mathrm{~mL})$ in $\mathrm{CH}_{2} \mathrm{Cl}_{2}(50.0 \mathrm{~mL})$ at $0^{\circ} \mathrm{C}$. The mixture was stirred for $3 \mathrm{hrs}$, followed by washing with water and saturated brine. The organic layer was dried with anhydrous sodium sulfate and then concentrated in vacuo. The remaining solid residue was purified with column chromatography (chloroform/methanol=10/1, silica gel) to give $\mathbf{2 - F}$ as a white solid (92 $\mathrm{mg}$, 25\%). mp: $259.6-264.7^{\circ} \mathrm{C} .{ }^{1} \mathrm{H}$ NMR (400 MHz, DMSO-d $)$ ) $\delta 10.08$ (s, 2H), $9.54(\mathrm{~s}, 2 \mathrm{H}), 9.30$ (s, 1H), 9.00 (s, 3H), $8.79(\mathrm{~d}, J=1.84 \mathrm{~Hz}, 2 \mathrm{H}), 8.11(\mathrm{~d}, J=6.84 \mathrm{~Hz}, 2 \mathrm{H}), 7.38(\mathrm{~d}, J=1.92 \mathrm{~Hz}, 2 \mathrm{H})$, $7.18(\mathrm{~d}, J=8.64 \mathrm{~Hz}, 2 \mathrm{H}), 6.99(\mathrm{~s}, 2 \mathrm{H}), 6.83(\mathrm{~s}, 1 \mathrm{H}), 4.58-4.52(\mathrm{~m}, 8 \mathrm{H}), 4.10-3.91(\mathrm{~m}, 22 \mathrm{H})$, 
3.52-3.47 (m, 8H), 1.58-1.51 (m, 6H), $1.44(\mathrm{~d}, J=7.28 \mathrm{~Hz}, 3 \mathrm{H}), 1.35-1.28(\mathrm{~m}, 10 \mathrm{H}), 0.89(\mathrm{t}, J=$ $7.32 \mathrm{~Hz}, 3 \mathrm{H}), 0.77-0.72(\mathrm{~m}, 24 \mathrm{H}) .{ }^{13} \mathrm{C} \mathrm{NMR}\left(101 \mathrm{MHz}, \mathrm{CDCl}_{3}\right) \delta 173.28,164.94,162.66,162.44$, $162.23,160.05,159.59,149.26,145.68,138.53,130.79,129.93,129.00,126.57,124.36,120.63$, $115.91,114.91,114.33,113.62,113.45,109.62,97.17,79.99,69.72,69.63,68.90,68.69,65.58$, $55.91,55.74,48.88,38.55,30.61,25.03,24.98,22.61,22.55,19.10,18.65,13.71$. HRMS (MALDI-FTICR) m/z Calcd. for $\mathrm{C}_{84} \mathrm{H}_{104} \mathrm{FN}_{5} \mathrm{O}_{19}: 1528.7201\left(\mathrm{M}+\mathrm{Na}^{+}\right)$, Found: $1528.7202(\mathrm{M}+$ $\left.\mathrm{Na}^{+}\right)$.

Macrocycle 2- $\mathrm{NH}_{2}$ : A solution of compound $1.5(356 \mathrm{mg}, 0.361 \mathrm{mmol})$ and $\mathrm{SOCl}_{2}(0.5 \mathrm{~mL})$ in $\mathrm{CH}_{2} \mathrm{Cl}_{2}(50.0 \mathrm{~mL})$ was heated under reflux for $2 \mathrm{hrs}$ with stirring. Concentrating the reaction mixture in vacuo left 3 as a yellow solid that was re-dissolved in dry $\mathrm{CH}_{2} \mathrm{Cl}_{2}(50.0 \mathrm{~mL})$. The solution of 3 was added dropwise to a solution of compound 4- $\mathbf{N H}_{2}(200 \mathrm{mg}, 0.361 \mathrm{mmol})$ and $\mathrm{Et}_{3} \mathrm{~N}(0.5 \mathrm{~mL})$ in $\mathrm{CH}_{2} \mathrm{Cl}_{2}(50.0 \mathrm{~mL})$ at $0^{\circ} \mathrm{C}$. The mixture was stirred for $3 \mathrm{hrs}$, followed by washing with water and saturated brine. The organic layer was dried with anhydrous sodium sulfate and then concentrated in vacuo. The remaining solid residue was purified with column chromatography (chloroform/methanol=10/1, silica gel) to give $\mathbf{2}-\mathbf{N H}_{\mathbf{2}}$ as a white solid (115 $\mathbf{m g}$, 21\%). mp: 210.5-212.3 ${ }^{\circ} \mathrm{C} .{ }^{1} \mathrm{H}$ NMR (400 MHz, DMSO-d 6 ) 89.99 (s, 2H), 9.65 (s, 2H), 9.32 (s, 1H), $8.99(\mathrm{~s}, 2 \mathrm{H}), 8.78(\mathrm{~d}, J=1.92 \mathrm{~Hz}, 2 \mathrm{H}), 8.63(\mathrm{~d}, J=6.40 \mathrm{~Hz}, 1 \mathrm{H}), 7.90(\mathrm{~s}, 2 \mathrm{H}), 7.30(\mathrm{~d}, J=$ $8.48 \mathrm{~Hz}, 2 \mathrm{H}), 7.17(\mathrm{~d}, J=8.76 \mathrm{~Hz}, 2 \mathrm{H}), 7.02(\mathrm{~s}, 2 \mathrm{H}), 6.84(\mathrm{~s}, 2 \mathrm{H}), 6.04(\mathrm{~s}, 2 \mathrm{H}), 4.58-4.55$ (m, $8 \mathrm{H}), 4.47-4.43(\mathrm{~m}, 1 \mathrm{H}), 4.10-4.07(\mathrm{~m}, 2 \mathrm{H}), 3.99-3.92(\mathrm{~m}, 20 \mathrm{H}), 3.53-3.44(\mathrm{~m}, 8 \mathrm{H}), 1.58-1.51$ (m, $6 \mathrm{H}), 1.40(\mathrm{~d}, J=7.32 \mathrm{~Hz}, 3 \mathrm{H}), 1.36-1.27(\mathrm{~m}, 10), 0.88(\mathrm{t}, J=7.40 \mathrm{~Hz}, 3 \mathrm{H}), 0.76-0.73(\mathrm{~m}$, 24H). ${ }^{13} \mathrm{C} \quad \mathrm{NMR} \quad\left(75 \mathrm{MHz}, \mathrm{CDCl}_{3}\right) \quad \delta 173.59, \quad 165.73, \quad 162.22,161.73,159.63,159.32$, $151.47,148.04,145.30,138.64,130.40,128.23,125.71,123.54,120.84,119.08,117.26$, $115.11,113.90,109.20,106.78,96.13,95.66,83.09,69.79,68.70,65.25,55.43,55.26$, 48.59,38.53, 30.62, 24.98, 22.62, 22.54, 19.09, 18.63, 13.71; HRMS (MALDI-FTICR) m/z Calcd.for $\mathrm{C}_{84} \mathrm{H}_{106} \mathrm{~N}_{6} \mathrm{O}_{19}: 1525.7405\left(\mathrm{M}+\mathrm{Na}^{+}\right)$, Found: $1525.7549\left(\mathrm{M}+\mathrm{Na}^{+}\right)$. 


\section{III ${ }^{1} \mathrm{H}$ and ${ }^{13} \mathrm{C}$ NMR Spectra of 2-H, 2-Me, 2-F, and 2-NH}

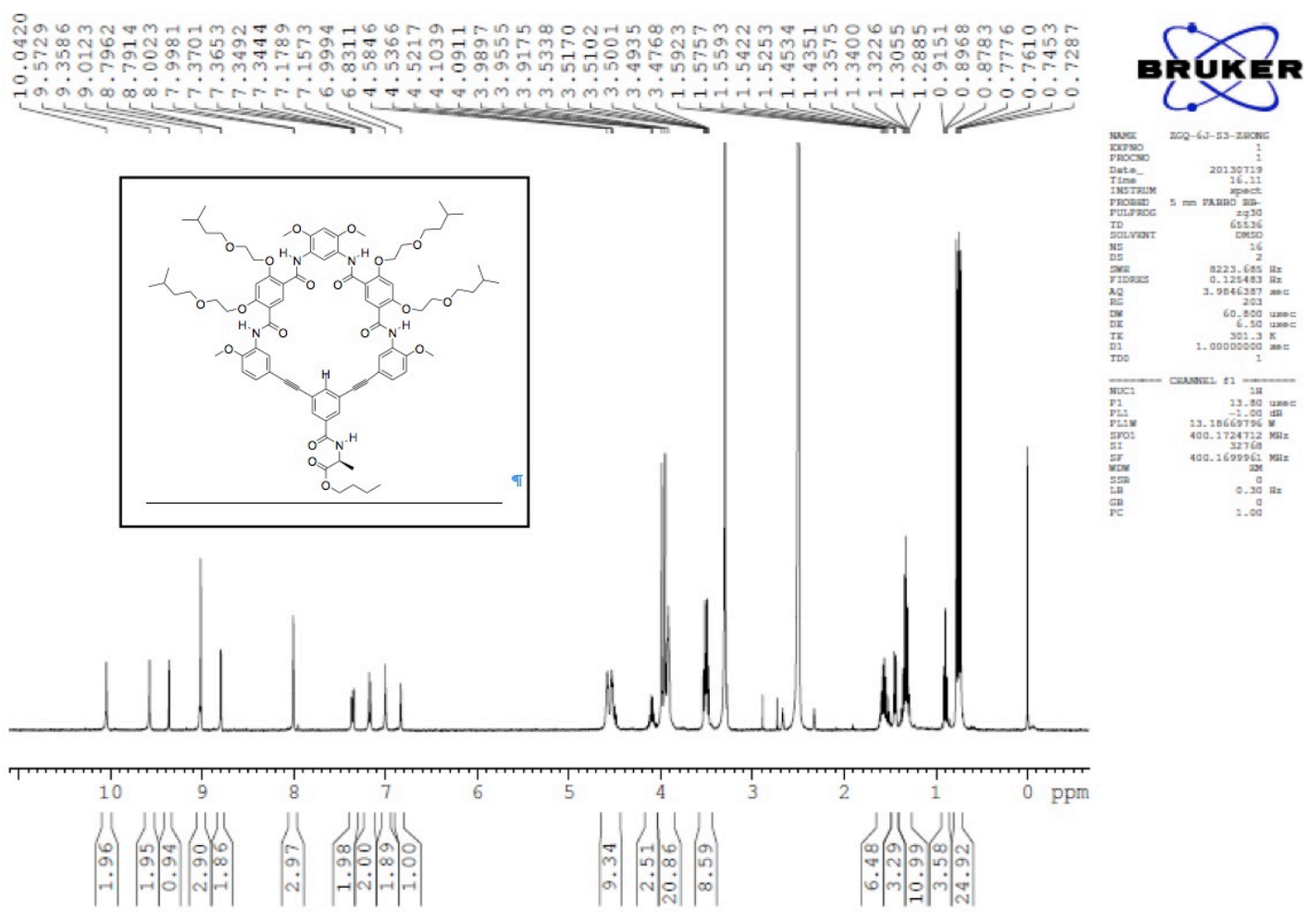

Figure S1. ${ }^{1} \mathrm{H}$ NMR Spectrum of compound 2-H in DMSO- $d_{6}$ at ambient temperature (400 MHz).

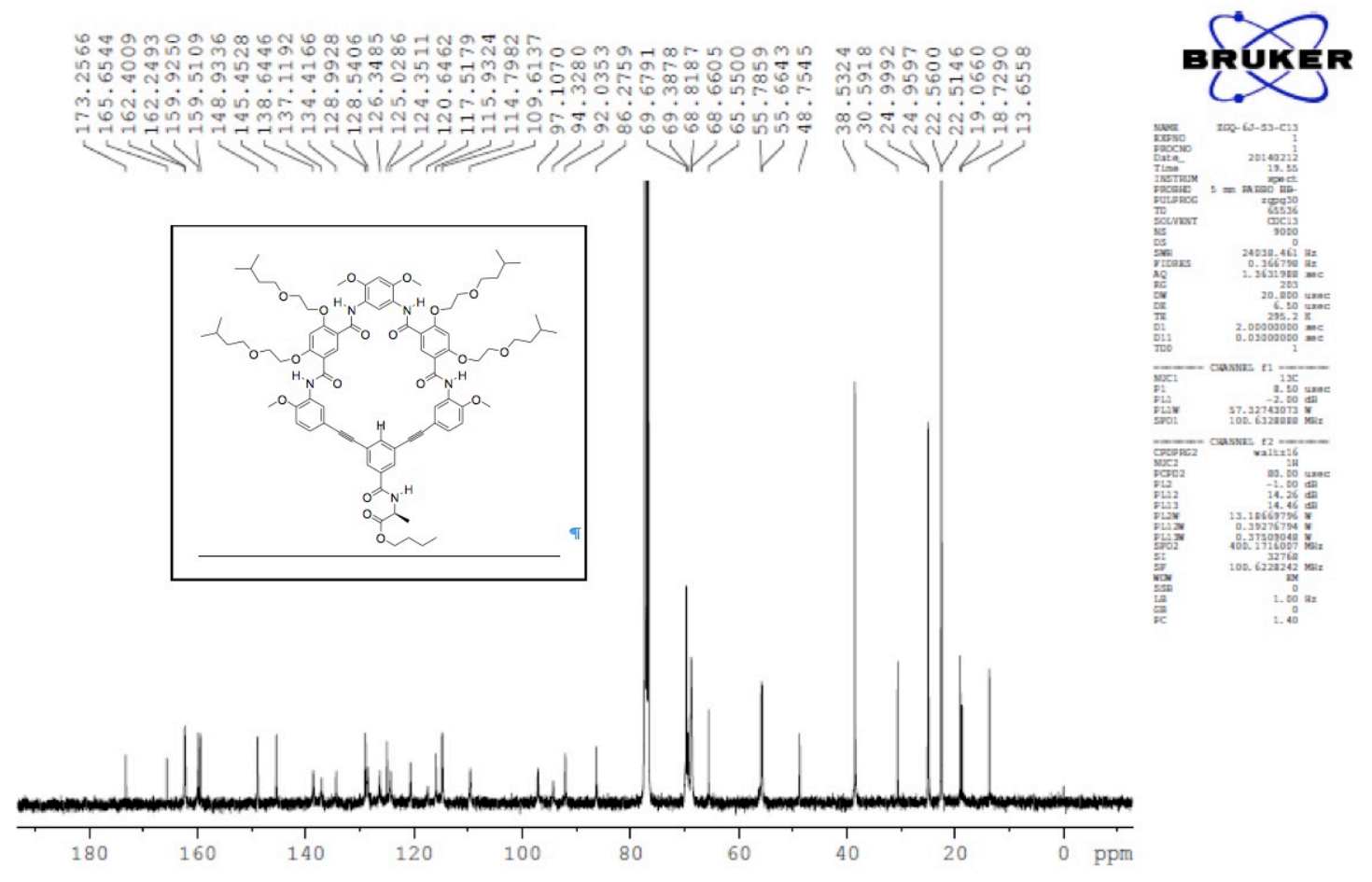

Figure S2. ${ }^{13} \mathrm{C}$ NMR Spectrum of compound 2-H in $\mathrm{CDCl}_{3}$ at ambient temperature (101 MHz). 


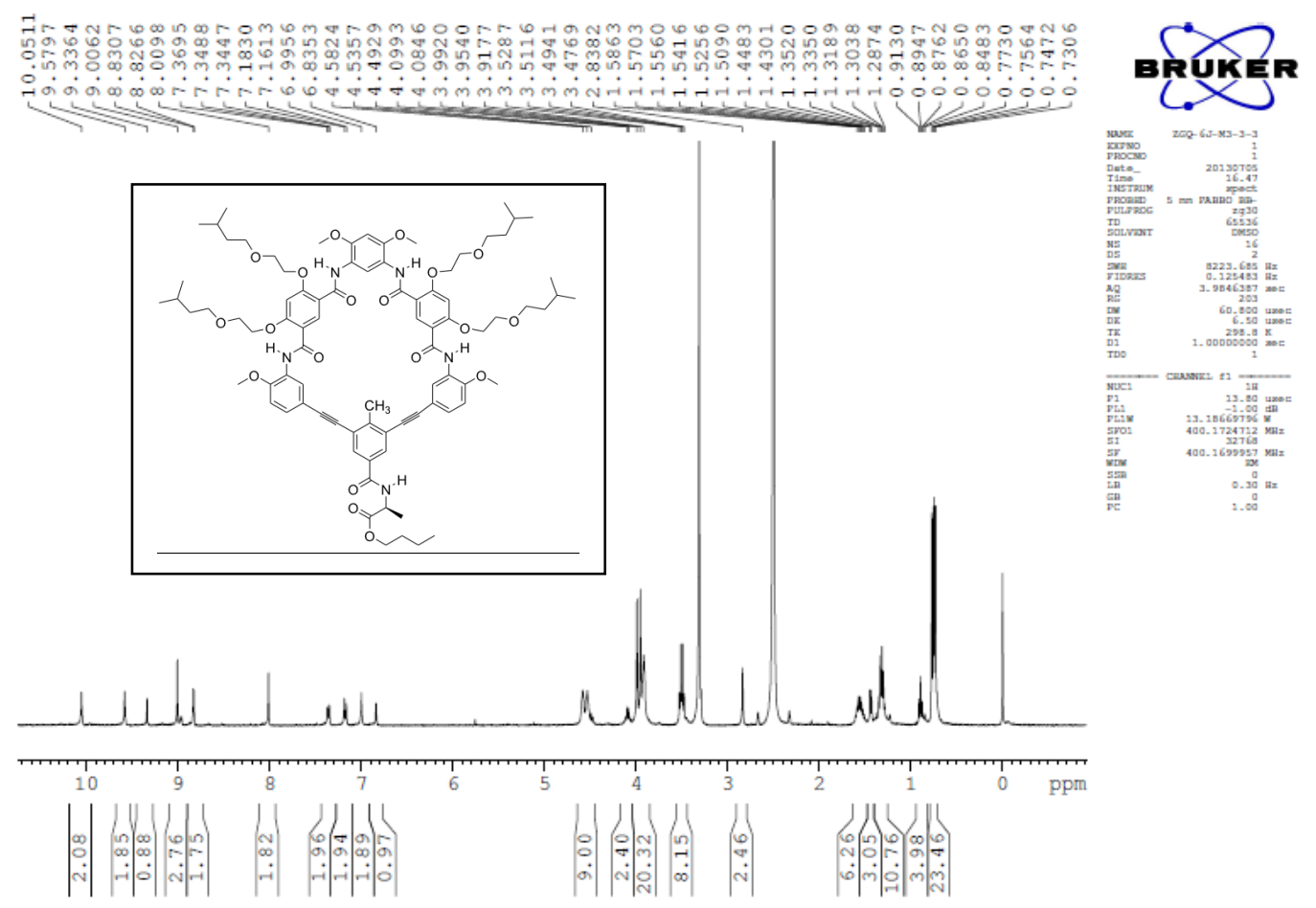

Figure S3. ${ }^{1} \mathrm{H}$ NMR Spectrum of compound 2-Me in DMSO- $d_{6}$ at ambient temperature (400 MHz).

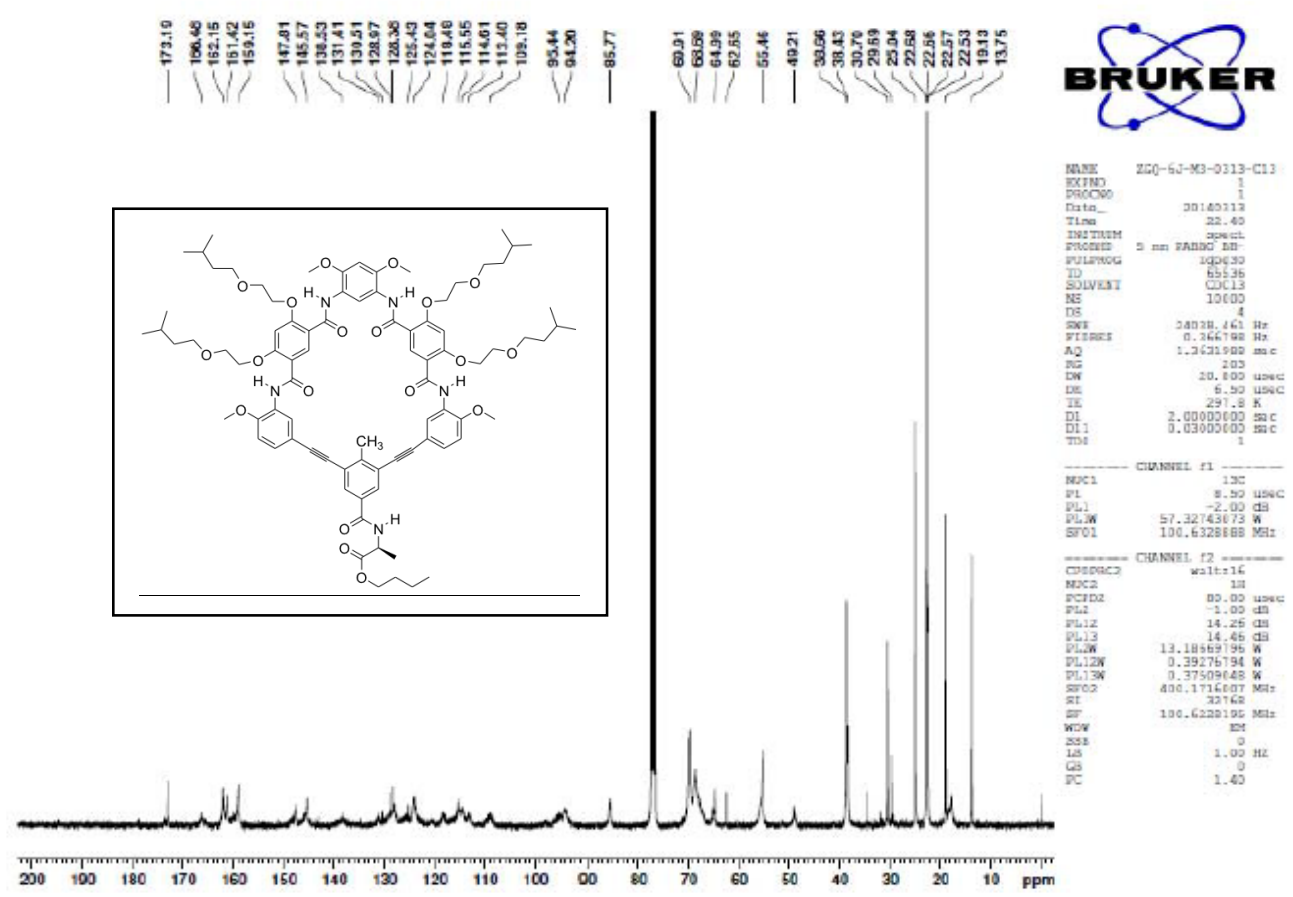

Figure S4. ${ }^{13} \mathrm{C}$ NMR Spectrum of compound 2-Me in $\mathrm{CDCl}_{3}$ at ambient temperature $(101 \mathrm{MHz})$. 


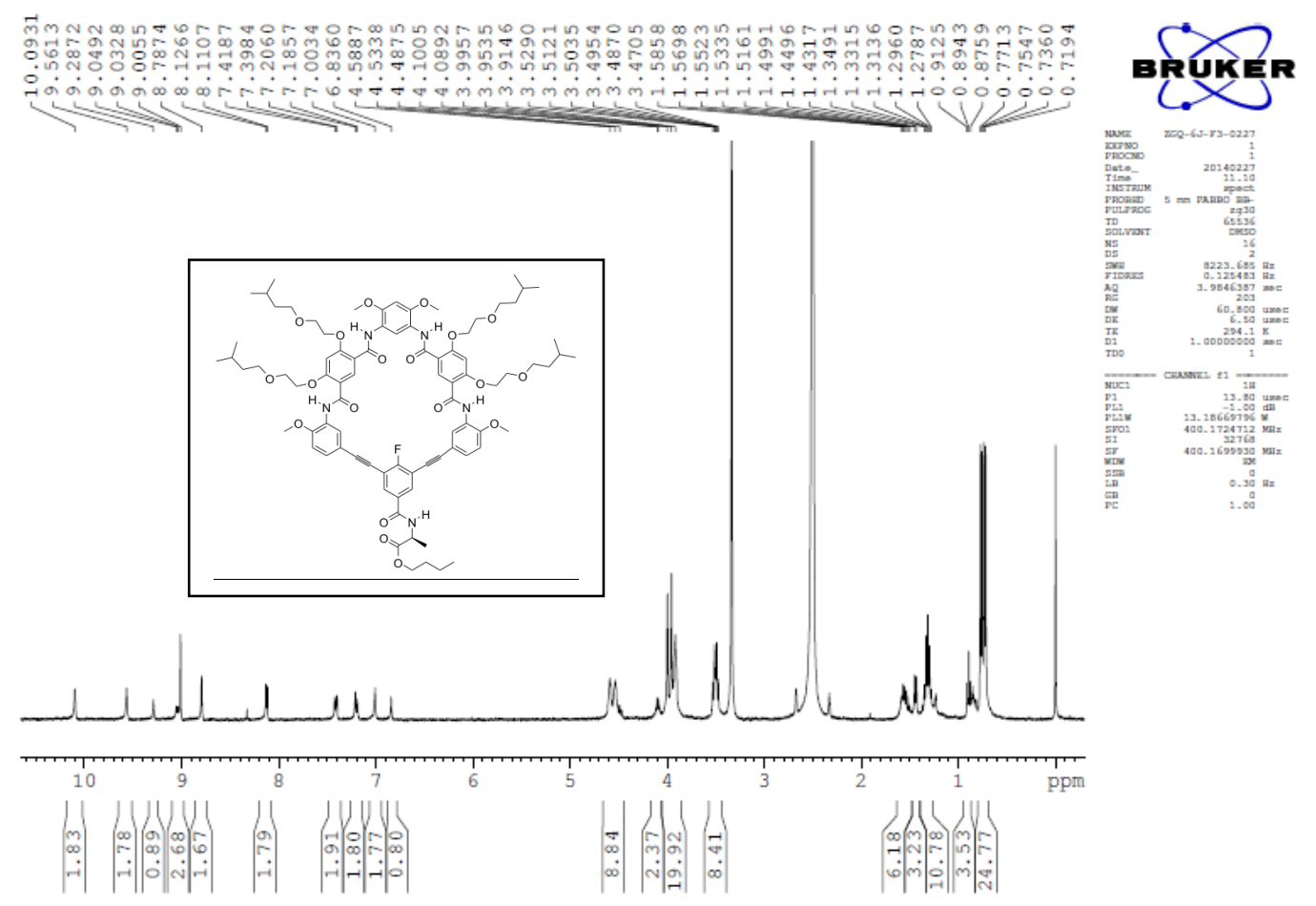

Figure S5. ${ }^{1} \mathrm{H}$ NMR Spectrum of compound 2-F in DMSO- $d_{6}$ at ambient temperature (400 MHz).

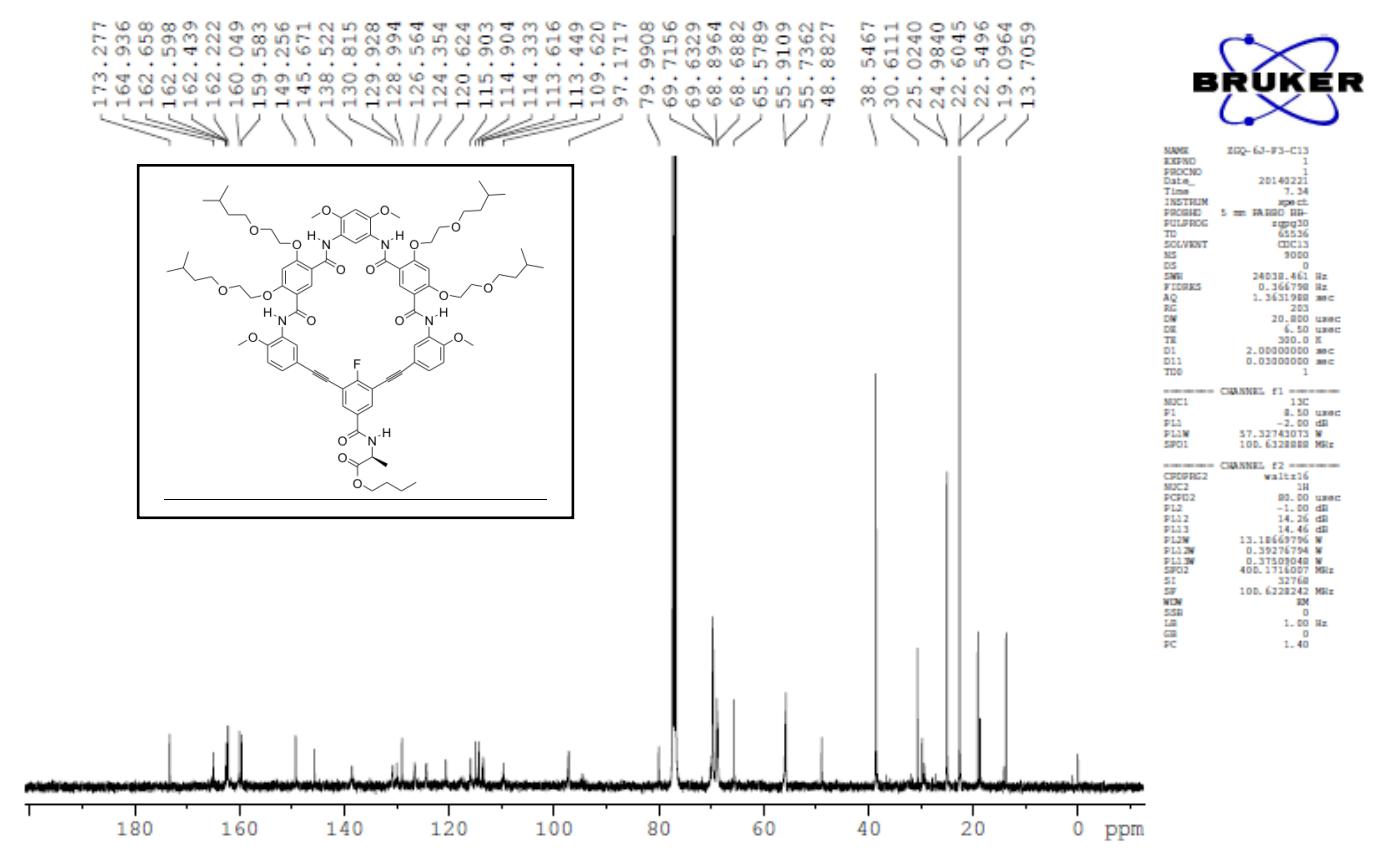

Figure S6. ${ }^{13} \mathrm{C}$ NMR Spectrum of compound 2-F in $\mathrm{CDCl}_{3}$ at ambient temperature $(101 \mathrm{MHz})$. 


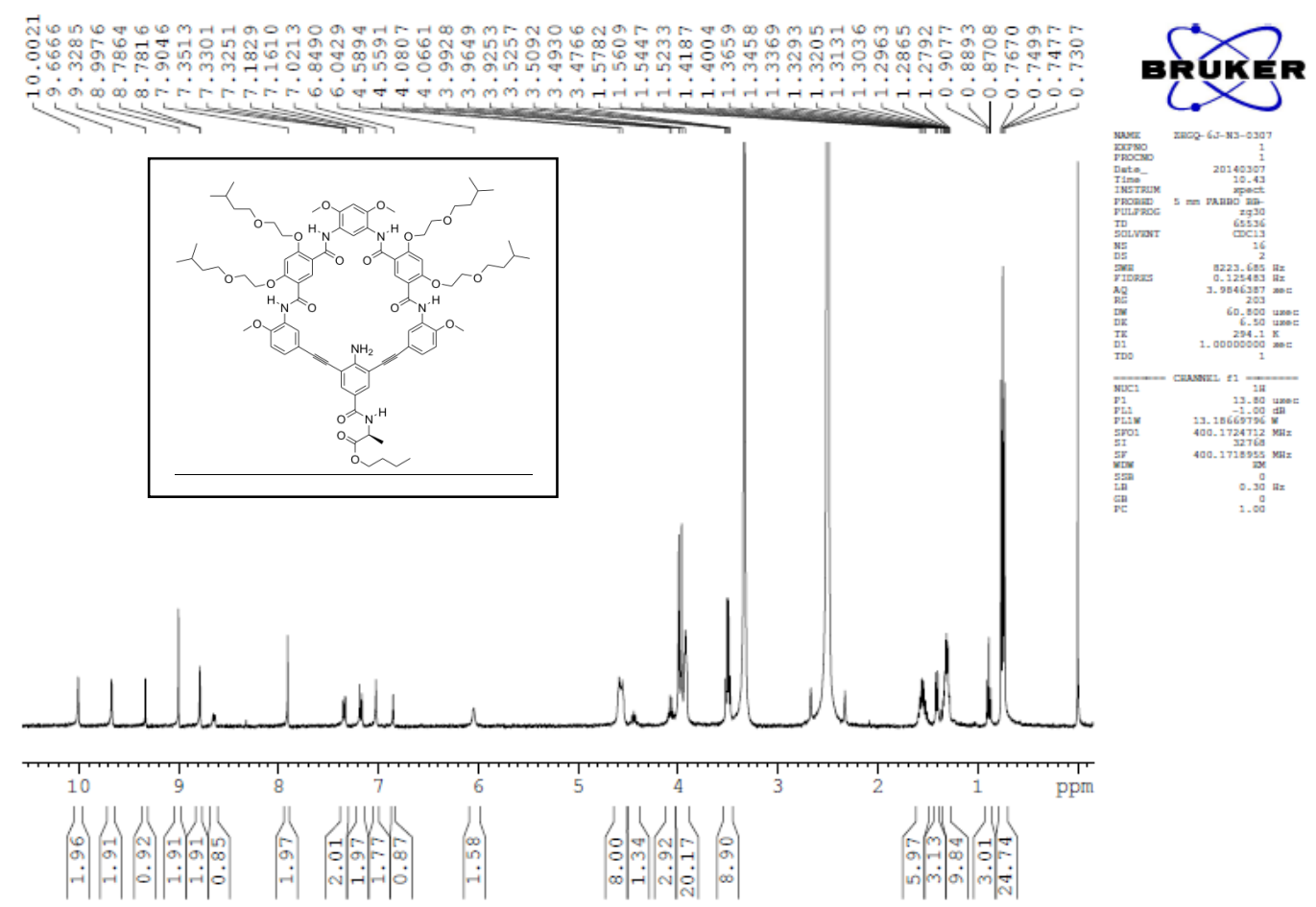

Figure S7. ${ }^{1} \mathrm{H}$ NMR Spectrum of compound $\mathbf{2}-\mathbf{N H}_{2}$ in DMSO- $d_{6}$ at ambient temperature (400 $\mathrm{MHz})$.

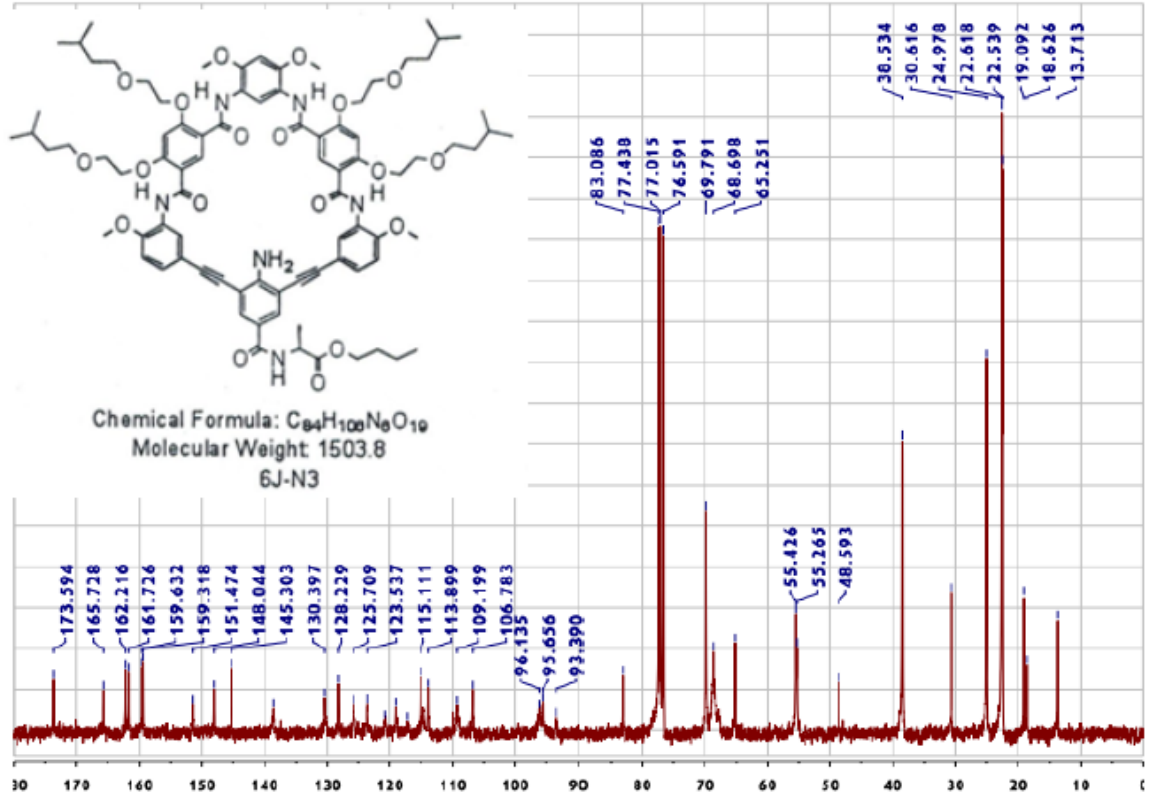

Figure S8. ${ }^{13} \mathrm{C}$ NMR Spectrum of compound $\mathbf{2}-\mathbf{N H}_{2}$ in $\mathrm{CDCl}_{3}$ at ambient temperature (75 MHz). 
IV. High-Resoltuion MALDI-FT-ICR Spectra of 2-H, 2-Me, 2-F, and 2-NH
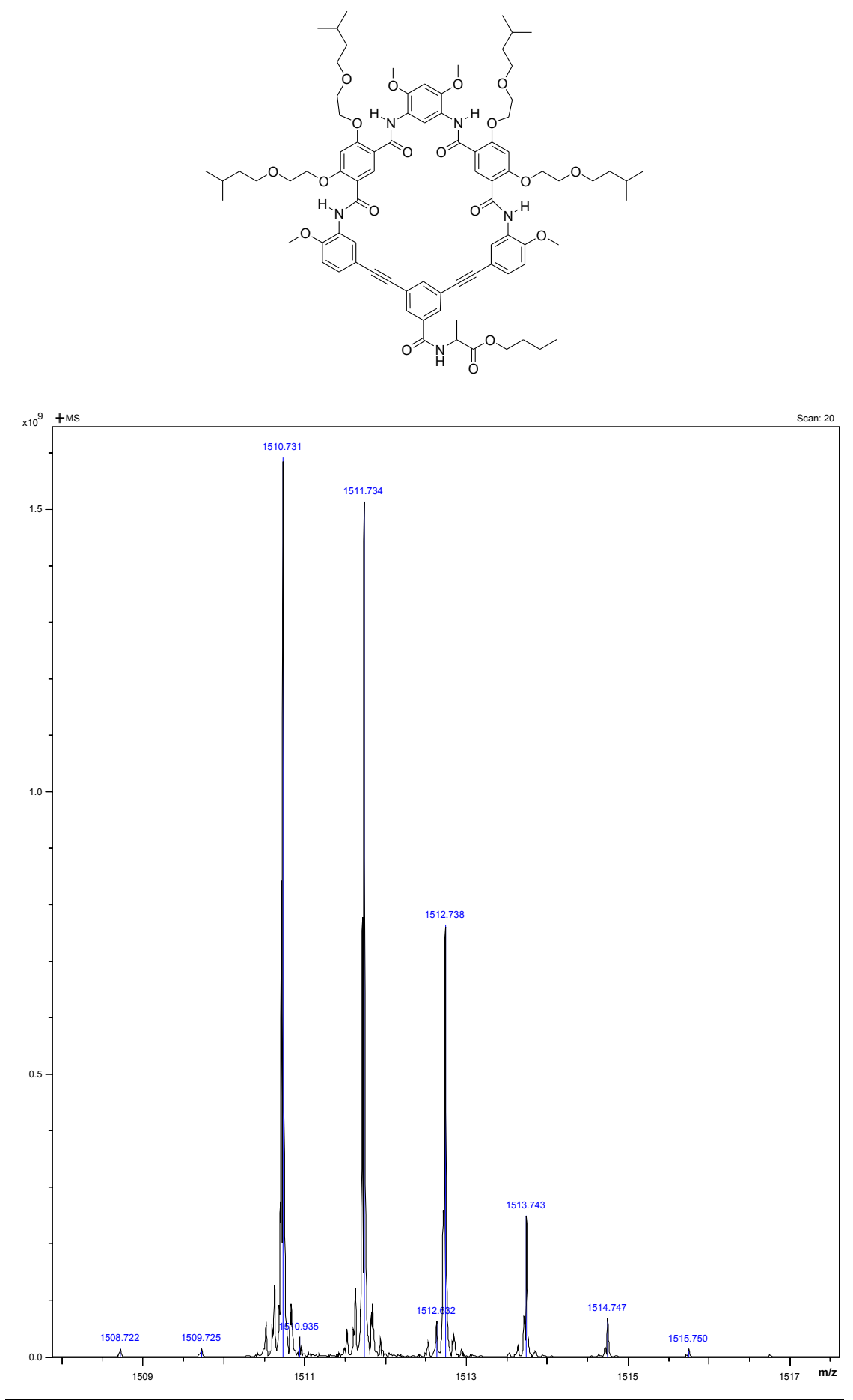

Figure S9. Partial MALDI spectrum of 2-H

\begin{tabular}{ccccccc}
\hline $\begin{array}{c}\text { Relative } \\
\text { abundance }\end{array}$ & $\mathbf{1}^{\text {st }}$ & $\mathbf{2}^{\text {nd }}$ & $\mathbf{3}^{\text {rd }}$ & $\mathbf{4}^{\text {th }}$ & $\mathbf{5}^{\text {th }}$ & $\mathbf{6}^{\text {th }}$ \\
\hline $\mathrm{m} / \mathbf{z}$ & 1510.7306 & 1511.7336 & 1512.7384 & 1513.7431 & 1514.7467 & 1515.7500 \\
\hline
\end{tabular}



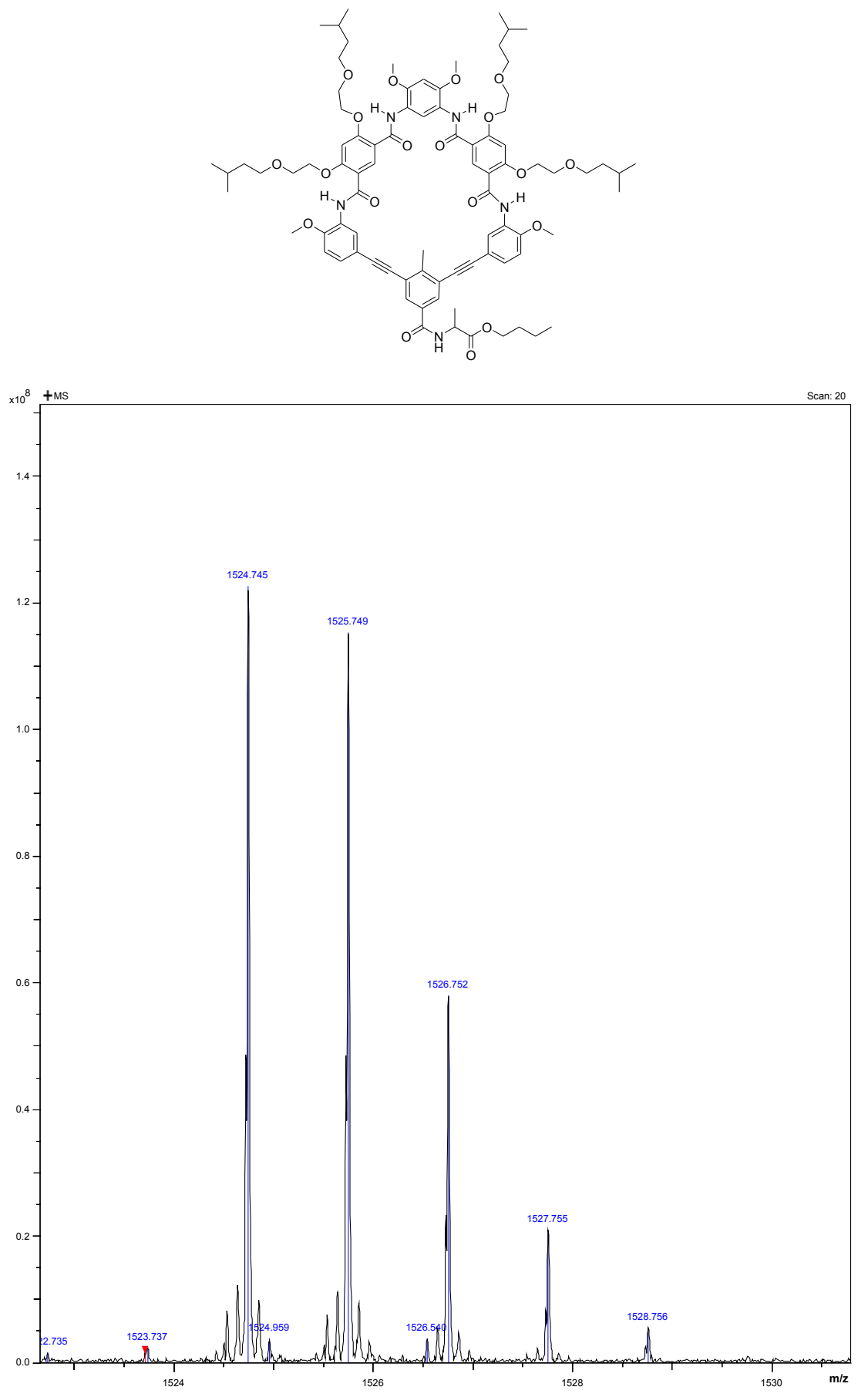

Figure S10. Partial MALDI spectrum of 2-Me.

\begin{tabular}{cccccc}
\hline $\begin{array}{c}\text { Relative } \\
\text { abundance }\end{array}$ & $\mathbf{1}^{\text {st }}$ & $\mathbf{2}^{\text {nd }}$ & $\mathbf{3}^{\text {rd }}$ & $\mathbf{4}^{\text {th }}$ & $\mathbf{5}^{\text {th }}$ \\
\hline $\mathrm{m} / \mathbf{z}$ & 1524.7445 & 1525.7486 & 1526.7524 & 1527.7547 & 1528.7563 \\
\hline
\end{tabular}



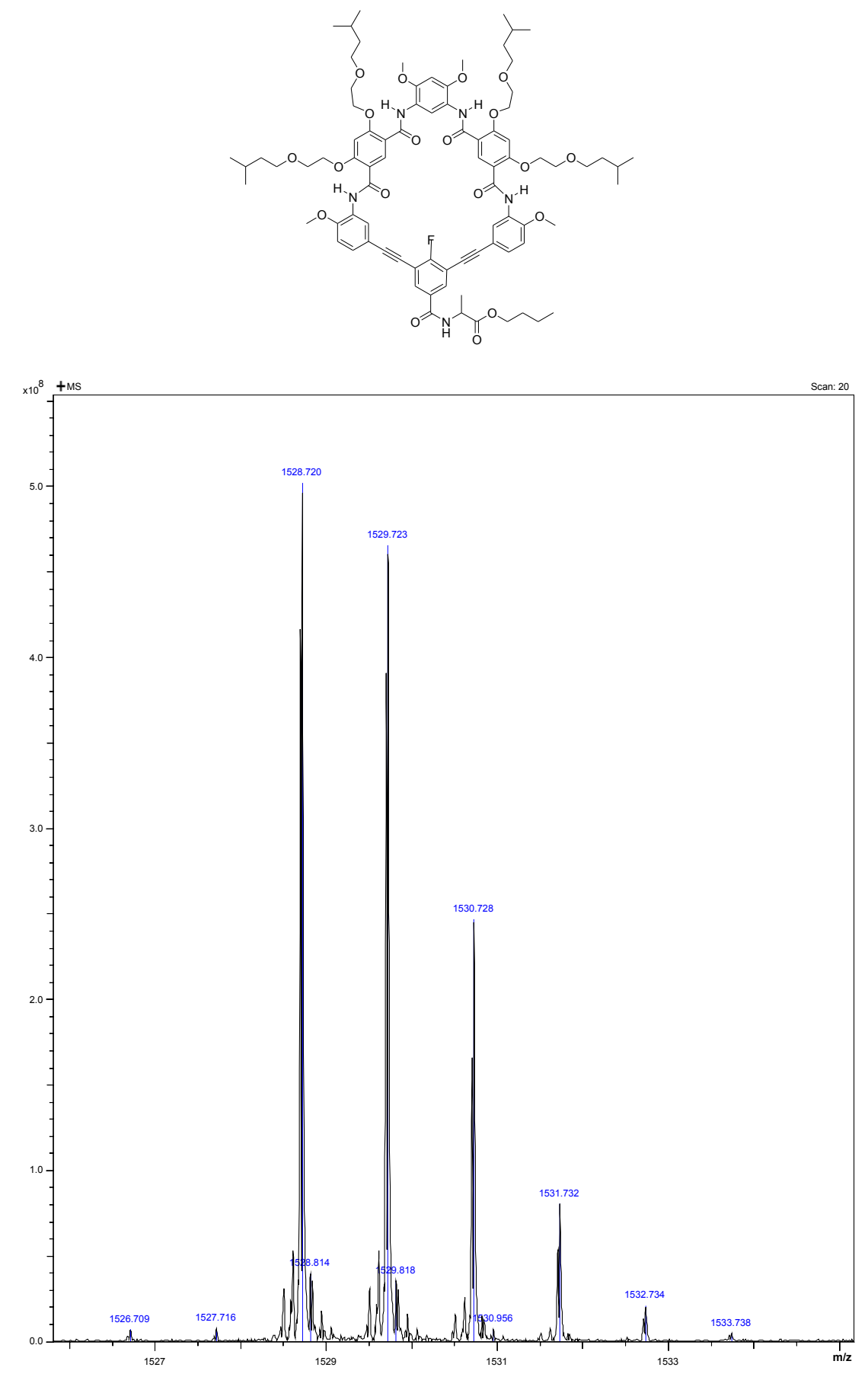

Figure S11. Partial MALDI spectrum of 2-F

\begin{tabular}{ccccccc}
\hline $\begin{array}{c}\text { Relative } \\
\text { abundance }\end{array}$ & $\mathbf{1}^{\text {st }}$ & $\mathbf{2}^{\text {nd }}$ & $\mathbf{3}^{\text {rd }}$ & $\mathbf{4}^{\text {th }}$ & $\mathbf{5}^{\text {th }}$ & $\mathbf{6}^{\text {th }}$ \\
\hline $\mathrm{m} / \mathbf{z}$ & 1528.7202 & 1529.7232 & 1530.7278 & 1531.7317 & 1532.7338 & 1533.7381 \\
\hline
\end{tabular}



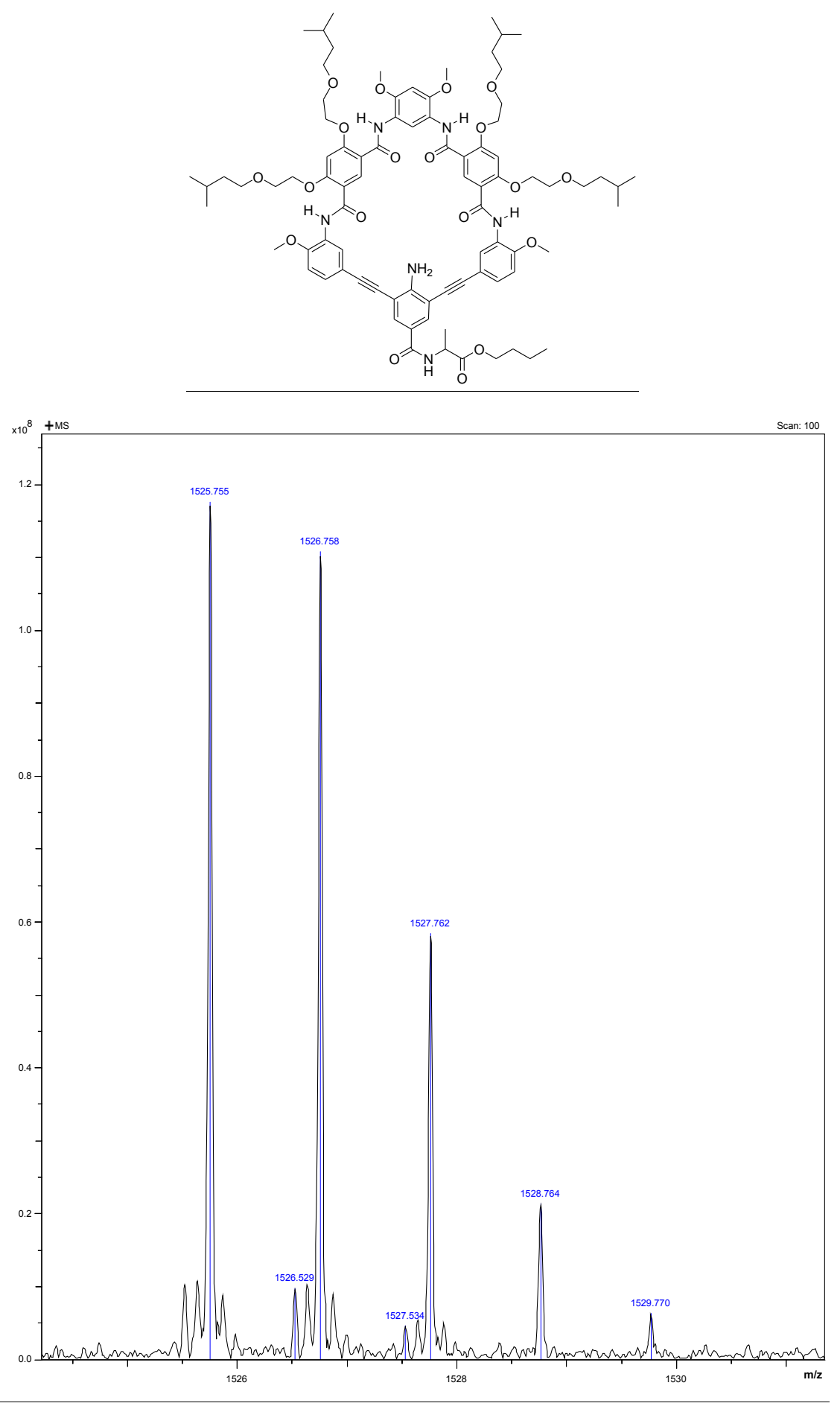

Figure S12. Partial MALDI spectrum of $\mathbf{2}-\mathbf{N H}_{\mathbf{2}}$

\begin{tabular}{cccccc}
\hline $\begin{array}{c}\text { Relative } \\
\text { abundance }\end{array}$ & $\mathbf{1}^{\text {st }}$ & $\mathbf{2}^{\text {nd }}$ & $\mathbf{3}^{\text {rd }}$ & $\mathbf{4}^{\text {th }}$ & $\mathbf{5}^{\text {th }}$ \\
\hline $\mathrm{m} / \mathbf{z}$ & 1525.7549 & 1526.7578 & 1527.7618 & 1528.7644 & 1529.7698 \\
\hline
\end{tabular}




\section{Synthesis and Characterization of Precursors}

Scheme S2. Synthesis of precursors.
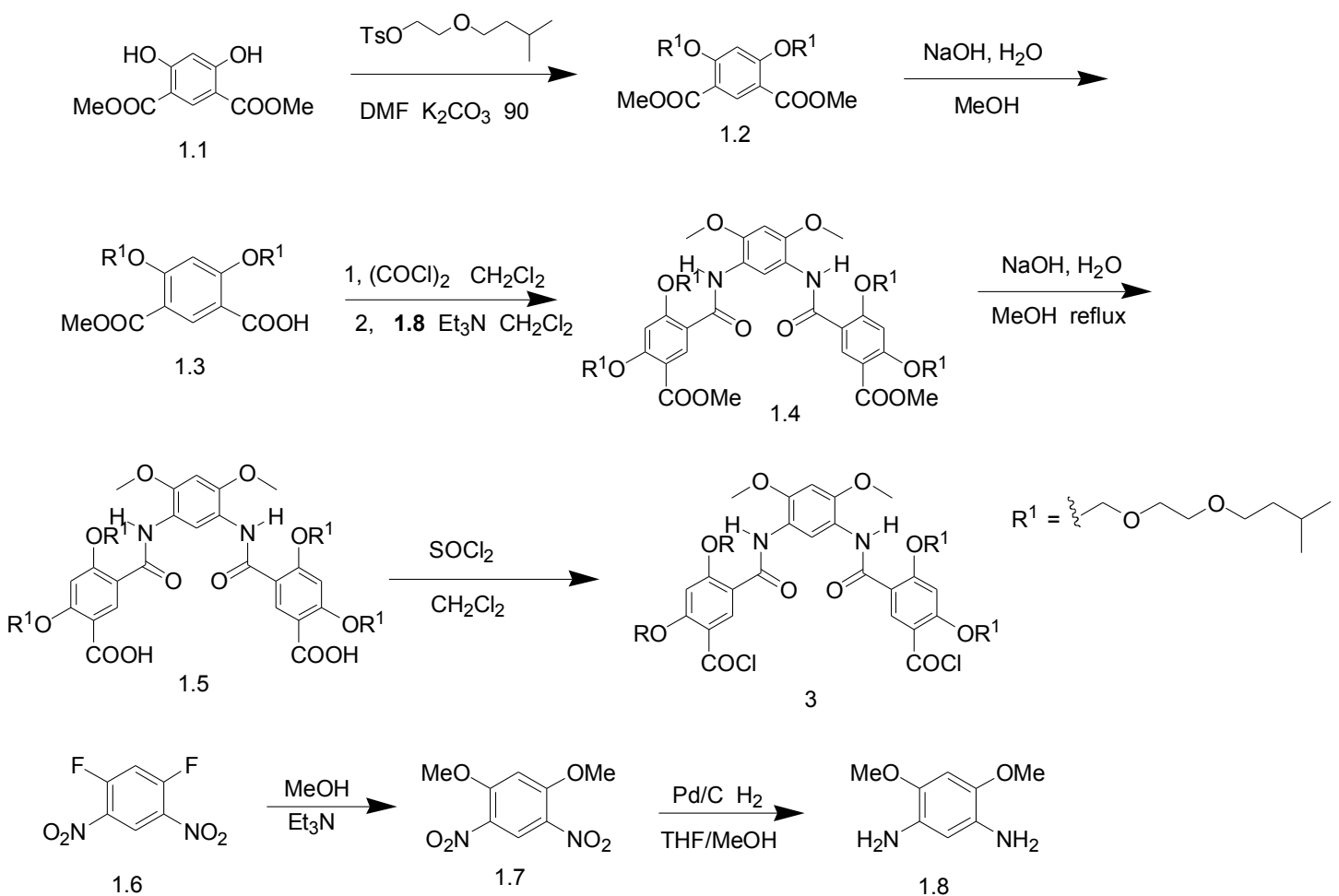

1, 5-Dimethoxy-2, 4-dinitrobenzene (1.7). A mixture of freshly distilled $\mathrm{Et}_{3} \mathrm{~N}$ (16.00 g, 158 mmol) and $\mathrm{MeOH}(4.93 \mathrm{~g}, 154 \mathrm{mmol})$ was cooled to $\sim{ }^{\circ} \mathrm{C}$, to which compound $\mathbf{1 . 6}$ (15.00 g, $73.5 \mathrm{mmol}$ ) was added portionwise. The reaction mixture was then stirred at room temperature for $1.5 \mathrm{hrs}$. The slurry was dissolved in $\mathrm{CH}_{2} \mathrm{Cl}_{2}(200 \mathrm{~mL})$, washed with diluted $\mathrm{HCl}$ and water. Removal of solvent afforded compound $\mathbf{1 . 7}$ as a yellow solid (12.42 g, 74\%). ${ }^{1} \mathrm{H}$ NMR (400 $\left.\mathrm{MHz}, \mathrm{CDCl}_{3}\right) \delta 8.76(\mathrm{~s}, 1 \mathrm{H}), 6.62(\mathrm{~s}, 1 \mathrm{H}), 4.09(\mathrm{~s}, 1 \mathrm{H})$.

4, 6-Dimethoxybenzene-1, 3-diamine (1.8). To the mixed solvent of THF (50 mL) and $\mathrm{MeOH}$ $(20 \mathrm{~mL})$ was added compound $1.7(1.50 \mathrm{~g}, 6.58 \mathrm{mmol})$. The reaction mixture was hydrogenated in the presence of $10 \% \mathrm{Pd} / \mathrm{C}(150 \mathrm{mg})$ at $0.3 \mathrm{MPa}$ for $10 \mathrm{hrs}$ at room temperature. The solution was filtered in darkness as fast as possible followed by immediate removal of solvent. The reduced diamine was immediately used for the subsequent step.

Dimethyl 4, 6-bis(2-(isopentyloxy)ethoxy)isophthalate (1.2). To a 250-mL round-bottomed flask was added $150 \mathrm{~mL}$ DMF and compound 1.1 (8.00 g, $35 \mathrm{mmol})$, 2-(isopentyloxy)ethyl-4-methylbenzenesulfonate (20 g, $70 \mathrm{mmol})$, and $\mathrm{K}_{2} \mathrm{CO}_{3}(20 \mathrm{~g}, 140 \mathrm{mmol})$. The solution was heated at $100{ }^{\circ} \mathrm{C}$ for $24 \mathrm{hrs}$. After filtration, the brown filtrate was evaporated in vacuo to afford a red oil, which was dissoved in ethyl acetate $(150 \mathrm{~mL})$. The organic layer was washed with twice with water, once with saturated brine, and then dried with anhydrous sodium sulfate. Concentration in vacuo afforded the crude product that was purified by column chromatography (petroleum ether/ethyl acetate $=4 / 1$, silica gel) to give a yellow oil $(9.50 \mathrm{~g}, 60 \%)$. mp: 
41.5-42.3 ${ }^{\circ} \mathrm{C} .{ }^{1} \mathrm{H}$ NMR $\left(400 \mathrm{MHz}, \mathrm{CDCl}_{3}\right)$ 88.44(s, 1H), $6.61(\mathrm{~s}, 1 \mathrm{H}), 4.22(\mathrm{t}, J=4.9 \mathrm{~Hz}, 4 \mathrm{H})$, 3.86-3.84 (m, 10H), $3.58(\mathrm{t}, J=6.80 \mathrm{~Hz}, 4 \mathrm{H}), 1.74-1.64(\mathrm{~m}, 2 \mathrm{H}), 1.48(\mathrm{q}, J=6.80 \mathrm{~Hz}, 4 \mathrm{H}), 0.89$ $(\mathrm{d}, J=6.60 \mathrm{~Hz}, 12 \mathrm{H}) .{ }^{13} \mathrm{C} \mathrm{NMR}\left(101 \mathrm{MHz}, \mathrm{CDCl}_{3}\right) \delta 165.20,163.34,136.86,112.34,98.86$, 70.25, 69.08, 68.90, 51.71, 38.46, 24.99, 22.57; MS (ESI) m/z Calcd. forC ${ }_{24} \mathrm{H}_{38} \mathrm{O}_{8}: 454.2\left(\mathrm{M}^{+}\right)$, Found: $455.2\left(\mathrm{M}+\mathrm{H}^{+}\right)$.

2, 4-Bis(2-(isopentyloxy)ethoxy)-5-(methoxycarbonyl)benzoic acid (1.3). To a solution of compound $1.2(7.00 \mathrm{~g}, 15 \mathrm{mmol})$ in $\mathrm{MeOH}(100 \mathrm{~mL})$ was added and $\mathrm{NaOH}$ (1 equiv., $15 \mathrm{~mL}$ of 1-M solution). The reaction mixture was heated under reflux for $4 \mathrm{hrs}$ under stirring. After cooling down to room temperature, concentrated $\mathrm{HCl}$ was added to the reaction mixture. The crude product was collected by filtration as a white solid and was purified by column chromatography (petroleum ether/acetone $=5 / 1$, silica gel) to give compound $\mathbf{1 . 3}$ as a white solid (3.68 g, 54\%). mp: 104.3-105.4 ${ }^{\circ} \mathrm{C} .{ }^{1} \mathrm{H}$ NMR (400 MHz, $\left.\mathrm{CDCl}_{3}\right) \delta 8.67$ (s, 1H), 6.67 (s, 1H), 4.37 $(\mathrm{t}, J=4.52 \mathrm{~Hz}, 2 \mathrm{H}), 4.26(\mathrm{t}, J=4.50 \mathrm{~Hz}, 2 \mathrm{H}), 3.85(\mathrm{~s}, 7 \mathrm{H}), 3.58(\mathrm{t}, J=6.28 \mathrm{~Hz}, 4 \mathrm{H}), 1.68-1.64(\mathrm{~m}$, $2 \mathrm{H}), 1.53-1.47(\mathrm{~m}, 4 \mathrm{H}), 0.89(\mathrm{~d}, J=6.16 \mathrm{~Hz}, 12 \mathrm{H}) .{ }^{13} \mathrm{C} \mathrm{NMR}\left(101 \mathrm{MHz}, \mathrm{CDCl}_{3}\right) \delta 164.65$, $164.56,163.98,161.29,138.15,114.84,110.69,98.64,70.28,70.25,69.53,69.46,68.96,67.91$, 51.85, 38.46, 38.18, 24.99, 24.93, 22.56, 22.53; MS (ESI) m/z Calcd. for $\mathrm{C}_{23} \mathrm{H}_{36} \mathrm{O}_{8}: 440.2\left(\mathrm{M}^{+}\right)$, Found: $439.2\left(\mathrm{M}-\mathrm{H}^{+}\right)$.

Compound (1.4). Compound $1.3(2.00 \mathrm{~g}, 4.52 \mathrm{mmol})$ and $(\mathrm{COCl})_{2}(1.70 \mathrm{~g}, 13.56 \mathrm{mmol})$ was dissolved in dry $\mathrm{CH}_{2} \mathrm{Cl}_{2}$. After being stirred for $4 \mathrm{hrs}$ at room temperature, the reaction mixture was evaporated in vacuo to afford a yellow solid that was dissolved in $\operatorname{dry} \mathrm{CH}_{2} \mathrm{Cl}_{2}$. The solution was added dropwise to the solution of compound $1.8(0.38 \mathrm{~g}, 2.26 \mathrm{mmol})$ and $\mathrm{Et}_{3} \mathrm{~N}(0.45 \mathrm{~g}, 4.52$ mmol) in $\mathrm{CH}_{2} \mathrm{Cl}_{2}$ at $0{ }^{\circ} \mathrm{C}$, the solution was washed with water and saturated brine, and dried with anhydrous sodium sulfate. Removing solvent in vacuo afforded a brown solid that was purified by column chromatography (petroleum ether/acetone $=3 / 1$, silica gel) to afford compound $\mathbf{1 . 4}$ as a white solid (2.01 g, 76\%). mp: 114.4-115.1 ${ }^{\circ} \mathrm{C} .{ }^{1} \mathrm{H}$ NMR (400 MHz, $\left.\mathrm{CDCl}_{3}\right) \delta 9.76(\mathrm{~s}, 2 \mathrm{H})$, $9.36(\mathrm{~s}, 1 \mathrm{H}), 8.89(\mathrm{~s}, 2 \mathrm{H}), 6.66(\mathrm{~s}, 2 \mathrm{H}), 6.53(\mathrm{~d}, J=4.48 \mathrm{~Hz}, 1 \mathrm{H}), 4.37(\mathrm{t}, J=5.04 \mathrm{~Hz}, 4 \mathrm{H}), 4.24$ $(\mathrm{t}, J=4.72 \mathrm{~Hz}, 4 \mathrm{H}), 3.93-3.91(\mathrm{~m}, 10 \mathrm{H}), 3.88-3.85(\mathrm{~m}, 10 \mathrm{H}), 3.59(\mathrm{t}, J=3.61 \mathrm{~Hz}, 4 \mathrm{H}), 3.52(\mathrm{t}, J$ $=3.50 \mathrm{~Hz}, 4 \mathrm{H}), 1.73-1.58(\mathrm{~m}, 4 \mathrm{H}), 1.49(\mathrm{dd}, J=13.72,6.88 \mathrm{~Hz}, 4 \mathrm{H}), 1.40(\mathrm{dd}, J=13.68,9.00$ $\mathrm{Hz}, 4 \mathrm{H}), 0.90(\mathrm{~d}, J=6.60 \mathrm{~Hz}, 12 \mathrm{H}), 0.81(\mathrm{~d}, J=6.60 \mathrm{~Hz}, 12 \mathrm{H}) .{ }^{13} \mathrm{C}$ NMR $\left(101 \mathrm{MHz}, \mathrm{CDCl}_{3}\right)$ 
$\delta 165.21,162.38,161.38,160.52,145.77,137.16,120.66,116.01,115.04,113.34,98.34,94.80$ $70.15,69.88,69.13,69.03,68.94,68.56,55.79,51.44,38.49,38.36,24.98,24.92,22.56,22.46$; MS (ESI) m/z Calcd. for $\mathrm{C}_{54} \mathrm{H}_{80} \mathrm{~N}_{2} \mathrm{O}_{16}: 1012.5\left(\mathrm{M}^{+}\right)$, Found: $1013.5\left(\mathrm{M}+\mathrm{H}^{+}\right)$.

Compound (1.5). Compound 1.4 (2.00 g, $1.97 \mathrm{mmol})$ and $\mathrm{NaOH}$ (5 mL of 1-M solution) was added to $\mathrm{MeOH}(100 \mathrm{~mL})$. The mixture was heated under reflux for $3 \mathrm{hrs}$. After cooling down to room temperature, concentrated $\mathrm{HCl}$ was added to the solution to precipitate product $\mathbf{1 . 5}$ as a white product (1.80 g, 92\%). mp: 204.2-205.3 ${ }^{\circ} \mathrm{C} .{ }^{1} \mathrm{H}$ NMR (400 MHz, $\left.\mathrm{CDCl}_{3}\right) \delta 9.56(\mathrm{~s}, 2 \mathrm{H})$, 9.18(s, 1H), $9.00(\mathrm{~s}, 2 \mathrm{H}), 6.66(\mathrm{~s}, 2 \mathrm{H}), 6.36(\mathrm{~s}, 1 \mathrm{H}), 4.46(\mathrm{~s}, 4 \mathrm{H}), 4.31(\mathrm{~s}, 4 \mathrm{H}), 4.46(\mathrm{~s}, 4 \mathrm{H}), 4.31$ (s, 6H), $3.92(\mathrm{~s}, 4 \mathrm{H}), 3.51(\mathrm{t}, J=4.68 \mathrm{~Hz}, 8 \mathrm{H}), 1.70-1.49(\mathrm{~m}, 4 \mathrm{H}), 1.47$ (dd, $J=13.56,6.72 \mathrm{~Hz}$, 4H), 1.37 (dd, $J=13.40,6.56 \mathrm{~Hz}, 4 \mathrm{H}), 0.88(\mathrm{~d}, J=6.56 \mathrm{~Hz}, 12 \mathrm{H}), 0.78(\mathrm{~d}, J=6.56 \mathrm{~Hz}$, 12H). ${ }^{13} \mathrm{C}$ NMR (101 MHz, DMSO-d 6 ) $\delta 165.81,161.88,160.81,160.16,145.69,135.77,119.82$, $114.89,113.79,113.70,99.05,95.79,69.19,68.99,68.93,68.73,68.34,67.98,56.03,38.07$, 37.91, 24.48, 24.41, 22.38, 22.22; MS (ESI) m/z Calcd. for $\mathrm{C}_{52} \mathrm{H}_{76} \mathrm{~N}_{2} \mathrm{O}_{16}: 984.5\left(\mathrm{M}^{+}\right)$, Found: $983.5\left(\mathrm{M}-\mathrm{H}^{+}\right)$. 
Scheme S3. Synthesis of precursors.
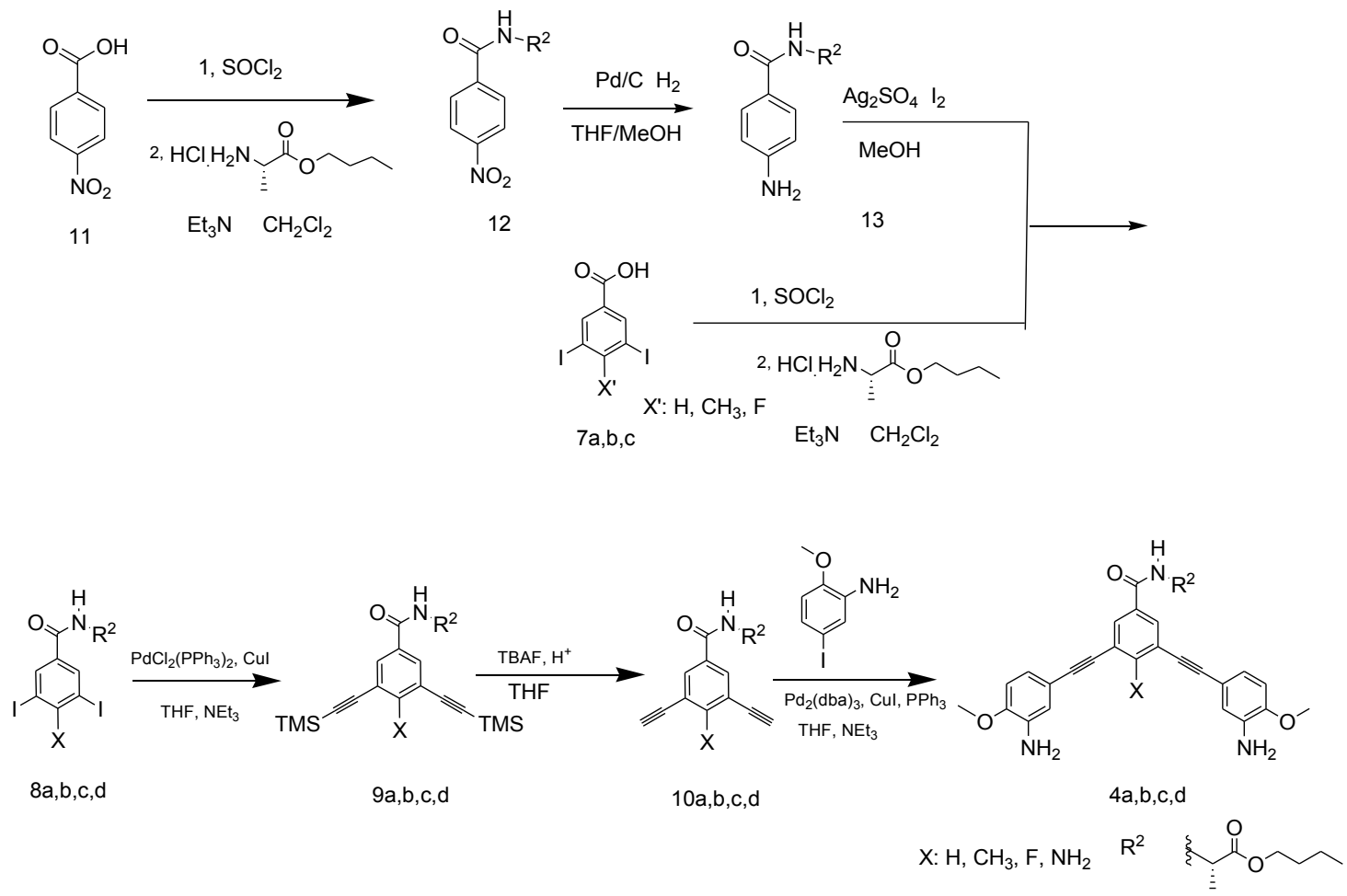

(S)-Butyl 2-(3, 5-diiodobenzamido)propanoate (8-H). To a 100-mL round-bottomed flask was added 7-H (3, 5-diiodobenzoic acid) $(5.00 \mathrm{~g}, 0.013 \mathrm{~mol})$ and $\mathrm{SOCl}_{2}(10 \mathrm{~mL})$. The reaction mixture was heated under reflux for 5 hrs. Removing unreacted $\mathrm{SOCl}_{2}$ in vacuo gave a yellow solid. To a dried, ice-cooled flask containing $\mathrm{Et}_{3} \mathrm{~N}(2.0 \mathrm{~mL}, 15 \mathrm{mmol})$ and $(S)$-butyl 2-aminopropanoate hydrochloride $(2.17 \mathrm{~g}, 15 \mathrm{mmol})$ was added the solution of the above solid in $\mathrm{CH}_{2} \mathrm{Cl}_{2}(15 \mathrm{~mL})$. The mixture was stirred for $7 \mathrm{~h}$ at room temperature, filtered, and concentrated in vacuo. The crude product was purified by column chromatography (petroleum ether/acetone $=$ 20/1, silica gel) to give compound 8-H $(5.1 \mathrm{~g}, 65 \%)$ as a white solid. mp: $105.5-106.4{ }^{\circ} \mathrm{C} .{ }^{1} \mathrm{H}$ NMR (400 MHz, $\left.\mathrm{CDCl}_{3}\right) \delta 8.16(\mathrm{~s}, 1 \mathrm{H}), 8.05$ (d, $\left.J=1.4 \mathrm{~Hz}, 2 \mathrm{H}\right), 6.77$ (s, 1H), $4.73(\mathrm{~m}, 1 \mathrm{H}), 4.19$ $(\mathrm{m}, 2 \mathrm{H}), 1.65(\mathrm{~m}, 2 \mathrm{H}), 1.50(\mathrm{t}, J=2.5 \mathrm{~Hz}, 3 \mathrm{H}), 1.39(\mathrm{~m}, 2 \mathrm{H}), 0.95(\mathrm{t}, J=7.4 \mathrm{~Hz}, 3 \mathrm{H}) ;{ }^{13} \mathrm{C} \mathrm{NMR}$ $\left(101 \mathrm{MHz}, \mathrm{CDCl}_{3}\right) \delta 173.0,163.8,148.1,137.3,135.4,94.8,65.7,48.8,30.5,19.1,18.6,13.7$; MS (ESI) m/z Calcd. for $\mathrm{C}_{14} \mathrm{H}_{17} \mathrm{I}_{2} \mathrm{NO}_{3}: 500.9\left(\mathrm{M}^{+}\right)$, Found: $501.2\left(\mathrm{M}+\mathrm{H}^{+}\right)$.

(S)-Butyl 2-(3, 5-bis((trimethylsilyl)ethynyl)benzamido)propanoate (9-H). Compound 8-H (5.00 g, $9.6 \mathrm{mmol}), \mathrm{Pd}\left(\mathrm{PPh}_{3}\right)_{2} \mathrm{Cl}_{2}(0.34 \mathrm{~g}, 0.48 \mathrm{mmol})$, and $\mathrm{CuI}(0.09 \mathrm{~g}, 0.48 \mathrm{mmol})$ were placed in a round-bottomed flask that was then degassed. THF $(50 \mathrm{~mL})$ and $\mathrm{Et}_{3} \mathrm{~N}(20 \mathrm{~mL})$ were injected into the flask using a syringe, followed by injecting trimethylsilylethylene $(3.4 \mathrm{~mL}, 24 \mathrm{mmol})$ into the solution. The reaction mixture was stirred overnight at room temperature. The crude mixture was filtered through a silica gel plug and concentrated in vacuo. The remaining solid residue was purified with column chromatography (petroleum ether/ethyl acetate $=20 / 1$, silica gel) to give the 9-H (3.60 g, 81\%) as a yellow oil. ${ }^{1} \mathrm{H}$ NMR (400 MHz, $\left.\mathrm{CDCl}_{3}\right) \delta 7.80(\mathrm{~d}, J=1.5$ $\mathrm{Hz}, 2 \mathrm{H}), 7.67$ (t, $J=1.5 \mathrm{~Hz}, 1 \mathrm{H}), 6.72$ (d, $J=7.2 \mathrm{~Hz}, 1 \mathrm{H}), 4.76(\mathrm{~m}, 1 \mathrm{H}), 4.19(\mathrm{~m}, 2 \mathrm{H}), 1.66(\mathrm{~m}$, 
2H), $1.50(\mathrm{~d}, J=7.1 \mathrm{~Hz}, 3 \mathrm{H}), 1.38(\mathrm{~m}, 2 \mathrm{H}), 0.95(\mathrm{t}, J=7.4 \mathrm{~Hz}, 3 \mathrm{H}), 0.003(\mathrm{~s}, 18 \mathrm{H}) ;{ }^{13} \mathrm{C} \mathrm{NMR}$ $\left(101 \mathrm{MHz}, \mathrm{CDCl}_{3}\right) \delta 173.4,165.4,138.1,134.6,130.4,124.2,103.2,96.5,65.8,48.9,30.7,19.2$, 18.9, 13.8; MS (ESI) m/z Calcd. for $\mathrm{C}_{24} \mathrm{H}_{35} \mathrm{NO}_{3} \mathrm{Si}_{2}: \quad 441.2\left(\mathrm{M}^{+}\right)$, Found: $442.1\left(\mathrm{M}+\mathrm{H}^{+}\right)$.

(S)-Butyl 2-(3, 5-diethynylbenzamido)propanoate (10-H). To a solution of 9-H (6.88 g, 15 $\mathrm{mmol})$ in THF $(30 \mathrm{~mL})$, tetrabutylammonium fluoride $(5.87 \mathrm{~g}, 22.5 \mathrm{mmol})$ dissolved in THF (30 $\mathrm{mL}$ ) was added slowly at room temperature. The reaction mixture was stirred for $2 \mathrm{hrs}$, followed by removal of solvent in vacuo to leave a brown solid residue. The solid residue was purified with column chromatography (petroleum ether/acetone $=3 / 1$, silica) to give $\mathbf{1 0 - H}(2.51 \mathrm{~g}, 56 \%)$ as a white solid. mp: 135.0-136.0 ${ }^{\circ} \mathrm{C} .{ }^{1} \mathrm{H}$ NMR (400 MHz, $\left.\mathrm{CDCl}_{3}\right) \delta 7.87(\mathrm{~d}, J=1.5 \mathrm{~Hz}, 2 \mathrm{H})$, $7.72(\mathrm{t}, J=1.5 \mathrm{~Hz}, 1 \mathrm{H}), 6.73(\mathrm{~d}, J=7.0 \mathrm{~Hz}, 1 \mathrm{H}), 4.76(\mathrm{~m}, 1 \mathrm{H}), 4.20(\mathrm{~m}, 2 \mathrm{H}), 3.15(\mathrm{~s}, 2 \mathrm{H}), 1.67$ $(\mathrm{m}, 2 \mathrm{H}), 1.52(\mathrm{~d}, J=7.1 \mathrm{~Hz}, 3 \mathrm{H}), 1.40(\mathrm{~m}, 2 \mathrm{H}), 0.95(\mathrm{t}, J=7.3 \mathrm{~Hz}, 3 \mathrm{H}) ;{ }^{13} \mathrm{C} \mathrm{NMR}(101 \mathrm{MHz}$, $\left.\mathrm{CDCl}_{3}\right) \delta 173.1,165.0,138.2,134.7,130.8,123.2,81.6,79.1,65.6,48.7,30.5,19.0,18.6,13.6$; MS (ESI) m/z Calcd. for $\mathrm{C}_{18} \mathrm{H}_{19} \mathrm{NO}_{3}$ : $297.1\left(\mathrm{M}^{+}\right)$, Found: $298.4\left(\mathrm{M}+\mathrm{H}^{+}\right)$.

Compound 4-H. To a dried, $\mathrm{N}_{2}$ purged flask containing 5-iodo-2-methoxyaniline (229 mg, 1.85 mmol), compound 10-H (250 mg, $0.841 \mathrm{mmol}), \mathrm{Pd}_{2}(\mathrm{dba})_{3}$ (73 mg, $\left.0.079 \mathrm{mmol}\right), \mathrm{CuI}$ (30 mg, 0.1 $\mathrm{mmol})$, and $\mathrm{PPh}_{3}(50 \mathrm{mg}, 0.19 \mathrm{mmol})$ was added THF $(20 \mathrm{~mL})$ and $\mathrm{Et}_{3} \mathrm{~N}(50 \mathrm{~mL})$ using a syringe. The reaction mixture was stirred at $50{ }^{\circ} \mathrm{C}$ for $4 \mathrm{hrs}$ and then filtered by diatomite. The filtrate was evaporated in vacuo to afford the crude product which was purified by column chromatography (petroleum ether/acetone $=3 / 1$, silica gel) to afford $\mathbf{4 - H}$ as a yellow solid (294 mg, 65\%). mp: 87.1-88.5 ${ }^{\circ} \mathrm{C} .{ }^{1} \mathrm{H}$ NMR (400 MHz, $\left.\mathrm{CDCl}_{3}\right) \delta 7.82$ (s, 2H), 7.73 (s, 1H), 6.96 (d, J $=1.80 \mathrm{~Hz}, 2 \mathrm{H}), 6.94(\mathrm{~d}, J=1.8 \mathrm{~Hz}, 2 \mathrm{H}), 6.88(\mathrm{~d}, J=1.76 \mathrm{~Hz}, 2 \mathrm{H}), 6.75(\mathrm{~d}, J=8.28 \mathrm{~Hz}, 2 \mathrm{H})$, $4.82(\mathrm{~m}, 1 \mathrm{H}), 4.22-4.18(\mathrm{~m}, 2 \mathrm{H}), 3.87(\mathrm{~s}, 9 \mathrm{H}), 1.70-1.63(\mathrm{~m}, 2 \mathrm{H}), 1.53(\mathrm{~d}, J=7.21 \mathrm{~Hz}, 3 \mathrm{H}), 1.41$ $(\mathrm{m}, 2 \mathrm{H}), 0.96(\mathrm{t}, J=7.3 \mathrm{~Hz}, 3 \mathrm{H}) ;{ }^{13} \mathrm{C}$ NMR $\left(101 \mathrm{MHz}, \mathrm{CDCl}_{3}\right) \delta 173.19,165.56,148.00,136.76$, $136.16,134.53,129.08,124.73,122.80,117.64,114.96,110.22,91.55,85.99,65.58,55.54$, 48.71, 30.59, 19.07, 18.76, 13.67; MS (ESI) m/z Calcd. for $\mathrm{C}_{32} \mathrm{H}_{33} \mathrm{~N}_{3} \mathrm{O}_{5}: 539.2\left(\mathrm{M}^{+}\right)$, Found: $540.2\left(\mathrm{M}+\mathrm{H}^{+}\right)$.

(S)-Butyl 2-(3， 5-diiodo-4-methylbenzamido)propanoate $\quad$ (8-Me). To a 100-mL round-bottomed flask was added 7-Me (3,5-diiodo-4-methylbenzoic acid) (10.00 g, $25.78 \mathrm{mmol})$ and $\mathrm{SOCl}_{2}(20 \mathrm{~mL})$. The mixture was heated under reflux for $5 \mathrm{hrs}$. Removing unreacted (excess) $\mathrm{SOCl}_{2}$ left a yellow solid. To a dried, ice-cooled flask containing $\mathrm{Et}_{3} \mathrm{~N}$ (5.0 mL, $\left.37.5 \mathrm{mmol}\right)$ and (S)-butyl 2-aminopropanoate hydrochloride $(6.20 \mathrm{~g}, 30.9 \mathrm{mmol})$ was added the solution of the above solid dissolved in $\mathrm{CH}_{2} \mathrm{Cl}_{2}(30 \mathrm{~mL})$. The reaction mixture was stirred for $7 \mathrm{hrs}$ at room temperature, and was filtered, and concentrated in vacuo afterwards. The crude product was purified by column chromatography (petroleum ether/acetone $=20 / 1$, silica gel) to give the 8-Me (10 g, 77\%) as a white solid. mp: $112.0-113.0^{\circ} \mathrm{C} ;{ }^{1} \mathrm{H}$ NMR (400 MHz, $\left.\mathrm{CDCl}_{3}\right) \delta 8.21$ (s, 2H), $6.71(\mathrm{~s}, 1 \mathrm{H}), 4.73-4.70(\mathrm{~m}, 1 \mathrm{H}), 4.27-4.10(\mathrm{~m}, 2 \mathrm{H}), 2.79(\mathrm{~s}, 3 \mathrm{H}), 1.65(\mathrm{~m}, 2 \mathrm{H}), 1.52(\mathrm{~d}, J=6.50$ 
$\mathrm{Hz}, 3 \mathrm{H}), 1.41-1.39(\mathrm{~m}, 2 \mathrm{H}), 0.97(\mathrm{t}, J=7.40 \mathrm{~Hz}, 3 \mathrm{H}) ;{ }^{13} \mathrm{C} \mathrm{NMR}\left(101 \mathrm{MHz}, \mathrm{CDCl}_{3}\right) \delta 173.12$, 163.39, 146.91, 138.01, 134.41, 98.99, 65.66, 48.72, 35.09, 35.07, 30.53, 19.05, 18.64, 13.68; MS (ESI) m/z Calcd. for $\mathrm{C}_{15} \mathrm{H}_{19} \mathrm{I}_{2} \mathrm{NO}_{3}$ : $\left(\mathrm{M}^{+}\right)$514.9, Found: $516.1\left(\mathrm{M}+\mathrm{H}^{+}\right)$.

(S)-Butyl 2-(4-methyl-3, 5-bis((trimethylsilyl)ethynyl)benzamido)propanoate (9-Me). A round-bottomed flask containing 8-Me $(8.60 \mathrm{~g}, 16.69 \mathrm{mmol}), \mathrm{Pd}\left(\mathrm{PPh}_{3}\right)_{2} \mathrm{Cl}_{2}(0.58 \mathrm{~g}, 0.83 \mathrm{mmol})$, $\mathrm{CuI}(0.31 \mathrm{~g}, 1.69 \mathrm{mmol})$, was first degassed, to which THF $(50 \mathrm{ml})$ and $\mathrm{Et}_{3} \mathrm{~N}(20 \mathrm{ml})$ were injected using a syringe, followed by the injection of trimethylsilylethylene $(7.11 \mathrm{~mL}, 50.08$ mmol). The reaction mixture was stirred over night at room temperature. The crude mixture was filtered through a silica gel plug and then concentrated in vacuo. The residue was purified by column chromatography (petroleum ether/ethyl acetate $=10 / 1$, silica gel) to give 9-Me $(3.60 \mathrm{~g}$, $81 \%$ ) as a yellow oil. ${ }^{1} \mathrm{H}$ NMR (400 MHz, $\left.\mathrm{CDCl}_{3}\right) \delta 7.80$ (s, 2H), $6.67(\mathrm{~s}, 1 \mathrm{H}), 4,76-4.72(\mathrm{~m}, 1 \mathrm{H})$, 4.30-4.09 (m, 2H), $2.57(\mathrm{~s}, 3 \mathrm{H}), 1.70-1.60(\mathrm{~m}, 2 \mathrm{H}), 1.52(\mathrm{~d}, J=7.10 \mathrm{~Hz}, 3 \mathrm{H}), 1.40-1.38(\mathrm{~m}, 2 \mathrm{H})$, $0.96(\mathrm{t}, J=7.40 \mathrm{~Hz}, 3 \mathrm{H}), 0.27$ (d, $J=3.40 \mathrm{~Hz}, 18 \mathrm{H}) ;{ }^{13} \mathrm{C} \mathrm{NMR}\left(101 \mathrm{MHz}, \mathrm{CDCl}_{3}\right) \delta 173.33$, $165.28,146.49,131.44,130.71,124.10,102.63,99.92,65.62,48.71,30.65,19.32,19.27,19.13$, 18.83, 13.73, -0.02; MS (ESI) m/z Calcd. for $\mathrm{C}_{25} \mathrm{H}_{37} \mathrm{NO}_{3} \mathrm{Si}_{2}: 455.2\left(\mathrm{M}^{+}\right)$, Found: $457.0\left(\mathrm{M}+\mathrm{H}^{+}\right)$.

(S)-Butyl 2-(3, 5-diethynyl-4-methylbenzamido)propanoate (10-Me). To a solution of 9-Me $(2.13 \mathrm{~g}, 4.65 \mathrm{mmol})$ in THF $(30 \mathrm{~mL})$, tetrabutylammonium fluoride $(4.40 \mathrm{~g}, 14.00 \mathrm{mmol})$ in THF $(30 \mathrm{~mL})$ was added slowly at room temperature. The solution was stirred for $2 \mathrm{hrs}$, and was then evaporated in vacuo to leave a brown solid residue. The solid residue was purified by column chromatography (petroleum ether/acetone $=3 / 1$, silica gel) to give $\mathbf{1 0 - M e}(1.25 \mathrm{~g}, 86 \%)$ as a white solid. mp: $108.4-109.7^{\circ} \mathrm{C} .{ }^{1} \mathrm{H}$ NMR $\left(400 \mathrm{MHz}, \mathrm{CDCl}_{3}\right) \delta 7.87$ (s, 2H), 6.70 (d, J=7.30 Hz, 1H), 4.77-4.75 (m, 1H), 4.28-4.02 (m, 2H), $3.33(\mathrm{~s}, 2 \mathrm{H}), 2.61(\mathrm{~s}, 3 \mathrm{H}), 1.66-1.64(\mathrm{~m}, 2 \mathrm{H}), 1.53(\mathrm{~d}$, $J=7.10 \mathrm{~Hz}, 3 \mathrm{H}), 1.45-1.41(\mathrm{~m}, 2 \mathrm{H}), 0.92(\mathrm{t}, J=7.40 \mathrm{~Hz}, 3 \mathrm{H}) ;{ }^{13} \mathrm{C}$ NMR $\left(101 \mathrm{MHz}, \mathrm{CDCl}_{3}\right)$ $\delta 173.20,165.01,146.90,131.58,131.33,123.16,82.38,82.35,81.14,67.97,65.59,48.65,30.56$, 25.63, 19.15, 19.13, 19.05, 18.71, 13.63; MS (ESI) m/z Calcd. for $\mathrm{C}_{19} \mathrm{H}_{21} \mathrm{NO}_{3}: 311.1\left(\mathrm{M}^{+}\right)$, Found: $312.7\left(\mathrm{M}+\mathrm{H}^{+}\right)$.

Compound 4-Me. To a dried, $\mathrm{N}_{2}$ purged flask containing 5-iodo-2-methoxyaniline ( $830 \mathrm{mg}, 3.2$ mmol), compound 10-Me (500 mg, $1.60 \mathrm{mmol}), \mathrm{Pd}_{2}(\mathrm{dba})_{3}$ (73 mg, $\left.0.079 \mathrm{mmol}\right)$, CuI (30 mg, $0.1 \mathrm{mmol})$, and $\mathrm{PPh}_{3}(50 \mathrm{mg}, 0.19 \mathrm{mmol})$ was added THF $(20 \mathrm{~mL})$ and $\mathrm{Et}_{3} \mathrm{~N}(50 \mathrm{~mL})$ using a syringe. The reaction mixture was stirred at $50{ }^{\circ} \mathrm{C}$ for $4 \mathrm{hrs}$ and then filtered by diatomite. The filtrate was evaporated in vacuo to afford the crude product which was purified by column chromatography (petroleum ether/acetone $=3 / 1$, silica gel) to afford 4-Me as a yellow solid (480 mg, 54\%). mp: $114.3-115.9{ }^{\circ} \mathrm{C} .{ }^{1} \mathrm{H}$ NMR (400 MHz, $\left.\mathrm{CDCl}_{3}\right) \delta 7.83$ (s, 2H), 6.97 (d, J=8.12 Hz, 2H), $6.77(\mathrm{~s}, 2 \mathrm{H}), 6.74(\mathrm{~d}, J=8.28 \mathrm{~Hz}, 2 \mathrm{H}), 4.79(\mathrm{~m}, 1 \mathrm{H}), 4.21-4.18(\mathrm{~m}, 2 \mathrm{H}), 3.88(\mathrm{~s}, 10 \mathrm{H}), 2.7$ (s, 3H), 1.68-1.63 (m, 2H), $1.52(\mathrm{~d}, J=7.04 \mathrm{~Hz}, 3 \mathrm{H}), 1.43-1.38(\mathrm{~m}, 2 \mathrm{H}), 0.95(\mathrm{t}, J=7.28 \mathrm{~Hz}$, $3 \mathrm{H}) .{ }^{13} \mathrm{C}$ NMR $\left(101 \mathrm{MHz}, \mathrm{CDCl}_{3}\right) \delta 173.30,165.68,147.90,144.98,136.18,131.42,129.58$, 
$124.50,122.59,117.53,115.18,110.17,94.99,85.51,65.51,55.52,48.66,30.56,19.38,19.07$, 18.65, 13.70; MS (ESI) m/z Calcd. for $\mathrm{C}_{33} \mathrm{H}_{35} \mathrm{~N}_{3} \mathrm{O}_{5}$ : 553.2( $\left(\mathrm{M}^{+}\right)$, Found: $554.2\left(\mathrm{M}+\mathrm{H}^{+}\right)$.

(S)-Butyl 2-(4-fluoro-3, 5-diiodobenzamido)propanoate (8-F). To a 100-mL round-bottomed flask was added 7-F (4-fluoro-3,5-diiodobenzoic acid) (5.00 g, $12.78 \mathrm{mmol}$ ) and $\mathrm{SOCl}_{2}(10 \mathrm{~mL})$. The mixture was heated under reflux for $5 \mathrm{hrs}$. Removing unreacted (excess) $\mathrm{SOCl}_{2}$ left a yellow solid. To a dried, ice-cooled flask containing $\mathrm{Et}_{3} \mathrm{~N}(2.5 \mathrm{~g}, 25.56 \mathrm{mmol})$ and $(S)$-butyl 2-aminopropanoate hydrochloride $(2.31 \mathrm{~g}, 12.78 \mathrm{mmol})$ was added the solution of the above solid dissolved in $\mathrm{CH}_{2} \mathrm{Cl}_{2}(40 \mathrm{~mL})$. The reaction mixture was stirred for $7 \mathrm{hrs}$ at room temperature, and was filtered and concentrated in vacuo afterwards. The crude product was purified by column chromatography (petroleum ether/acetone $=20 / 1$, silica gel) to give $\mathbf{8 - F}(4.47$ g, 67\%) as a white solid. mp: 106.3-107.3 ${ }^{\circ} \mathrm{C} .{ }^{1} \mathrm{H}$ NMR (400 MHz, DMSO-d 6 ) $\delta 8.88$ (d, $J=5.28$ $\mathrm{Hz}, 1 \mathrm{H}), 8.03(\mathrm{~d}, J=6.08 \mathrm{~Hz}, 2 \mathrm{H}), 4.46-4.41(\mathrm{~m}, 1 \mathrm{H}), 4.14-4.03(\mathrm{~m}, 2 \mathrm{H}), 1.61-1.45(\mathrm{~m}, 2 \mathrm{H})$, $1.44(\mathrm{~d}, J=7.12 \mathrm{~Hz}, 3 \mathrm{H}), 1.36-1.29(\mathrm{~m}, 2 \mathrm{H}), 0.88(\mathrm{t}, J=7.44 \mathrm{~Hz}, 3 \mathrm{H}) .{ }^{13} \mathrm{C} \mathrm{NMR}(101 \mathrm{MHz}$, $\left.\mathrm{CDCl}_{3}\right) \delta 173.27,163.02,138.66,133.02,80.60,80.31,65.73,48.80,30.52,19.04,18.44,13.66$; MS (ESI) m/z Calcd. for $\mathrm{C}_{14} \mathrm{H}_{16} \mathrm{FI}_{2} \mathrm{NO}_{3}: 518.9\left(\mathrm{M}^{+}\right)$, Found: $519.9\left(\mathrm{M}+\mathrm{H}^{+}\right)$.

(S)-Butyl 2-(4-fluoro-3, 5-bis((trimethylsilyl)ethynyl)benzamido)propanoate (9-F). A round-bottomed flask containing 8-F (3.00 g, $5.78 \mathrm{mmol}), \mathrm{Pd}\left(\mathrm{PPh}_{3}\right)_{2} \mathrm{Cl}_{2}(0.35 \mathrm{~g}, 0.50 \mathrm{mmol})$, $\mathrm{CuI}(26 \mathrm{mg}, 0.5 \mathrm{mmol})$, was first degassed, to which THF $(50 \mathrm{~mL})$ and $\mathrm{Et}_{3} \mathrm{~N}(20 \mathrm{~mL})$ were injected using a syringe, followed by the injection of trimethylsilylethylene $(2.26 \mathrm{~mL}, 17.34$ $\mathrm{mmol}$ ). The reaction mixture was stirred over night at room temperature. The crude mixture was filtered through a silica gel plug and then concentrated in vacuo. The residue was purified by column chromatography (petroleum ether/ethyl acetate $=20 / 1$, silica gel) to give 9-F (1.98 g, $75 \%)$ as a yellow oil. ${ }^{1} \mathrm{H}$ NMR $\left(400 \mathrm{MHz}, \mathrm{CDCl}_{3}\right) \delta 7.80(\mathrm{~d}, J=6.16 \mathrm{~Hz}, 2 \mathrm{H}), 6.79(\mathrm{~d}, J=7.04$ $\mathrm{Hz}, 1 \mathrm{H}), 4.73-4.66(\mathrm{~m}, 1 \mathrm{H}), 4.20-4.10(\mathrm{~m}, 2 \mathrm{H}), 1.65-1.49(\mathrm{~m}, 2 \mathrm{H}), 1.48(\mathrm{~d}, J=7.16 \mathrm{~Hz}, 3 \mathrm{H})$, $0.91(\mathrm{t}, J=7.36 \mathrm{~Hz}, 3 \mathrm{H}) ;{ }^{13} \mathrm{C} \mathrm{NMR}\left(101 \mathrm{MHz}, \mathrm{CDCl}_{3}\right) \delta 173.43,164.68,132.85,132.83,130.20$, $130.16,113.06,112.90,102.50,102.46,96.42,65.89,49.03,30.84,19.34,18.88,13.94,0.00 ; \mathrm{MS}$ (ESI) $\mathrm{m} / \mathrm{z}$ Calcd. for $\mathrm{C}_{24} \mathrm{H}_{34} \mathrm{FNO}_{3} \mathrm{Si}_{2}: 459.2(\mathrm{M}+)$, Found: $460.2\left(\mathrm{M}+\mathrm{H}^{+}\right)$.

(S)-Butyl 2-(3, 5-diethynyl-4-fluorobenzamido)propanoate (10-F). To a solution of 9-F (2.00 $\mathrm{g}, 4.35 \mathrm{mmol})$ in THF $(30 \mathrm{~mL})$, tetrabutylammonium fluoride $(1.13 \mathrm{~g}, 8.70 \mathrm{mmol})$ in THF (30 $\mathrm{mL}$ ) was added slowly at room temperature. The solution was stirred for $2 \mathrm{hrs}$, and was then evaporated in vacuo to leave a brown solid residue. The solid residue was purified by column chromatography (petroleum ether/acetone $=5 / 1$, silica gel) to give $\mathbf{1 0 - F}(0.83 \mathrm{~g}, 61 \%)$ as a white solid. mp: 104.8-106.4 ${ }^{\circ} \mathrm{C} .{ }^{1} \mathrm{H}$ NMR $\left(400 \mathrm{MHz}, \mathrm{CDCl}_{3}\right) \delta 7.90(\mathrm{~d}, J=6.12 \mathrm{~Hz}, 2 \mathrm{H}), 6.77(\mathrm{~d}, J=$ $6.80 \mathrm{~Hz}, 1 \mathrm{H}), 4.78-4.70(\mathrm{~m}, 1 \mathrm{H}), 4.22-4.15(\mathrm{~m}, 2 \mathrm{H}), 3.38(\mathrm{~s}, 2 \mathrm{H}), 1.69-1.62(\mathrm{~m}, 2 \mathrm{H}), 1.51(\mathrm{~d}, J=$ $7.16 \mathrm{~Hz}, 3 \mathrm{H}), 1.44-1.35(\mathrm{~m}, 2 \mathrm{H}), 0.95(\mathrm{t}, J=7.36 \mathrm{~Hz}, 3 \mathrm{H}) ;{ }^{13} \mathrm{C}$ NMR $\left(101 \mathrm{MHz}, \mathrm{CDCl}_{3}\right)$ $\delta 173.08,164.09,133.20,111.84,111.67,84.20,84.17,75.30,65.67,48.75,30.52,19.02,18.58$, 
13.62; MS (ESI) m/z Calcd. for $\mathrm{C}_{18} \mathrm{H}_{18} \mathrm{FNO}_{3}: 315.1\left(\mathrm{M}^{+}\right)$, Found: $316.1\left(\mathrm{M}+\mathrm{H}^{+}\right)$.

Compound 4-F. To a dried, $\mathrm{N}_{2}$ purged flask containing 5-iodo-2-methoxyaniline $(830 \mathrm{mg}, 3.2$ mmol), compound 10-F (500 mg, $1.58 \mathrm{mmol}), \mathrm{Pd}_{2}(\mathrm{dba})_{3}$ (146 mg, $\left.0.159 \mathrm{mmol}\right), \mathrm{CuI}$ (30 mg, $0.157 \mathrm{mmol})$, and $\mathrm{PPh}_{3}(50 \mathrm{mg}, 0.19 \mathrm{mmol})$ was added THF $(30 \mathrm{~mL})$ and $\mathrm{Et}_{3} \mathrm{~N}(40 \mathrm{~mL})$ using a syringe. The reaction mixture was stirred at $50{ }^{\circ} \mathrm{C}$ for $4 \mathrm{hrs}$ and then filtered by diatomite. The filtrate was evaporated in vacuo to afford the crude product which was purified by column chromatography (petroleum ether/acetone $=3 / 1$, silica gel) to afford $\mathbf{4 - F}$ as a yellow solid (510 mg, 58\%). mp: 92.6-93.7 ${ }^{\circ} \mathrm{C} .{ }^{1} \mathrm{H}$ NMR (400 MHz, $\left.\mathrm{CDCl}_{3}\right) \delta 8.10(\mathrm{~d}, J=1.28 \mathrm{~Hz}, 2 \mathrm{H}), 7.80(\mathrm{~s}$, $1 \mathrm{H}), 6.96(\mathrm{dd}, J=7.84,1.72 \mathrm{~Hz}, 2 \mathrm{H}), 6.89(\mathrm{~d}, J=1.52 \mathrm{~Hz}, 2 \mathrm{H}), 7.75(\mathrm{~d}, J=8.28 \mathrm{~Hz}), 5.34(\mathrm{q}, J$ $=6.96 \mathrm{~Hz}, 1 \mathrm{H}), 4.20-4.16(\mathrm{~m}, 2 \mathrm{H}), 3.88(\mathrm{~s}, 10 \mathrm{H}), 1.67-1.60(\mathrm{~m}, 5 \mathrm{H}), 1.42-1.32(\mathrm{~m}, 2 \mathrm{H}), 0.92(\mathrm{t}$, $J=7.36 \mathrm{~Hz}, 3 \mathrm{H}) ;{ }^{13} \mathrm{C} \mathrm{NMR}\left(101 \mathrm{MHz}, \mathrm{CDCl}_{3}\right) \delta 173.18,165.55,147.99,136.75,136.16,134.53$, $129.07,124.72,122.80,117.63,114.95,110.22,91.54,85.98,65.58,55.54,48.70,30.58,19.06$, 18.75, 13.66. MS (ESI) m/z Calcd. for $\mathrm{C}_{32} \mathrm{H}_{32} \mathrm{FN}_{3} \mathrm{O}_{5}:$ 557.2( $\left.\mathrm{M}^{+}\right)$, Found: $558.2\left(\mathrm{M}+\mathrm{H}^{+}\right)$.

(S)-Butyl 2-(4-nitrobenzamido)propanoate (12). Compound 11 (4-nitrobenzoic acid) (10.00 g, $59 \mathrm{mmol})$ and $\mathrm{SOCl}_{2}(20 \mathrm{~mL})$ were mixed in a $100-\mathrm{mL}$ round-bottomed flask and then heated under reflux for $5 \mathrm{hrs}$. Removing unreacted (excess) $\mathrm{SOCl}_{2}$ in vacuo gave a yellow solid. To a dried, ice-cooled flask containing $\mathrm{Et}_{3} \mathrm{~N}(16.50 \mathrm{~mL}, 118 \mathrm{mmol})$ and $(\mathrm{S})$-butyl 2-aminopropanoate hydrochloride $(10.8 \mathrm{~g}, 59 \mathrm{mmol})$ was added the solution of the above solid dissolved in $\mathrm{CH}_{2} \mathrm{Cl}_{2}$ $(30 \mathrm{~mL})$. The reaction mixture was stirred for $7 \mathrm{hrs}$ at room temperature, and then filtered and concentrated in vacuo. The crude product was purified by column chromatography (petroleum ether/acetone $=20 / 1$, silica gel) to give $11(16.40 \mathrm{~g}, 94 \%)$ as a white solid. $\mathrm{mp}: 115.9-116.2{ }^{\circ} \mathrm{C}$.

${ }^{1} \mathrm{H}$ NMR (400 MHz, $\mathrm{CDCl}_{3}$ ) $\delta 8.30(\mathrm{dd}, J=6.92,2.12 \mathrm{~Hz}, 2 \mathrm{H}), 8.29(\mathrm{dd}, J=6.92,1.92 \mathrm{~Hz}, 2 \mathrm{H})$, $6.90(\mathrm{~d}, J=6.68 \mathrm{~Hz}, 1 \mathrm{H}), 4.82-4.75(\mathrm{~m}, 1 \mathrm{H}), 4.26-4.16(\mathrm{~m}, 2 \mathrm{H}), 1.70-1.63(\mathrm{~m}, 2 \mathrm{H}), 1.54(\mathrm{~d}, J=$ $7.12 \mathrm{~Hz}, 3 \mathrm{H}), 1.45-1.36(\mathrm{~m}, 2 \mathrm{H}), 0.95(\mathrm{t}, J=7.36 \mathrm{~Hz}, 3 \mathrm{H}) ;{ }^{13} \mathrm{C}$ NMR $\left(101 \mathrm{MHz}, \mathrm{CDCl}_{3}\right)$ $\delta 172.11,163.84,148.63,138.40,127.33,122.67,64.68,47.85,29.51,18.01,17.26,12.62 ; \mathrm{MS}$ (ESI) $\mathrm{m} / \mathrm{z}$ Calcd. for $\mathrm{C}_{14} \mathrm{H}_{18} \mathrm{~N}_{2} \mathrm{O}_{5}: 294.1\left(\mathrm{M}^{+}\right)$, Found: $295.1\left(\mathrm{M}+\mathrm{H}^{+}\right)$.

(S)-Butyl 2-(4-aminobenzamido)propanoate (13). A solution of 12 (2.00 g, $6.80 \mathrm{mmol})$ in THF $(50 \mathrm{~mL})$ and $\mathrm{MeOH}(20 \mathrm{~mL})$ was hydrogenated in the presence of $10 \% \mathrm{Pd} / \mathrm{C}(200 \mathrm{mg})$ at $0.3 \mathrm{MPa}$ for $7 \mathrm{hrs}$ at room temperature. The reaction mixture was filtered and concentrated in vacuo to give a white solid (1.70g, 95\%). mp: 135.4-137.2 ${ }^{\circ} \mathrm{C} .{ }^{1} \mathrm{H}$ NMR (400 MHz, $\left.\mathrm{CDCl}_{3}\right) \delta 7.63$ $(\mathrm{d}, J=8.52 \mathrm{~Hz}, 2 \mathrm{H}), 6.65(\mathrm{~d}, J=8.52 \mathrm{~Hz}, 2 \mathrm{H}), 6.58(\mathrm{~d}, J=6.52 \mathrm{~Hz}, 1 \mathrm{H}), 4.80-4.73(\mathrm{~m}, 1 \mathrm{H})$, 4.21-4.14 (m, 2H), 1.68-1.61 (m, 2H), 1.49 (d, $J=7.12 \mathrm{~Hz}, 3 \mathrm{H}), 1.44-1.35$ (m, 2H), 0.94 (t, $J=$ $8.40 \mathrm{~Hz}, 3 \mathrm{H}) ;{ }^{13} \mathrm{C} \mathrm{NMR}\left(101 \mathrm{MHz}, \mathrm{CDCl}_{3}\right) \delta 173.64,166.49,149.74,128.82,123.54,114.11$, 65.34, 48.41, 30.55, 19.03, 18.90, 13.64; MS (ESI) m/z Calcd. for $\mathrm{C}_{14} \mathrm{H}_{20} \mathrm{~N}_{2} \mathrm{O}_{3}: 264.1\left(\mathrm{M}^{+}\right)$, Found: $265.1\left(\mathrm{M}+\mathrm{H}^{+}\right)$.

(S)-Butyl 2-(4-amino-3, 5-diiodobenzamido)propanoate (8- $\left.\mathbf{N H}_{2}\right)$. Compound $\mathbf{1 3}$ (2.00 g, 7.57 
mmol ), $\mathrm{I}_{2}(4.23 \mathrm{~g}, 16.67 \mathrm{mmol})$, and silver sulfate $(5.18 \mathrm{~g}, 16.67 \mathrm{mmol})$ were mixed in ethanol $(50 \mathrm{~mL})$. The mixture was stirred for $6 \mathrm{hrs}$ at room temperature, and was filtered and concentrated in vacuo. The crude product was purified by column chromatography (petroleum ether/acetone $=5 / 1)$ to give $\mathbf{8}-\mathbf{N H}_{2}(2.10 \mathrm{~g}, 54 \%)$ as a white solid.mp: $140.2-141.6{ }^{\circ} \mathrm{C} .{ }^{1} \mathrm{H}$ NMR $\left(400 \mathrm{MHz}, \mathrm{CDCl}_{3}\right) \delta 8.08(\mathrm{~s}, 2 \mathrm{H}), 6.51(\mathrm{~s}, 1 \mathrm{H}), 4.95(\mathrm{~s}, 2 \mathrm{H}), 4.76-4.69(\mathrm{~m}, 1 \mathrm{H}), 4.23-4.14(\mathrm{~m}$, 2H), 1.69-1.62 (m, 2H), $1.50(\mathrm{~d}, J=7.12 \mathrm{~Hz}, 3 \mathrm{H}), 1.52-1.35(\mathrm{~m}, 2 \mathrm{H}), 0.95(\mathrm{t}, J=8.36 \mathrm{~Hz}, 3 \mathrm{H})$; ${ }^{13} \mathrm{C}$ NMR $\left(101 \mathrm{MHz}, \mathrm{CDCl}_{3}\right) \delta 173.46,163.63,148.48,138.47,126.22,79.94,65.53,48.58$, 30.54, 19.04, 18.67, 13.66; MS (ESI) m/z Calcd. for $\mathrm{C}_{14} \mathrm{H}_{18} \mathrm{I}_{2} \mathrm{~N}_{2} \mathrm{O}_{3}: 515.9\left(\mathrm{M}^{+}\right)$, Found: 516.9 (M $\left.+\mathrm{H}^{+}\right)$.

\section{(S)-Butyl 2-(4-amino-3, 5-bis((trimethylsilyl)ethynyl)benzamido)propanoate (9-- $\left.\mathrm{NH}_{2}\right)$.}

A round-bottomed flask containing 8- $\mathbf{N H}_{2}(1.00 \mathrm{~g}, 1.90 \mathrm{mmol}), \mathrm{Pd}\left(\mathrm{PPh}_{3}\right)_{2} \mathrm{Cl}_{2}(133 \mathrm{mg}, 0.19$ $\mathrm{mmol}), \mathrm{CuI}(36 \mathrm{mg}, 0.19 \mathrm{mmol})$ was first degassed, to which THF $(50 \mathrm{~mL})$ and $\mathrm{Et}_{3} \mathrm{~N}(20 \mathrm{~mL})$ were injected using a syringe, followed by the injection of trimethylsilylethylene $(0.57 \mathrm{~mL}, 5.80$ mmol). The reaction mixture was stirred over night at room temperature. The crude mixture was filtered through a silica gel plug and then concentrated in vacuo. The residue was purified by column chromatography (petroleum ether/ethyl acetate $=20 / 1$, silica gel) to give $\mathbf{9}-\mathbf{N H}_{\mathbf{2}}(0.70 \mathrm{~g}$, $89 \%$ ) as a yellow oil. ${ }^{1} \mathrm{H}$ NMR $\left(400 \mathrm{MHz}, \mathrm{CDCl}_{3}\right) \delta 7.71(\mathrm{~s}, 1 \mathrm{H}), 6.60(\mathrm{~d}, J=7.24 \mathrm{~Hz}, 1 \mathrm{H}), 5.12$ (s, 2H), 4.74-4.67 (m, 1H), 4.19-4.10 (m, 2H), 1.65-1.58 (m, 2H), 1.45 (d, J= 7.12 Hz, 3H), $1.40-1.31(\mathrm{~m}, 2 \mathrm{H}), 0.91(\mathrm{t}, J=7.36 \mathrm{~Hz}, 3 \mathrm{H}), 0.23(\mathrm{~s}, 18 \mathrm{H}) ;{ }^{13} \mathrm{C}$ NMR $\left(101 \mathrm{MHz}, \mathrm{CDCl}_{3}\right)$ $\delta 173.47,165.17,151.94,131.71,122.31,106.85,101.12,100.12,65.40,48.47,30.54,19.04$, 18.80, 13.67, 0.00; MS (ESI) m/z Calcd. for $\mathrm{C}_{24} \mathrm{H}_{36} \mathrm{~N}_{2} \mathrm{O}_{3} \mathrm{Si}_{2}: 456.2\left(\mathrm{M}^{+}\right)$, Found: 457.2 (M + $\left.\mathrm{H}^{+}\right)$.

(S)-Butyl 2-(4-amino-3, 5-diethynylbenzamido)propanoate (10- $\left.\mathbf{N H}_{2}\right)$. To a solution of 9-NH $(2.70 \mathrm{~g}, 5.92 \mathrm{mmol})$ in THF $(30 \mathrm{~mL})$, tetrabutylammonium fluoride $(4.60 \mathrm{~g}, 17.6 \mathrm{mmol})$ in THF $(30 \mathrm{~mL})$ was added slowly at room temperature. The solution was stirred for $2 \mathrm{hrs}$, and was then evaporated in vacuo to leave a brown solid residue. The solid residue was purified by column chromatography (petroleum ether/acetone $=3 / 1$, silica gel) to give $\mathbf{1 0}-\mathbf{N H}_{\mathbf{2}}(0.90 \mathrm{~g}, 49 \%)$ as a white solid. mp: $113.5-114.2^{\circ} \mathrm{C} .{ }^{1} \mathrm{H}$ NMR $\left(400 \mathrm{MHz}, \mathrm{CDCl}_{3}\right) \delta 7.79$ (s, 2H), 6.55 (d, J=6.96 Hz, $1 \mathrm{H}), 5.17(\mathrm{~s}, 1 \mathrm{H}), 4.77-4.70(\mathrm{~m}, 1 \mathrm{H}), 4.23-4.13(\mathrm{~m}, 2 \mathrm{H}), 3.43(\mathrm{~s}, 2 \mathrm{H}), 1.68-1.61(\mathrm{~m}, 2 \mathrm{H}), 1.49(\mathrm{~d}$, $J=7.12 \mathrm{~Hz}, 3 \mathrm{H}), 1.44-1.35(\mathrm{~m}, 2 \mathrm{H}), 0.94(\mathrm{t}, J=7.36 \mathrm{~Hz}, 3 \mathrm{H}) ;{ }^{13} \mathrm{C}$ NMR $\left(101 \mathrm{MHz}, \mathrm{CDCl}_{3}\right)$ $\delta 173.43,165.04,152.48,132.46,122.62,105.95,83.59,79.10,65.49,48.56,30.60,19.07,18.83$, 13.65; MS (ESI) m/z Calcd. for $\mathrm{C}_{18} \mathrm{H}_{2} \mathrm{ON}_{2} \mathrm{O}_{3}: \quad 312.1\left(\mathrm{M}^{+}\right)$, Found: $313.1\left(\mathrm{M}+\mathrm{H}^{+}\right)$.

Compound 4- $\mathbf{N H}_{2}$. To a dried, $\mathrm{N}_{2}$ purged flask containing 5-iodo-2-methoxyaniline (661 mg, $2.60 \mathrm{mmol}$ ), compound 10- $\mathbf{N H}_{2}$ (416 mg, $\left.1.30 \mathrm{mmol}\right), \mathrm{Pd}_{2}(\mathrm{dba})_{3}(238 \mathrm{mg}, 0.13 \mathrm{mmol}), \mathrm{CuI}(49$ $\mathrm{mg}, 0.13 \mathrm{mmol})$, and $\mathrm{PPh}_{3}(68 \mathrm{mg}, 0.13 \mathrm{mmol})$ was added THF $(20 \mathrm{~mL})$ and $\mathrm{Et}_{3} \mathrm{~N}(50 \mathrm{~mL})$ using a syringe. The reaction mixture was stirred at $50{ }^{\circ} \mathrm{C}$ for $4 \mathrm{hrs}$ and then filtered by diatomite. The 
filtrate was evaporated in vacuo to afford the crude product which was purified by column chromatography (petroleum ether/acetone $=3 / 1$, silica gel) to afford $\mathbf{4}-\mathbf{N H}_{\mathbf{2}}$ as a yellow solid (403 mg, 56\%). mp: 90.1-91.6 ${ }^{\circ} \mathrm{C} .{ }^{1} \mathrm{H}$ NMR (400 MHz, $\left.\mathrm{CDCl}_{3}\right) \delta 7.78$ (s, 2H), 6.95 (d, $J=8.08$ Hz, 2H), 6.89 (s, 2H), $6.76(\mathrm{~d}, J=8.08 \mathrm{~Hz}, 2 \mathrm{H}), 6.59$ (d, $J=7.00 \mathrm{~Hz}, 1 \mathrm{H}), 5.17(\mathrm{~s}, 1 \mathrm{H})$, 4.79-4.75 (m, 1H), 4.20-4.17 (m, 2H), $3.88(\mathrm{~s}, 10 \mathrm{H}), 1.67-1.62(\mathrm{~m}, 2 \mathrm{H}), 1.50$ (d, $J=7.00 \mathrm{~Hz}$, $3 \mathrm{H}), 1.42-1.37$ (m, 2H), 0.94 (t, $J=7.32 \mathrm{~Hz}, 3 \mathrm{H}) ;{ }^{13} \mathrm{C} \mathrm{NMR}\left(101 \mathrm{MHz}, \mathrm{CDCl}_{3}\right) \delta 173.20,164.79$, $148.19,136.18,131.25,130.01,122.92,117.64,114.60,113.35,113.19,110.16,96.60,79.64$, 65.61, 55.53, 48.75, 30.56, 19.06, 18.67, 13.67; MS (ESI) m/z Calcd for $\mathrm{C}_{32} \mathrm{H}_{34} \mathrm{~N}_{4} \mathrm{O}_{5}: 554.2\left(\mathrm{M}^{+}\right)$, Found: $555.2\left(\mathrm{M}+\mathrm{H}^{+}\right)$. 


\section{VI. ${ }^{1} \mathrm{H}$ and ${ }^{13} \mathrm{C}$ NMR Spectra of Precursors}

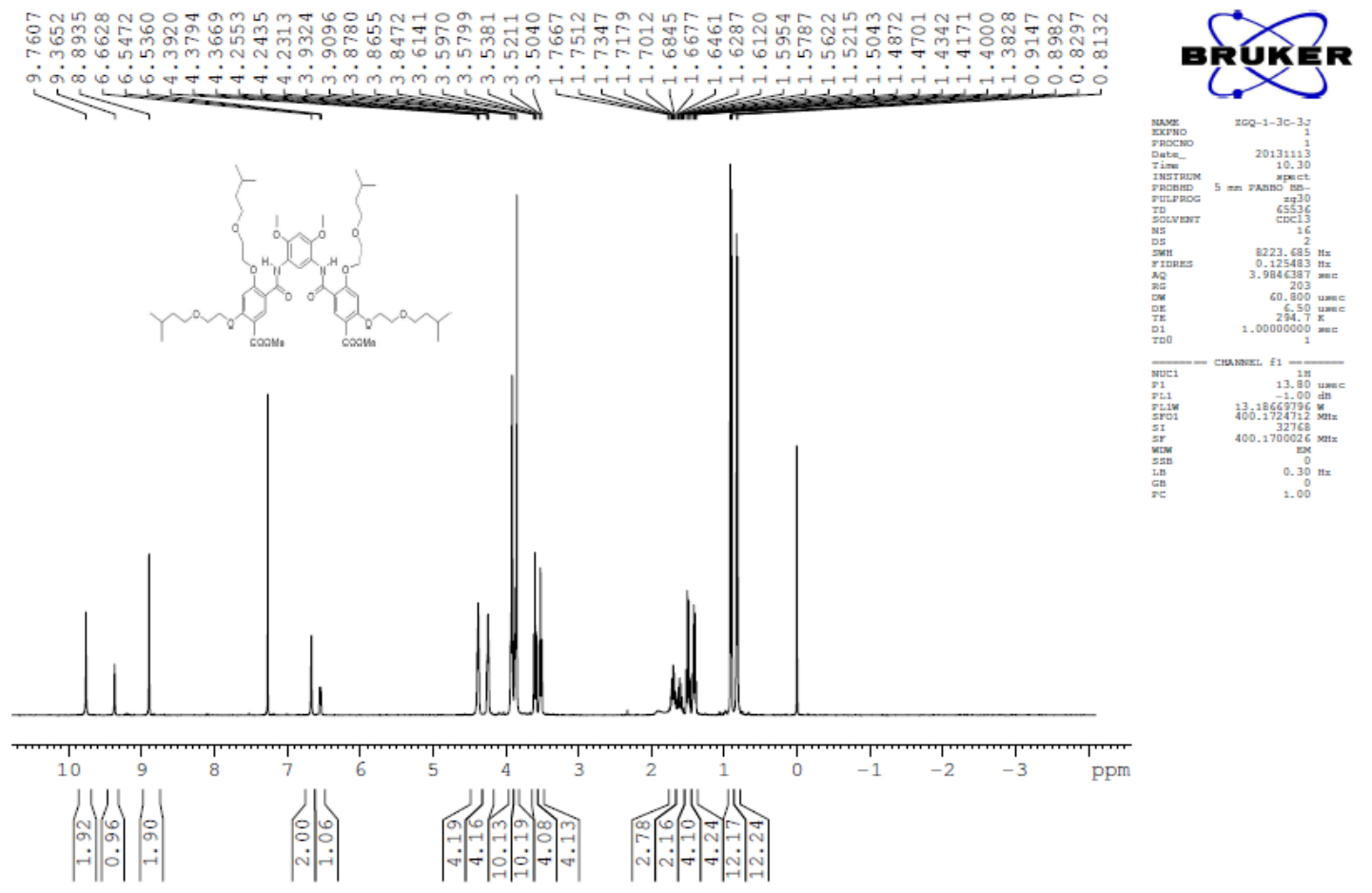

Figure S13. ${ }^{1} \mathrm{H}$ NMR Spectrum of compound 1.4 in $\mathrm{CDCl}_{3}$ at ambient temperature (400 MHz).

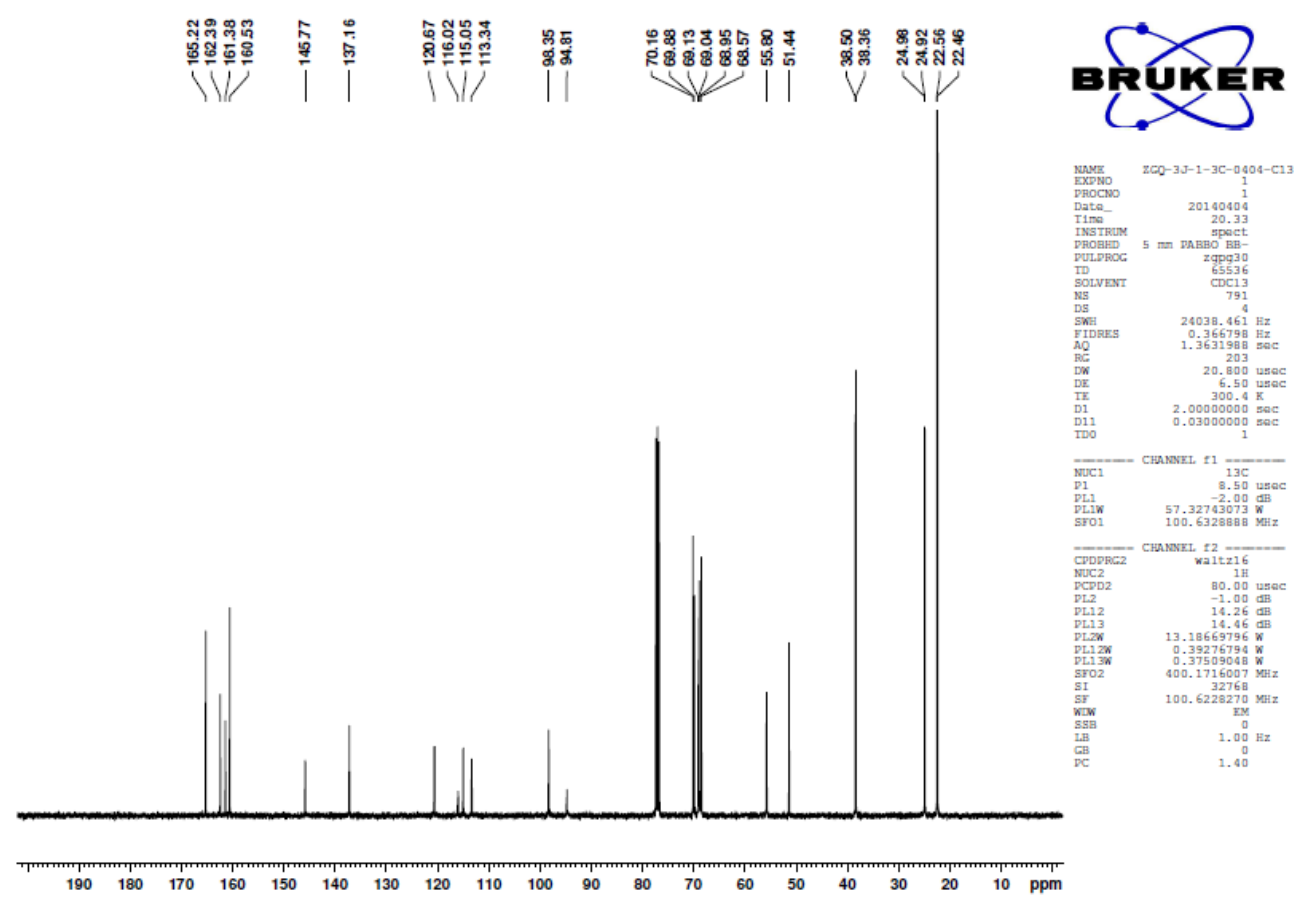

Figure S14. ${ }^{13} \mathrm{C}$ NMR Spectrum of compound 1.4 in $\mathrm{CDCl}_{3}$ at ambient temperature $(101 \mathrm{MHz})$. 


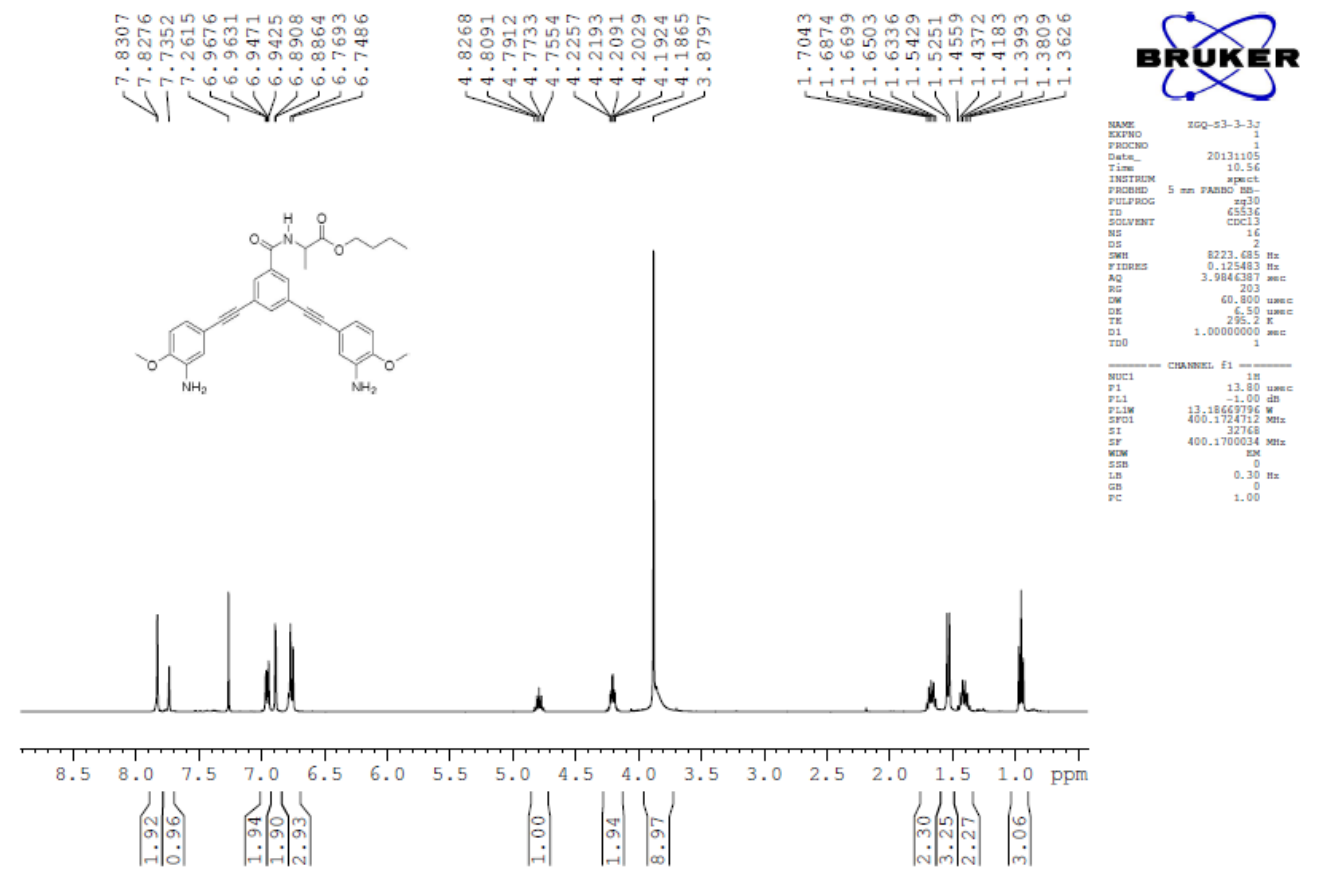

Figure S15. ${ }^{1} \mathrm{H}$ NMR Spectrum of compound $\mathbf{4 - H}$ in $\mathrm{CDCl}_{3}$ at ambient temperature (400 MHz).

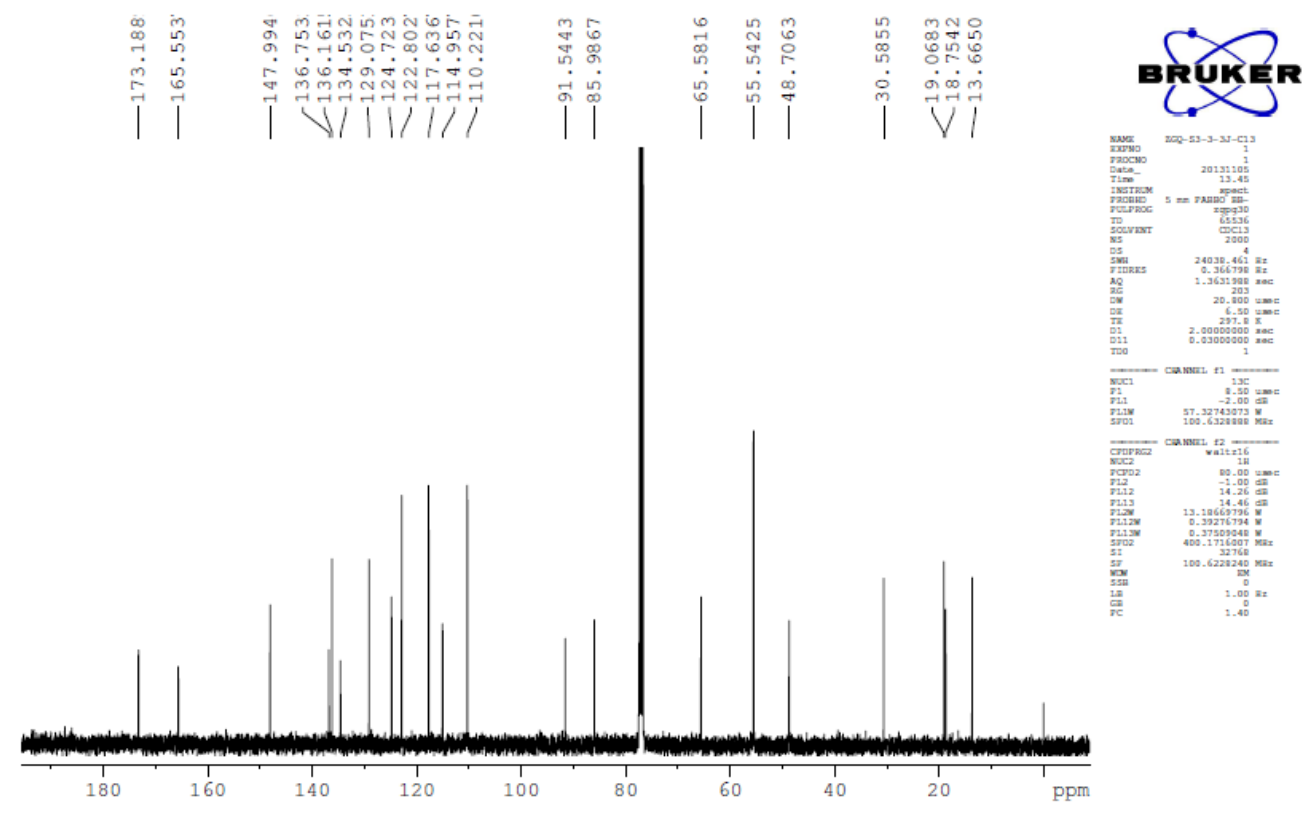

Figure S16. ${ }^{13} \mathrm{C}$ NMR Spectrum of compound $\mathbf{4 - H}$ in $\mathrm{CDCl}_{3}$ at ambient temperature (101 MHz). 


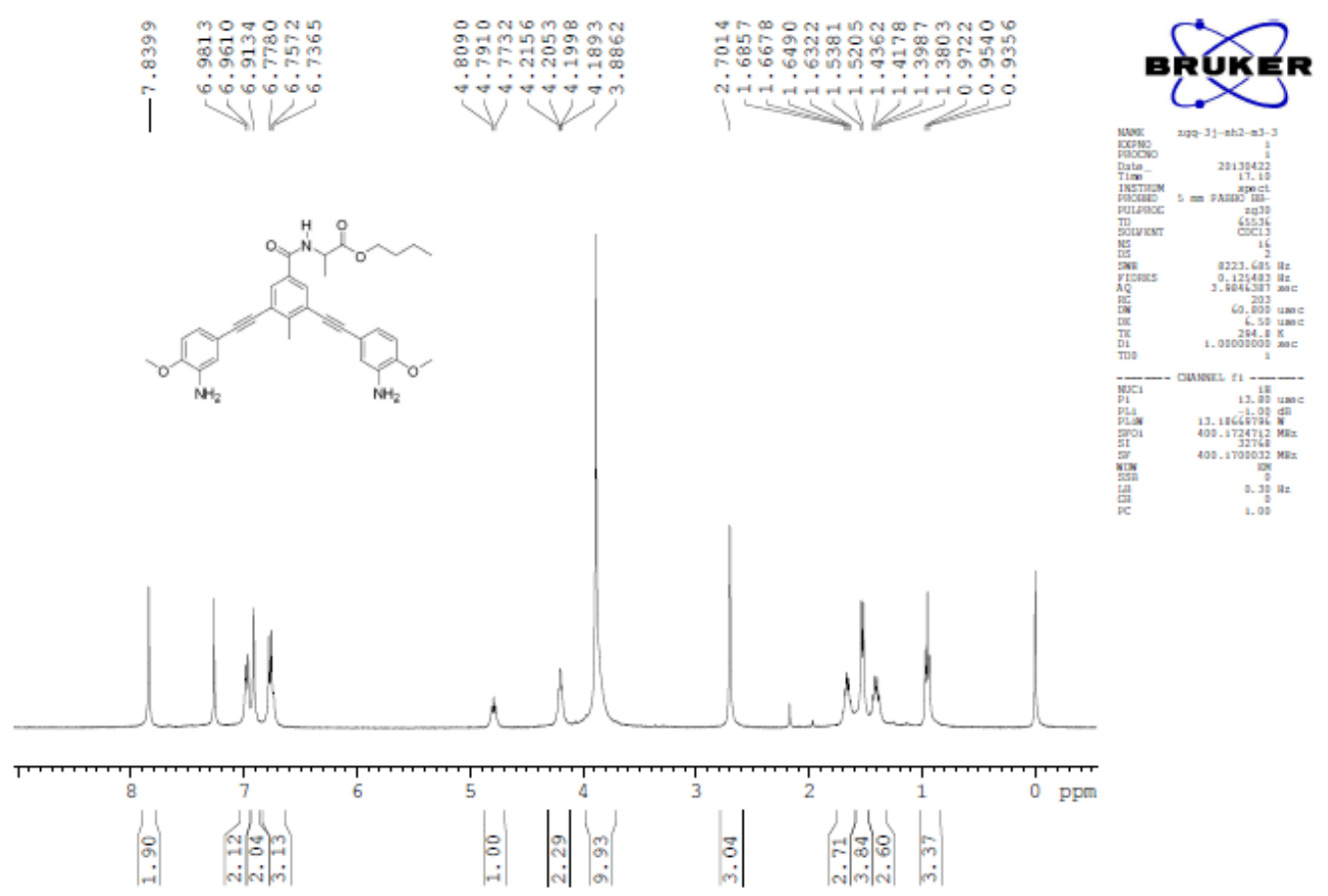

Figure S17. ${ }^{1} \mathrm{H}$ NMR Spectrum of compound 4-Me in $\mathrm{CDCl}_{3}$ at ambient temperature (400 MHz).

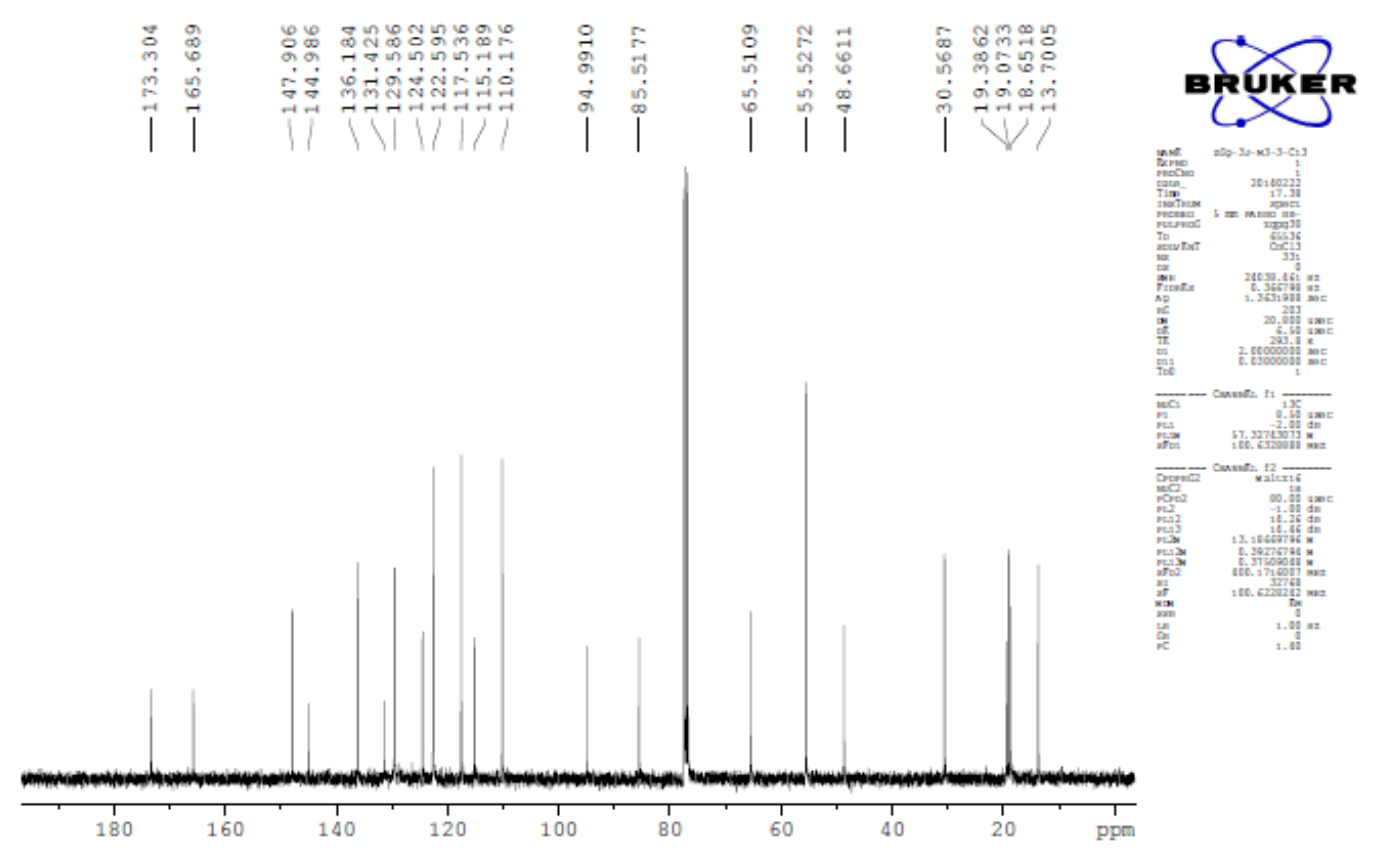

Figure S18. ${ }^{13} \mathrm{C}$ NMR Spectrum of compound 4-Me in $\mathrm{CDCl}_{3}$ at ambient temperature (101 MHz). 


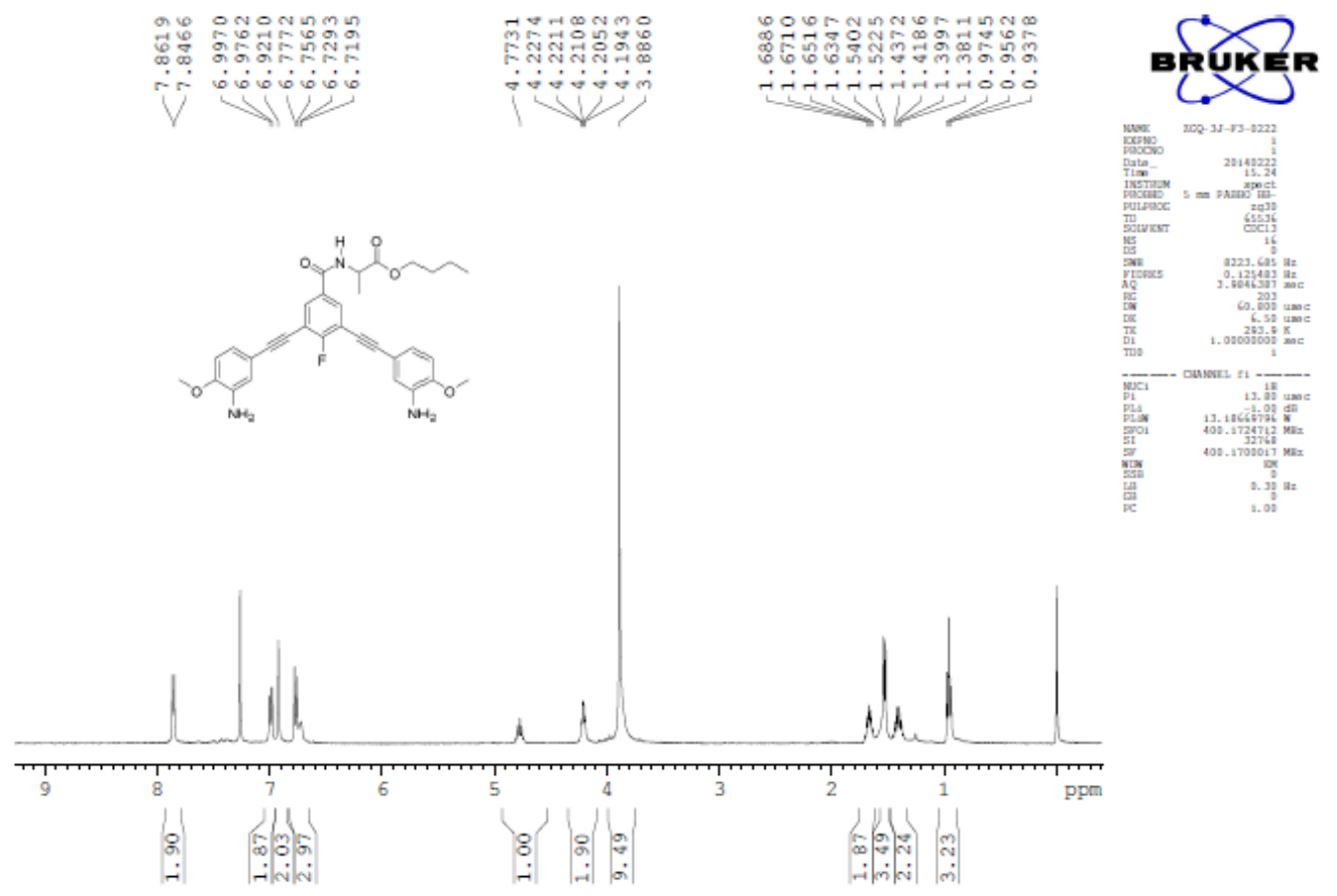

Figure S19. ${ }^{1} \mathrm{H}$ NMR Spectrum of compound 4-F in $\mathrm{CDCl}_{3}$ at ambient temperature (400 MHz).

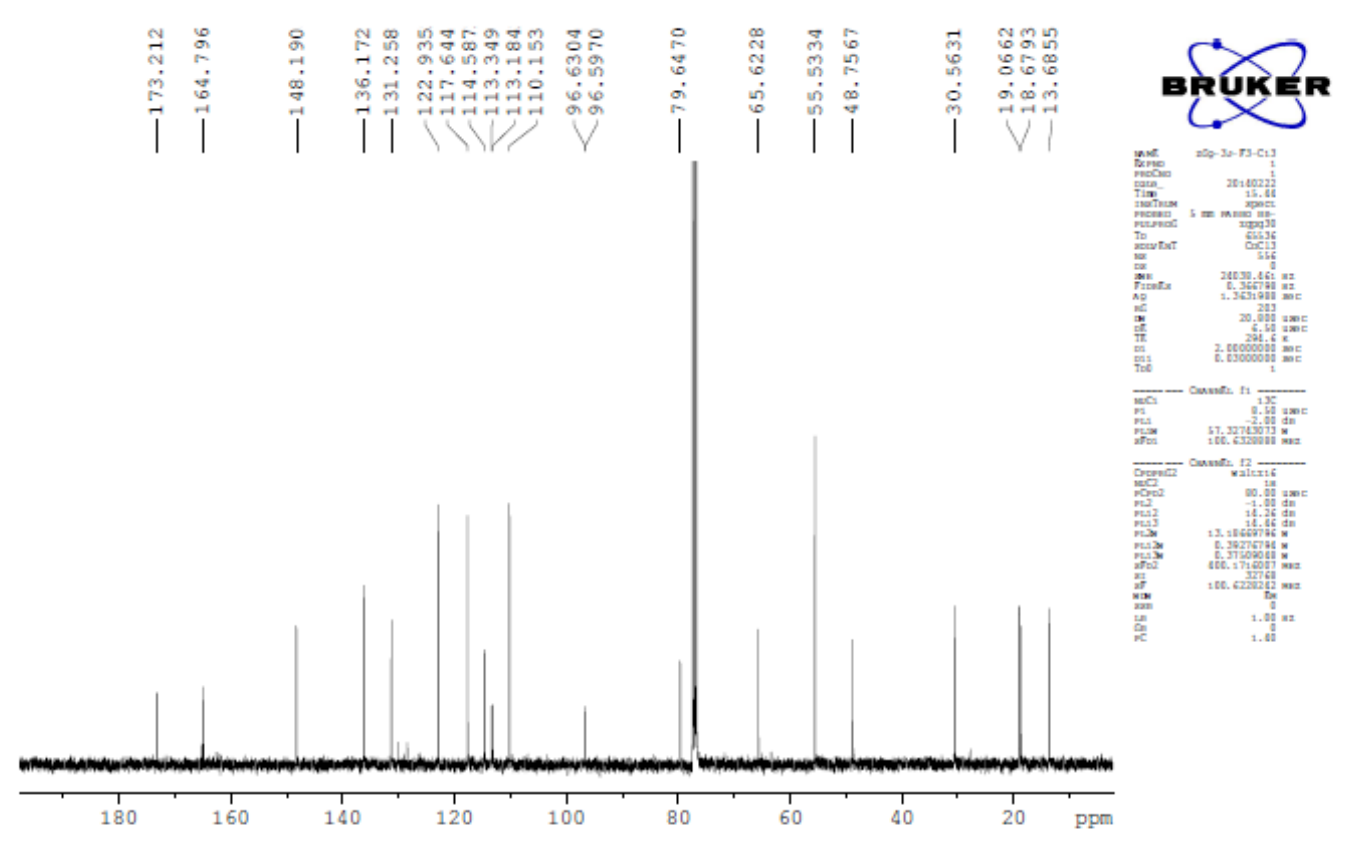

Figure S20. ${ }^{13} \mathrm{C}$ NMR Spectrum of compound $4-F$ in $\mathrm{CDCl}_{3}$ at ambient temperature $(101 \mathrm{MHz})$. 
Figure S21. ${ }^{1} \mathrm{H}$ NMR Spectrum of compound $\mathbf{4 - \mathbf { N H } _ { 2 }}$ in $\mathrm{CDCl}_{3}$ at ambient temperature (400 $\left.\mathrm{MHz}\right)$.
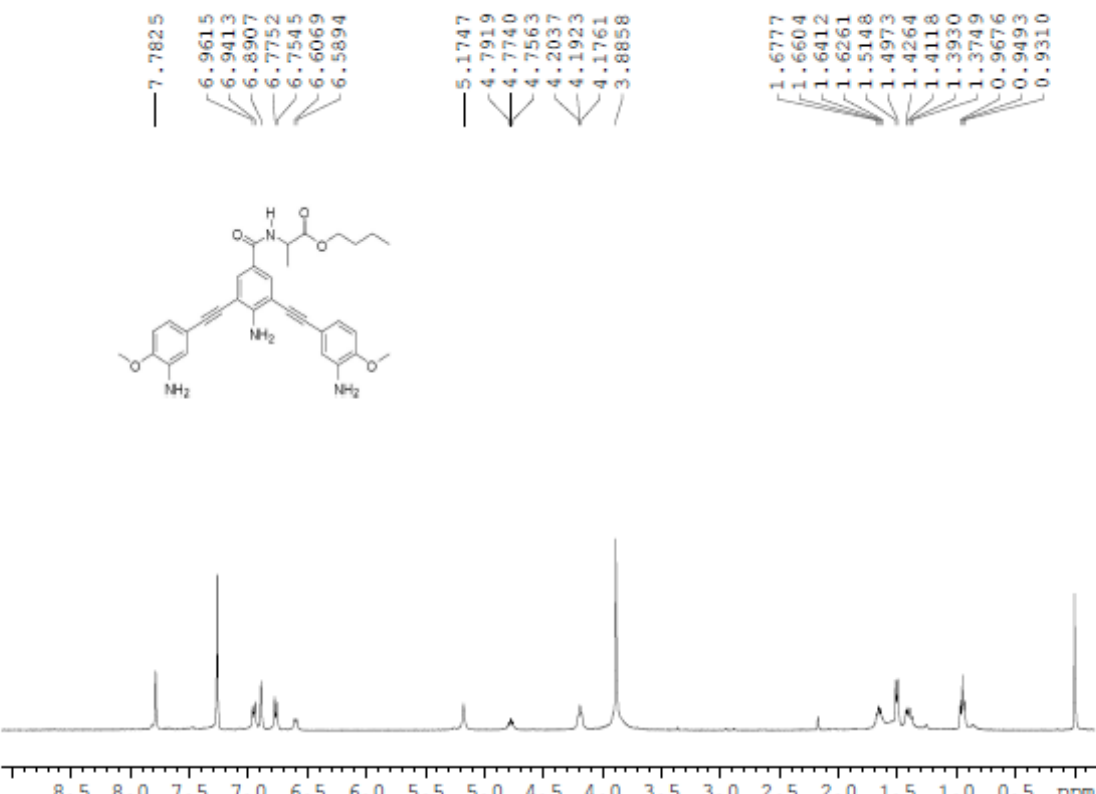

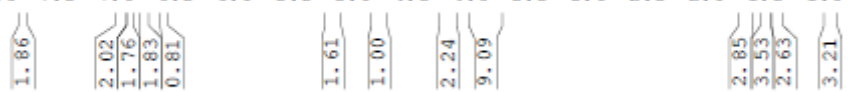
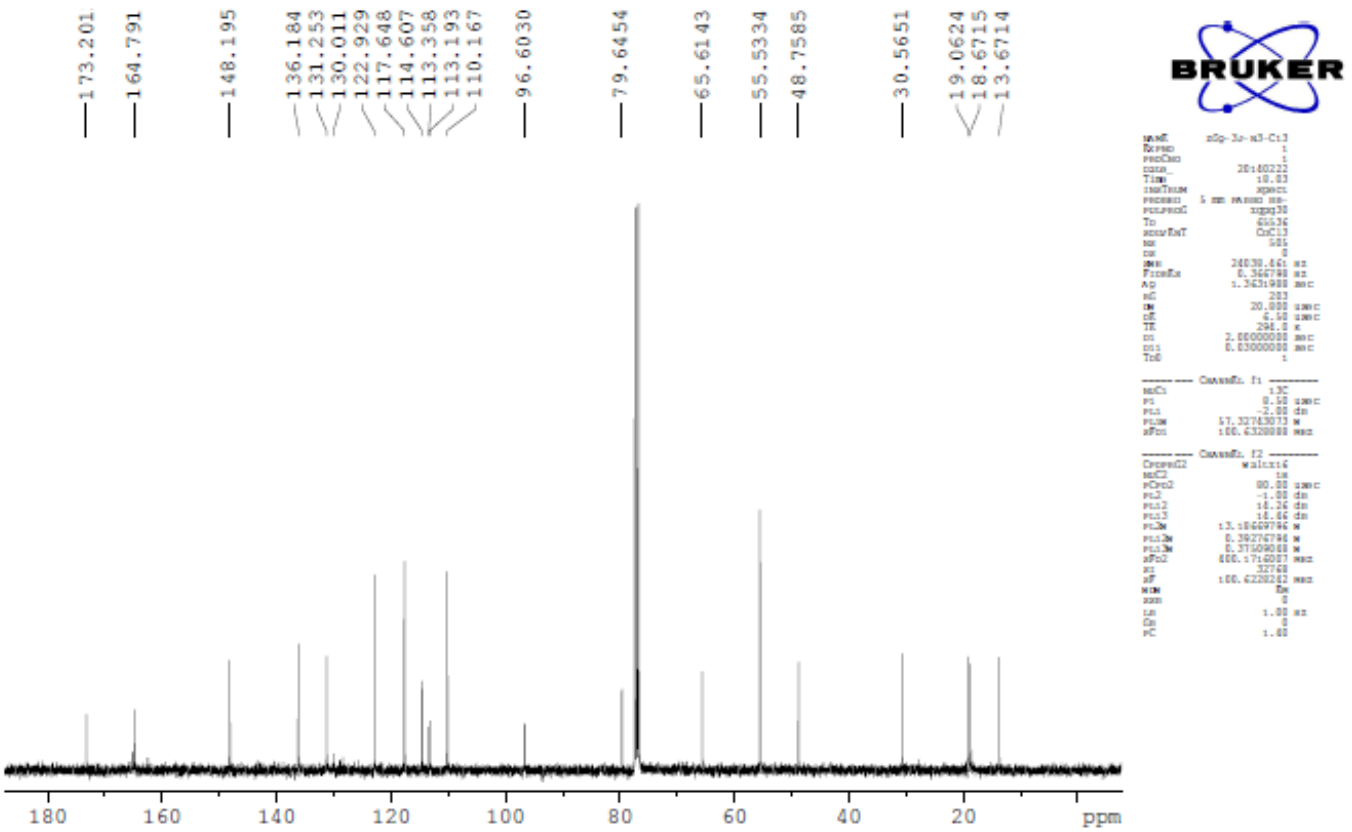

Figure S22. ${ }^{13} \mathrm{C}$ NMR Spectrum of compound $\mathbf{4}-\mathbf{N H}_{2}$ in $\mathrm{CDCl}_{3}$ at ambient temperature $(101 \mathrm{MHz})$. 
VII. ${ }^{1} \mathrm{H}$ NMR Comparison of 2-H, 2-Me, 2-F and 2-NH $\mathrm{NH}_{2}$ in Different Solvents
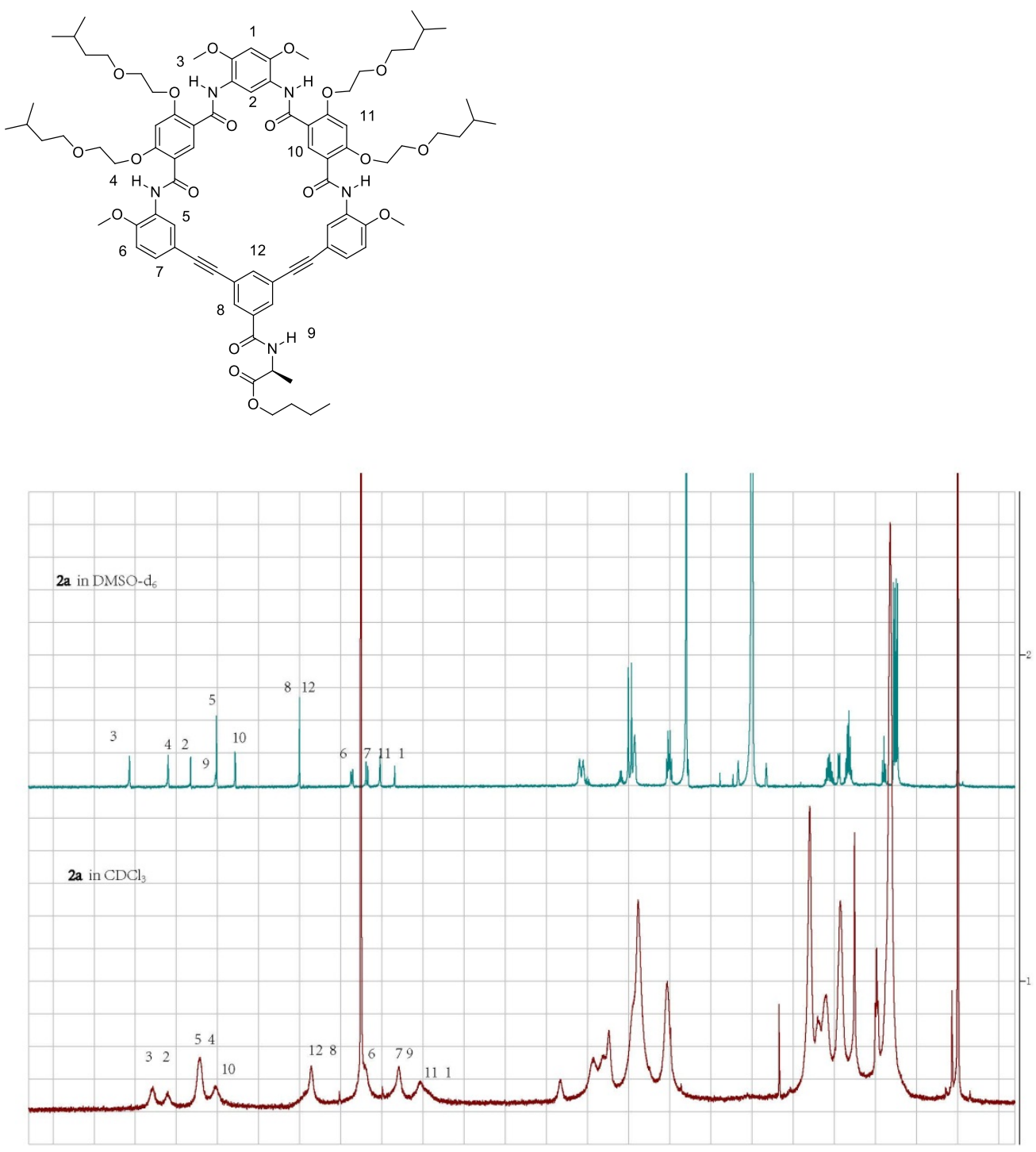

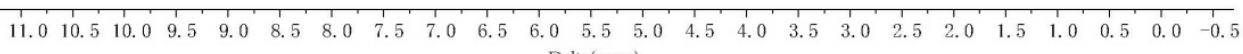

Delta(ppm)

Figure S23. ${ }^{1} \mathrm{H}$ NMR spectra of 2a in DMSO-d $\mathrm{d}_{6}$ and $\mathrm{CDCl}_{3}(0.3 \mathrm{mM}, 400 \mathrm{MHz}, 293 \mathrm{~K})$ 


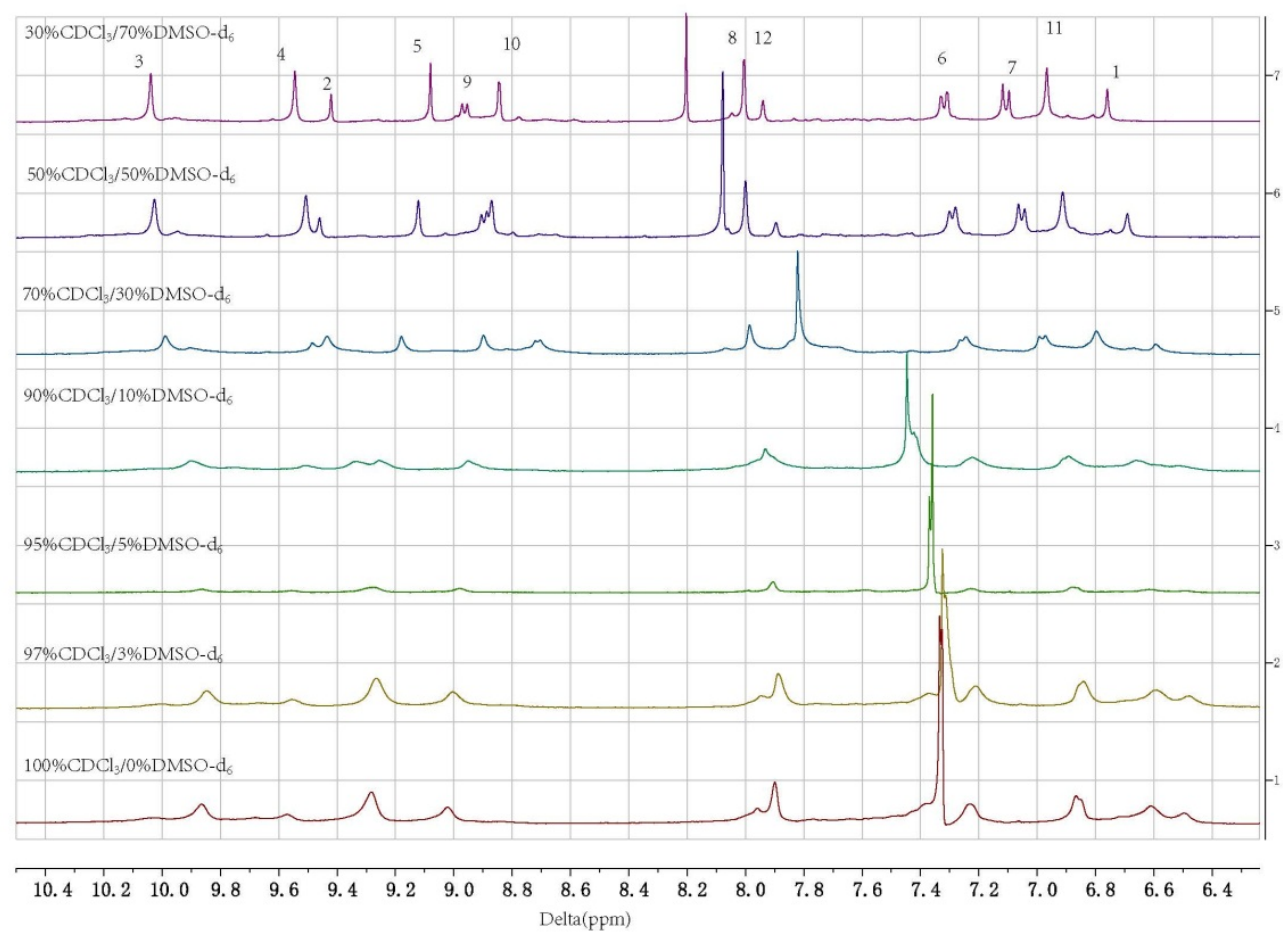

Figure S24. ${ }^{1} \mathrm{H}$ NMR spectra of $\mathbf{2}-\mathbf{H}$ in $\mathrm{CDCl}_{3}$ and varying ratios of $\mathrm{CDCl}_{3} / \mathrm{DMSO}_{-} \mathrm{d}_{6}(0.3 \mathrm{mM}, 400 \mathrm{MHz}$, $297 \mathrm{~K})$.

Table S1. Cyclic hexamer 2-H interior and exterior aromatic protons and amide proton with varying ratios of $\mathrm{CDCl}_{3} / \mathrm{DMSO}-\mathrm{d}_{6}$

\begin{tabular}{|l|l|l|l|l|l|l|l|l|l|l|l|l|}
\hline & $3(\mathrm{ppm})$ & $4(\mathrm{ppm})$ & $2(\mathrm{ppm})$ & $5(\mathrm{ppm})$ & $9(\mathrm{ppm})$ & $10(\mathrm{ppm})$ & $8(\mathrm{ppm})$ & $12(\mathrm{ppm})$ & $6(\mathrm{ppm})$ & $7(\mathrm{ppm})$ & $11(\mathrm{ppm})$ & $1(\mathrm{ppm})$ \\
\hline $70 \%$ & 10.10 & 9.56 & 9.42 & 9.07 & 8.98 & 8.85 & 8.01 & 7.94 & 7.33 & 7.10 & 6.97 & 6.75 \\
\hline $50 \%$ & 10.09 & 9.54 & 9.46 & 9.13 & 8.90 & 8.87 & 8.00 & 7.90 & 7.30 & 7.06 & 6.92 & 6.70 \\
\hline $30 \%$ & 9.98 & 9.44 & 9.47 & 9.18 & 8.71 & 8.90 & 7.98 & 7.84 & 7.25 & 6.97 & 6.90 & 6.60 \\
\hline $10 \%$ & 9.90 & 9.35 & 9.50 & 9.26 & 7.87 & 8.95 & 7.94 & 7.92 & 7.23 & 6.90 & 6.67 & 6.50 \\
\hline $5 \%$ & 9.87 & 9.28 & 9.55 & 9.27 & 7.60 & 8.97 & 7.90 & 7.96 & 7.22 & 6.88 & 6.60 & 6.50 \\
\hline $3 \%$ & 9.85 & 9.28 & 9.57 & 9.28 & 6.83 & 9.01 & 7.90 & 7.96 & 7.20 & 6.85 & 6.60 & 6.50 \\
\hline $0 \%$ & 9.85 & 9.29 & 9.58 & 9.28 & 6.80 & 9.02 & 7.90 & 7.96 & 7.22 & 6.80 & 6.60 & 6.50 \\
\hline
\end{tabular}



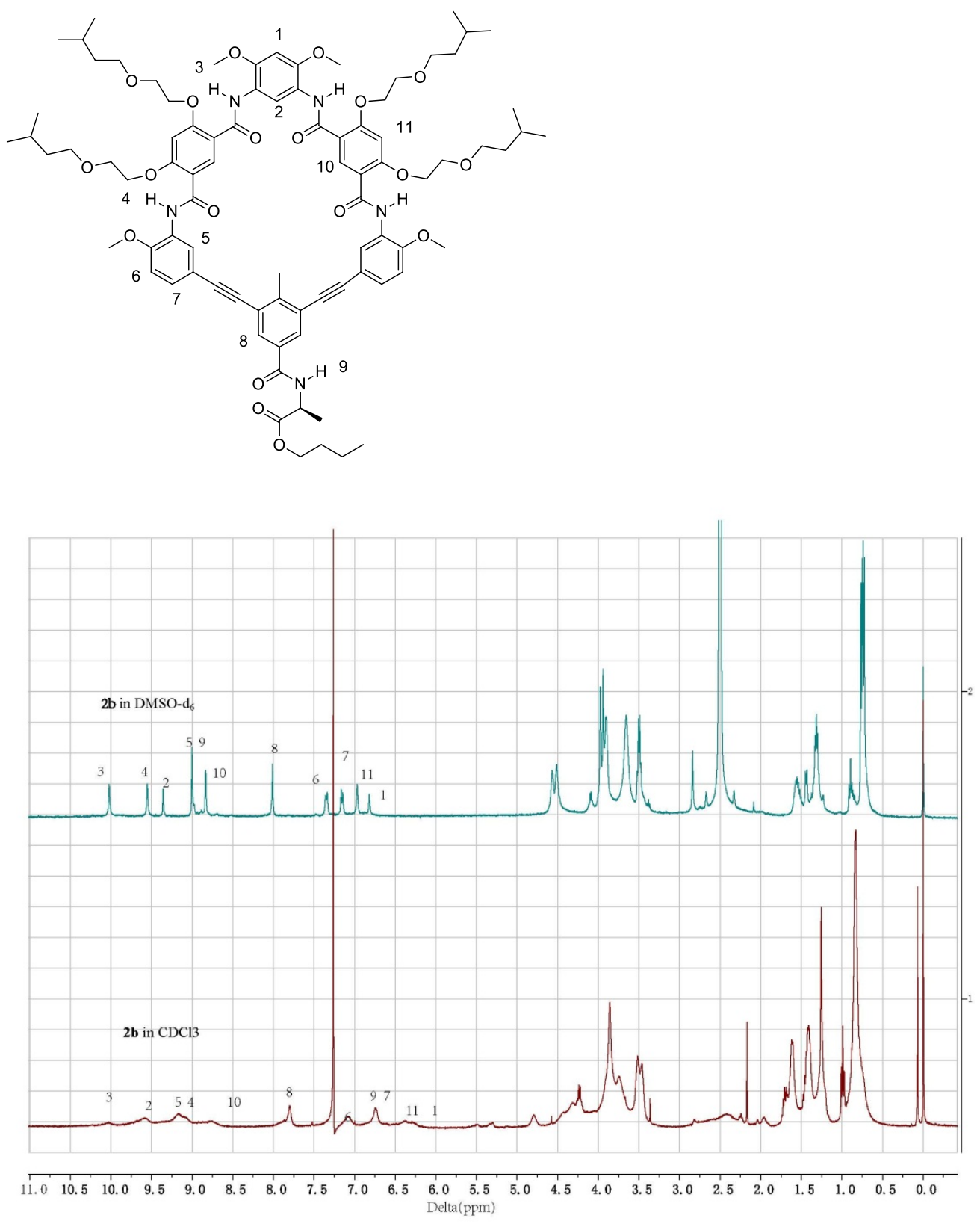

Figure S25. ${ }^{1} \mathrm{H}$ NMR spectra of 2-Me in DMSO-d ${ }_{6}$ and $\mathrm{CDCl}_{3}(0.3 \mathrm{mM}, 400 \mathrm{MHz}, 293 \mathrm{~K})$ 


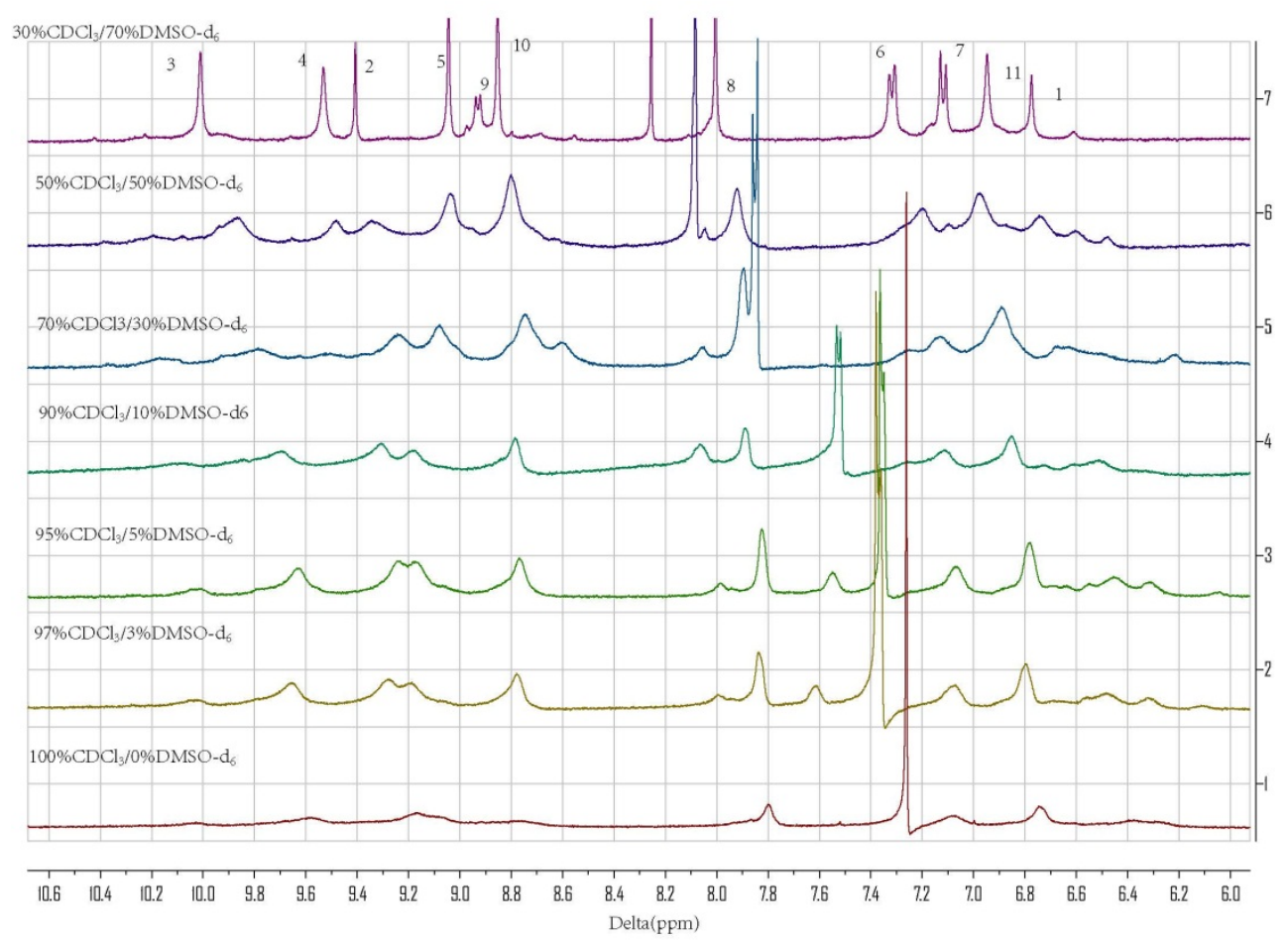

Figure S26. ${ }^{1} \mathrm{H}$ NMR spectra of 2-Me in $\mathrm{CDCl}_{3}$ and varying ratios of $\mathrm{CDCl}_{3} / \mathrm{DMSO}^{-\mathrm{d}_{6}}(0.3 \mathrm{mM}, 400 \mathrm{MHz}$, $293 \mathrm{~K})$.

Table S2. Cyclic hexamer 2-Me interior and exterior aromatic protons and amide proton with varying ratios of $\mathrm{CDCl}_{3} / \mathrm{DMSO}-\mathrm{d}_{6}$

\begin{tabular}{|l|l|l|l|l|l|l|l|l|l|l|l|}
\hline & $3(\mathrm{ppm})$ & $4(\mathrm{ppm})$ & $2(\mathrm{ppm})$ & $5(\mathrm{ppm})$ & $9(\mathrm{ppm})$ & $10(\mathrm{ppm})$ & $8(\mathrm{ppm})$ & $6(\mathrm{ppm})$ & $7(\mathrm{ppm})$ & $11(\mathrm{ppm})$ & $1(\mathrm{ppm})$ \\
\hline $70 \%$ & 10.01 & 9.52 & 9.41 & 9.05 & 8.92 & 8.82 & 8.00 & 7.31 & 7.13 & 6.93 & 6.78 \\
\hline $50 \%$ & 9.88 & 9.48 & 9.35 & 9.05 & 8.62 & 8.80 & 7.86 & 7.20 & 6.97 & 6.72 & 6.75 \\
\hline $30 \%$ & 9.80 & 9.25 & 9.25 & 9.08 & 8.60 & 8.78 & 7.85 & 7.13 & 6.90 & 6.60 & 6.50 \\
\hline $10 \%$ & 9.70 & 9.30 & 9.30 & 9.20 & 7.45 & 8.78 & 7.84 & 7.10 & 6.85 & 6.50 & 6.33 \\
\hline $5 \%$ & 9.65 & 9.25 & 9.25 & 9.18 & 6.83 & 8.78 & 7.82 & 7.08 & 6.78 & 6.45 & 6.30 \\
\hline $3 \%$ & 9.65 & 9.25 & 9.25 & 9.20 & 6.80 & 8.79 & 7.82 & 7.08 & 6.80 & 6.45 & 6.30 \\
\hline $0 \%$ & 9.60 & 9.20 & 9.20 & 9.20 & 6.80 & 8.80 & 7.80 & 7.08 & 6.75 & 6.30 & 6.21 \\
\hline
\end{tabular}



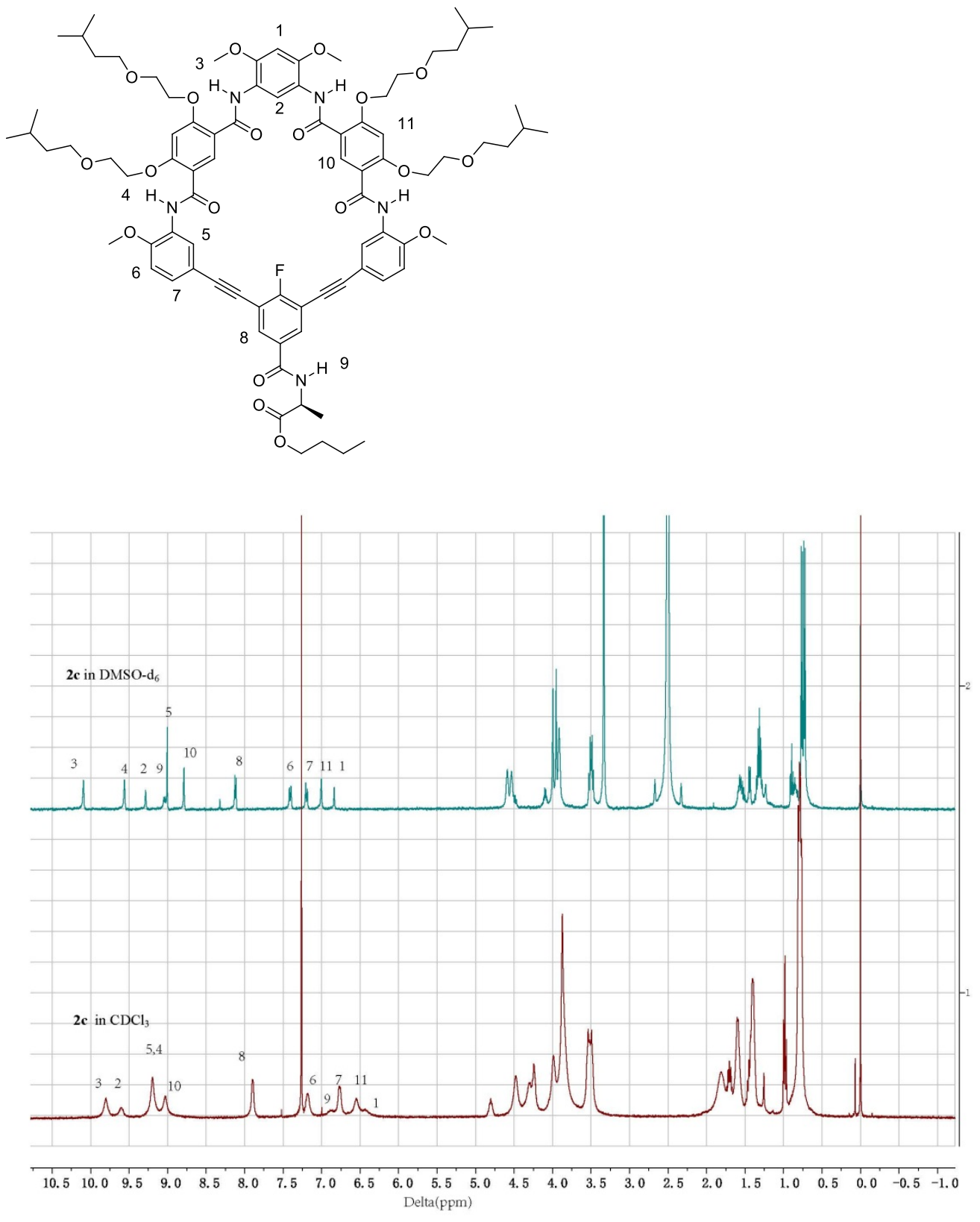

Figure S27. ${ }^{1} \mathrm{H}$ NMR spectra of $\mathbf{2 - F}$ in $\mathrm{DMSO}_{-} \mathrm{d}_{6}$ and $\mathrm{CDCl}_{3}(0.3 \mathrm{mM}, 400 \mathrm{MHz}, 293 \mathrm{~K})$ 


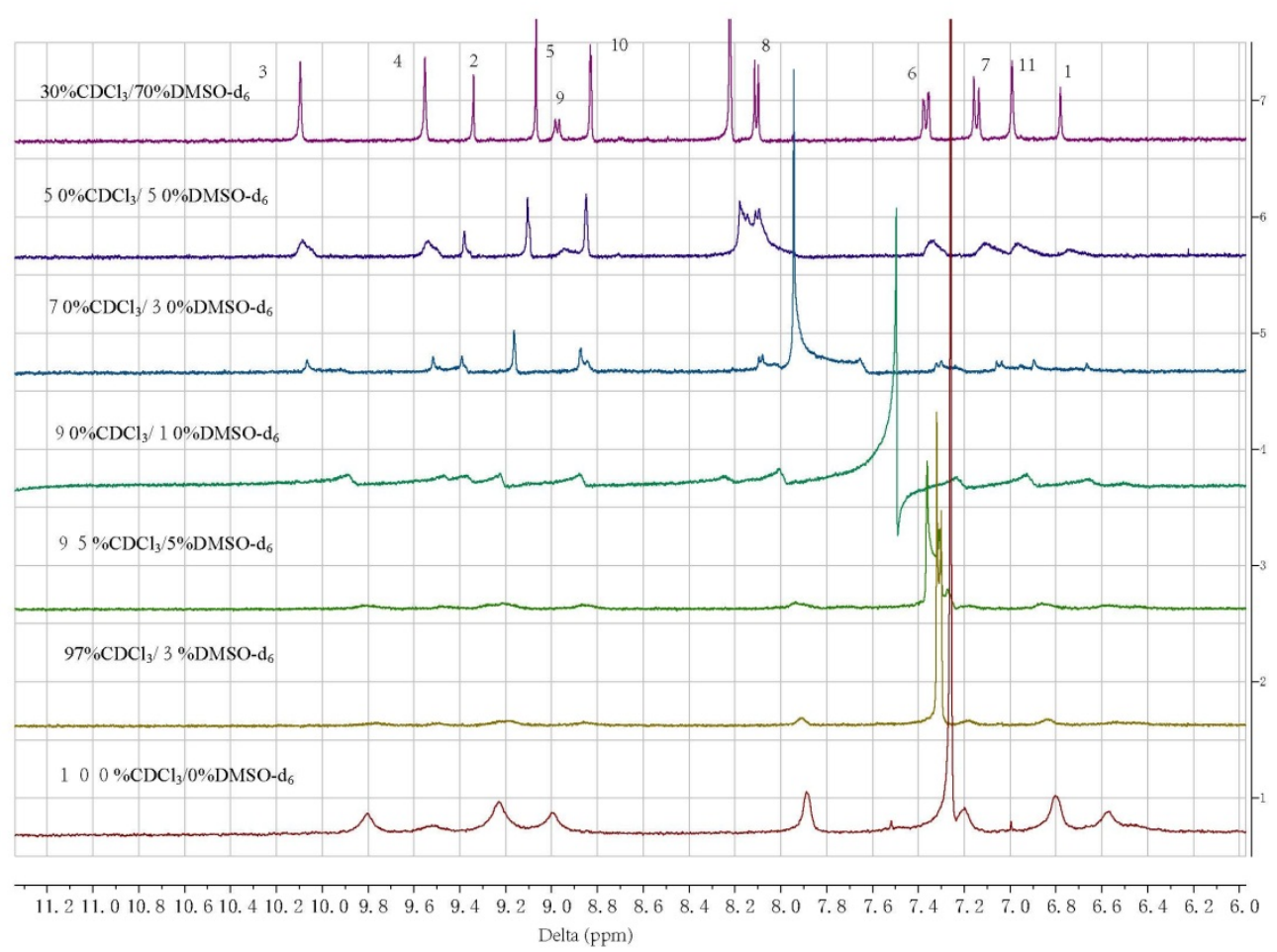

Figure S28. ${ }^{1} \mathrm{H}$ NMR spectra of $\mathbf{2 - F}$ in $\mathrm{CDCl}_{3}$ and varying ratios of $\mathrm{CDCl}_{3} / \mathrm{DMSO}_{-} \mathrm{d}_{6}(0.3 \mathrm{mM}, 400 \mathrm{MHz}$, $293 \mathrm{~K})$.

Table S3. Cyclic hexamer 2-F interior and exterior aromatic protons and amide proton with varying ratios of $\mathrm{CDCl}_{3} / \mathrm{DMSO}-\mathrm{d}_{6}$

\begin{tabular}{|l|l|l|l|l|l|l|l|l|l|l|l|}
\hline & $3(\mathrm{ppm})$ & $4(\mathrm{ppm})$ & $2(\mathrm{ppm})$ & $5(\mathrm{ppm})$ & $9(\mathrm{ppm})$ & $10(\mathrm{ppm})$ & $8(\mathrm{ppm})$ & $6(\mathrm{ppm})$ & $7(\mathrm{ppm})$ & $11(\mathrm{ppm})$ & $1(\mathrm{ppm})$ \\
\hline $70 \%$ & 10.07 & 9.52 & 9.31 & 9.02 & 8.95 & 8.80 & 8.08 & 7.32 & 7.12 & 6.95 & 6.76 \\
\hline $50 \%$ & 10.07 & 9.52 & 9.33 & 9.06 & 8.90 & 8.82 & 8.06 & 7.30 & 7.05 & 6.92 & 6.70 \\
\hline $30 \%$ & 9.99 & 9.51 & 9.38 & 9.16 & 8.85 & 8.87 & 8.08 & 7.30 & 7.05 & 6.90 & 6.66 \\
\hline $10 \%$ & 9.86 & 9.38 & 9.48 & 9.21 & 8.25 & 8.88 & 8.00 & 7.28 & 6.92 & 6.65 & 6.50 \\
\hline $5 \%$ & 9.80 & 9.25 & 9.50 & 9.25 & 6.81 & 8.88 & 7.92 & 7.20 & 6.87 & 6.60 & 6.45 \\
\hline $3 \%$ & 9.80 & 9.25 & 9.50 & 9.25 & 6.80 & 8.88 & 7.92 & 7.20 & 6.85 & 6.60 & 6.45 \\
\hline $0 \%$ & 9.80 & 9.23 & 9.52 & 9.25 & 6.81 & 9.00 & 7.89 & 7.20 & 6.80 & 6.57 & 6.45 \\
\hline
\end{tabular}



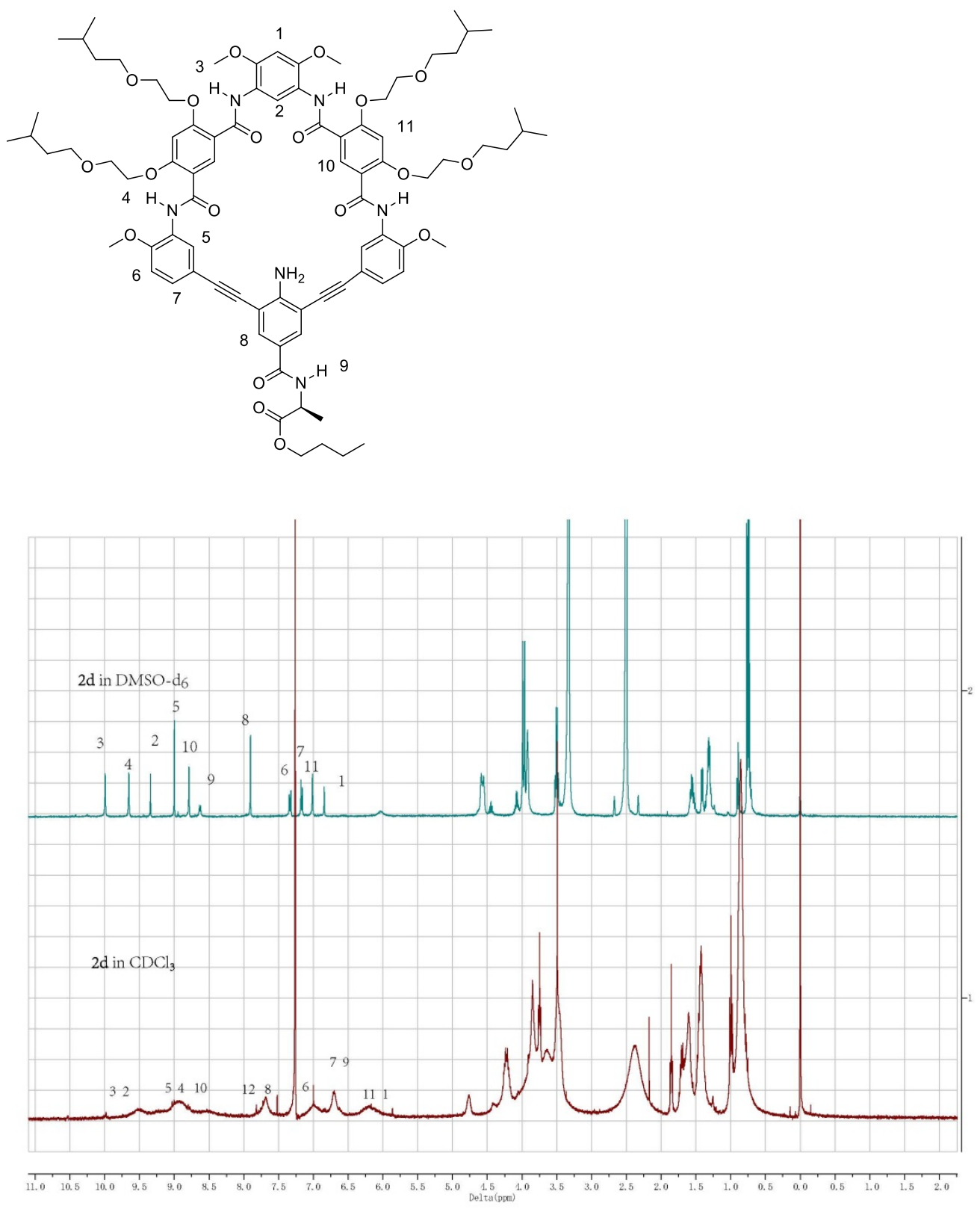

Figure S29. ${ }^{1} \mathrm{H}$ NMR spectra of $\mathbf{2}-\mathbf{N H}_{2}$ in $\mathrm{DMSO}_{-} \mathrm{d}_{6}$ and $\mathrm{CDCl}_{3}(0.3 \mathrm{mM}, 400 \mathrm{MHz}, 293 \mathrm{~K})$ 


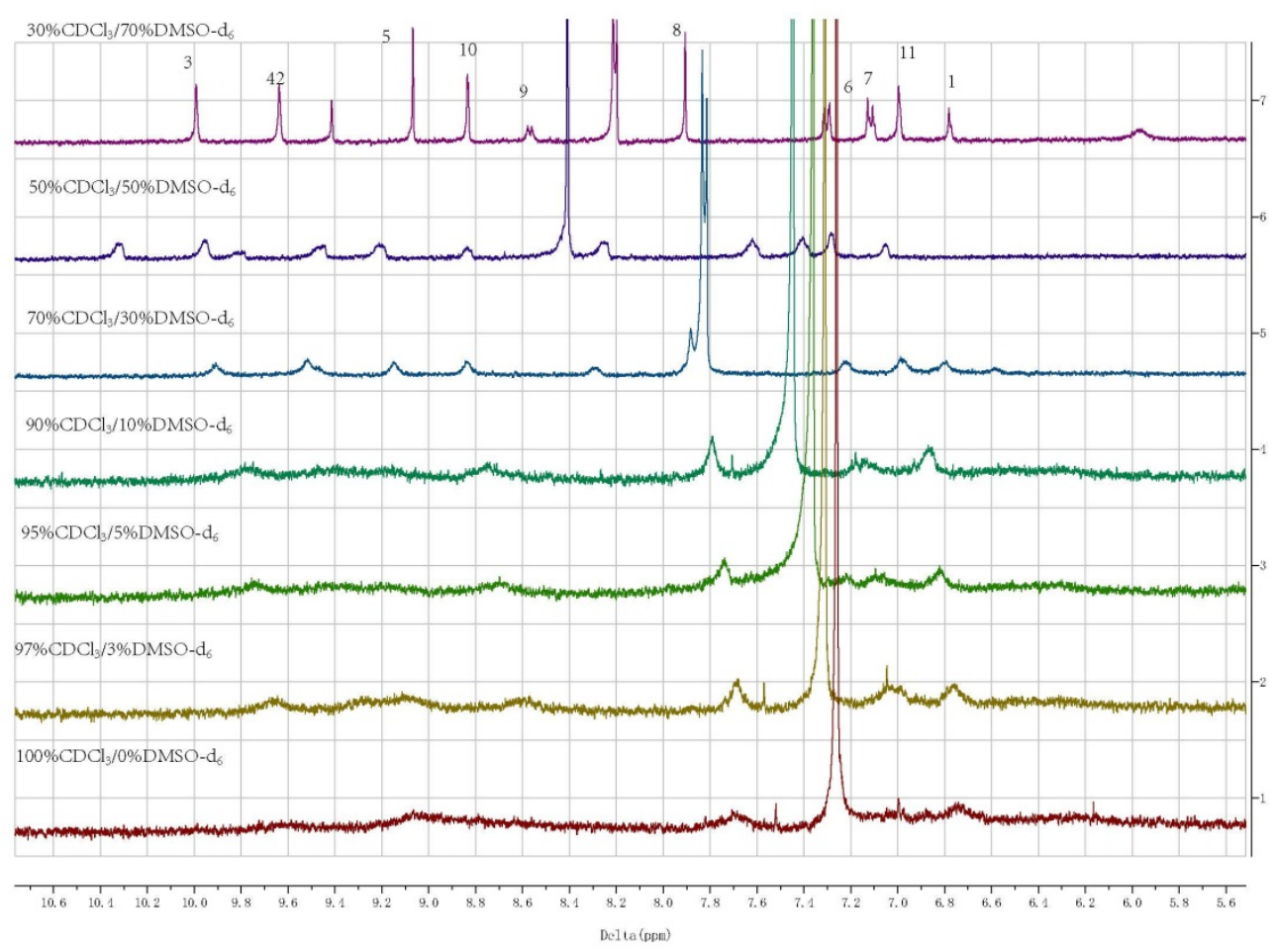

Figure S30. ${ }^{1} \mathrm{H}$ NMR spectra of $\mathbf{2}-\mathbf{N H}_{2}$ in $\mathrm{CDCl}_{3}$ and varying ratios of $\mathrm{CDCl}_{3} / \mathrm{DMSO}^{-\mathrm{d}_{6}}(0.3 \mathrm{mM}, 400$ MHz, $297 \mathrm{~K})$.

Table S4. Cyclic hexamer $\mathbf{2}-\mathbf{N H}_{2}$ interior and exterior aromatic protons and amide proton with varying ratios of $\mathrm{CDCl}_{3} / \mathrm{DMSO}-\mathrm{d}_{6}$

\begin{tabular}{|l|l|l|l|l|l|l|l|l|l|l|l|}
\hline & $3(\mathrm{ppm})$ & $4(\mathrm{ppm})$ & $2(\mathrm{ppm})$ & $5(\mathrm{ppm})$ & $10(\mathrm{ppm})$ & $9(\mathrm{ppm})$ & $8(\mathrm{ppm})$ & $6(\mathrm{ppm})$ & $7(\mathrm{ppm})$ & $11(\mathrm{ppm})$ & $1(\mathrm{ppm})$ \\
\hline $70 \%$ & 9.98 & 9.63 & 9.42 & 9.06 & 8.83 & 8.53 & 7.90 & 7.30 & 7.12 & 7.00 & 6.73 \\
\hline $50 \%$ & 9.97 & 9.60 & 9.45 & 9.10 & 8.85 & 8.44 & 7.90 & 7.27 & 7.05 & 6.96 & 6.70 \\
\hline $30 \%$ & 9.90 & 9.52 & 9.52 & 9.15 & 8.84 & 8.30 & 7.78 & 7.22 & 6.97 & 6.80 & 6.57 \\
\hline $10 \%$ & 9.77 & 9.40 & 9.40 & 9.15 & 8.75 & 7.95 & 7.78 & 7.15 & 6.87 & 6.75 & 6.35 \\
\hline $5 \%$ & 9.75 & 9.35 & 9.35 & 9.20 & 8.70 & 7.90 & 7.74 & 7.10 & 6.82 & 6.67 & 6.30 \\
\hline $3 \%$ & 9.60 & 9.25 & 9.25 & 9.05 & 8.55 & 7.80 & 7.65 & 7.00 & 6.70 & 6.50 & 6.30 \\
\hline $0 \%$ & 9.60 & 9.15 & 9.15 & 9.05 & 8.60 & 7.70 & 7.70 & 7.00 & 6.75 & 6.50 & 6.30 \\
\hline
\end{tabular}




\section{Fluorescence Spectra}
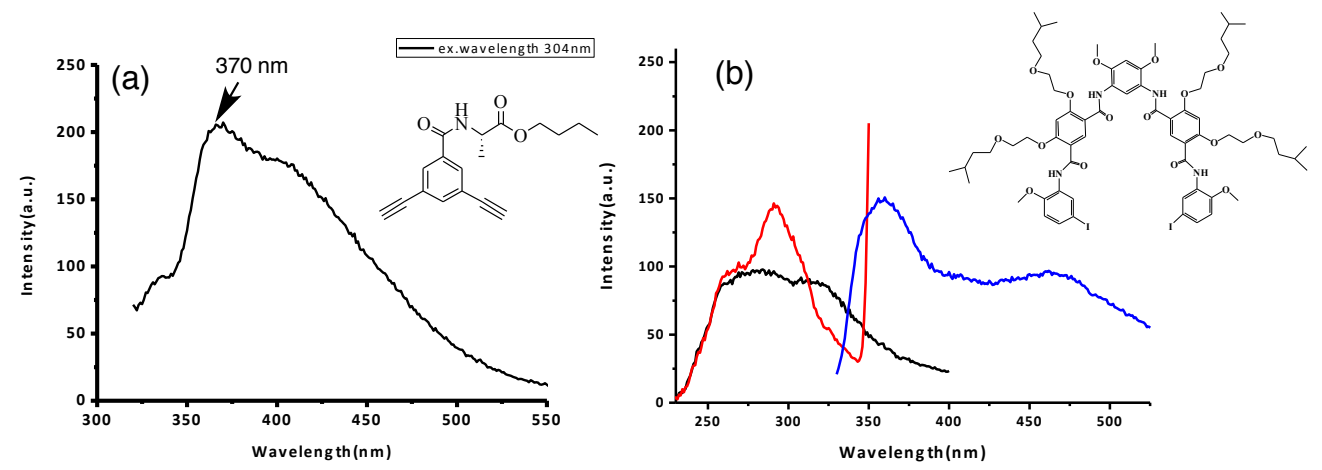

Figure S31. (a) The emsission spectrum of the shown compound $\left(10 \mu \mathrm{M}\right.$ in $\left.\mathrm{CHCl}_{3}\right)$ excited at $304 \mathrm{~nm}$ $\left(\right.$ slit $_{\mathrm{ex}}=10 \mathrm{~nm}$, slit $\mathrm{em}=10 \mathrm{~nm}$ ). (b) The emission spectrum (blue, excited at $291 \mathrm{~nm}$ ) and excitation spectra (red, monitored at $361 \mathrm{~nm}$; black, monitored at $464 \mathrm{~nm})$ of the shown compound $(10 \mu \mathrm{M}$ in $\mathrm{CHCl}_{3}$. slit $\left._{\mathrm{ex}}=10 \mathrm{~nm}, \mathrm{slit}_{\mathrm{em}}=10 \mathrm{~nm}\right)$.

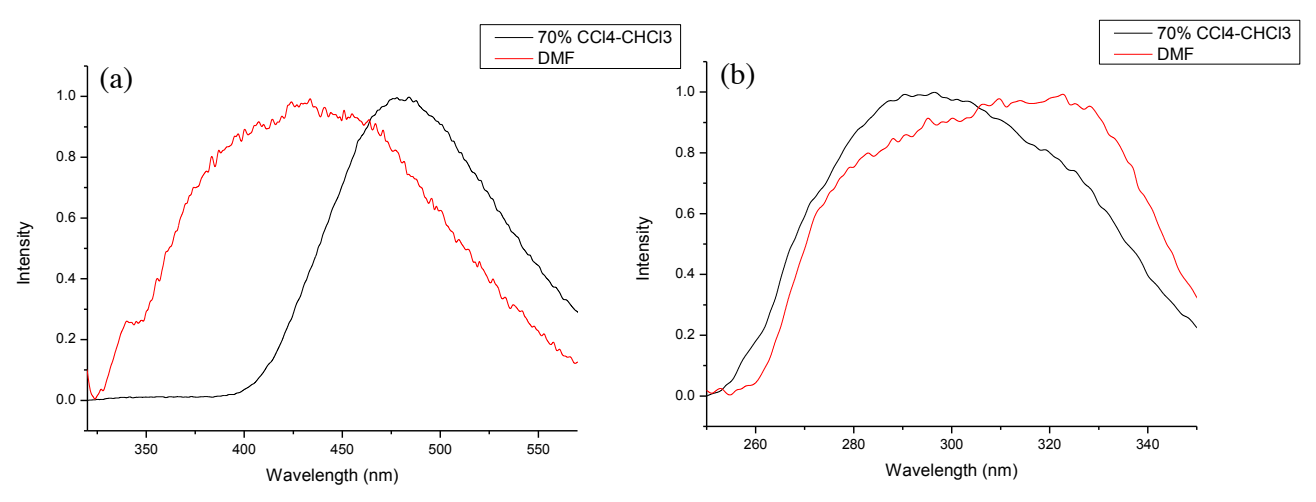

Figure S32. (a) Normalized emission spectra of 2-Me (5 $\mu \mathrm{M})$ in DMF (red) and $\mathrm{CCl}_{4} / \mathrm{CHCl}_{3}(7 / 3$, v/v) (black). In DMF: excited at $310 \mathrm{~nm}$ ( slit $_{\mathrm{ex}}=10 \mathrm{~nm}$, slit ${ }_{\mathrm{em}}=10 \mathrm{~nm}$ ); in $\mathrm{CCl}_{4} / \mathrm{CHCl}_{3}(7 / 3)$ : excited at 295 $\mathrm{nm}\left(\mathrm{slit}_{\mathrm{ex}}=5 \mathrm{~nm}\right.$, slit ${ }_{\mathrm{em}}=10 \mathrm{~nm}$ ). Emission $\lambda_{\max }=431 \mathrm{~nm}$ (in DMF) and $478 \mathrm{~nm}$ (in $\mathrm{CCl}_{4} / \mathrm{CHCl}_{3}$ ). (b) Normalized excitation spectra of 2-Me $(5 \mu \mathrm{M})$ in DMF (red) and $\mathrm{CCl}_{4} / \mathrm{CHCl}_{3}$ (7/3, v/v) (black) monitored at $410 \mathrm{~nm}$ (red) and $480 \mathrm{~nm}$ (black) with background subtraction (in DMF: slit $_{\mathrm{ex}}=10 \mathrm{~nm}$, slit $_{\mathrm{em}}=10 \mathrm{~nm}$; in $\mathrm{CCl}_{4} / \mathrm{CHCl}_{3}(7 / 3, \mathrm{v} / \mathrm{v}): \mathrm{slit}_{\mathrm{ex}}=5 \mathrm{~nm}$, slit $\left.\mathrm{em}=10 \mathrm{~nm}\right)$. Excitation $\lambda_{\max }=323 \mathrm{~nm}(\mathrm{DMF})$ and $296 \mathrm{~nm}$ (in $\left.\mathrm{CCl}_{4} / \mathrm{CHCl}_{3}\right)$. 


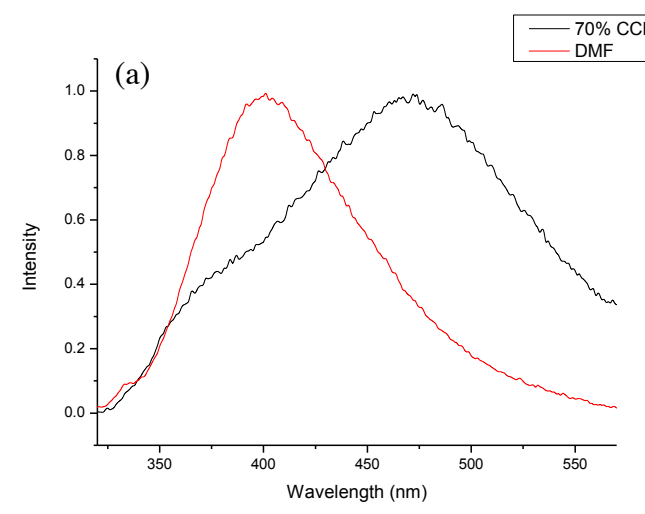

(b)

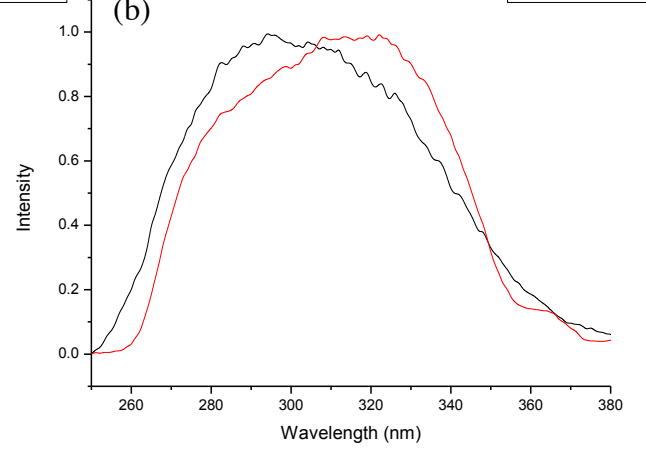

Figure S33. (a) Normalized emission spectra of 2-F (5 $\mu \mathrm{M})$ in DMF (red) and $\mathrm{CCl}_{4} / \mathrm{CHCl}_{3}(7 / 3, \mathrm{v} / \mathrm{v})$ (black). In DMF: excited at $310 \mathrm{~nm}\left(\right.$ slit $_{\mathrm{ex}}=10 \mathrm{~nm}$, slit $\left.{ }_{\mathrm{em}}=10 \mathrm{~nm}\right)$; in $\mathrm{CCl}_{4} / \mathrm{CHCl}_{3}(7 / 3)$ : excited at $295 \mathrm{~nm}\left(\right.$ slit $_{\mathrm{ex}}=10$ $\mathrm{nm}$, slit $\mathrm{em}_{\mathrm{m}}=10 \mathrm{~nm}$ ). Emission $\lambda_{\max }=401 \mathrm{~nm}$ (in DMF) and $474 \mathrm{~nm}$ (in $\mathrm{CCl}_{4} / \mathrm{CHCl}_{3}$ ). (b) Normalized excitation spectra of 2-F (5 $\mu \mathrm{M})$ in DMF (red) and $\mathrm{CCl}_{4} / \mathrm{CHCl}_{3}(7 / 3, \mathrm{v} / \mathrm{v})$ (black) monitored at $410 \mathrm{~nm}$ (red) and $480 \mathrm{~nm}$ (black) with background subtraction (in DMF: slit $\mathrm{ex}_{\mathrm{ex}}=10 \mathrm{~nm}$, slit $\mathrm{em}=10 \mathrm{~nm}$; in $\mathrm{CCl}_{4} / \mathrm{CHCl}_{3}\left(7 / 3, \mathrm{v} / \mathrm{v}\right.$ ): $\mathrm{slit}_{\mathrm{ex}}=10$ $\mathrm{nm}$, slit $\mathrm{em}=10 \mathrm{~nm})$. Excitation $\lambda_{\max }=322 \mathrm{~nm}(\mathrm{DMF})$ and $294 \mathrm{~nm}\left(\mathrm{in} \mathrm{CCl}_{4} / \mathrm{CHCl}_{3}\right)$.
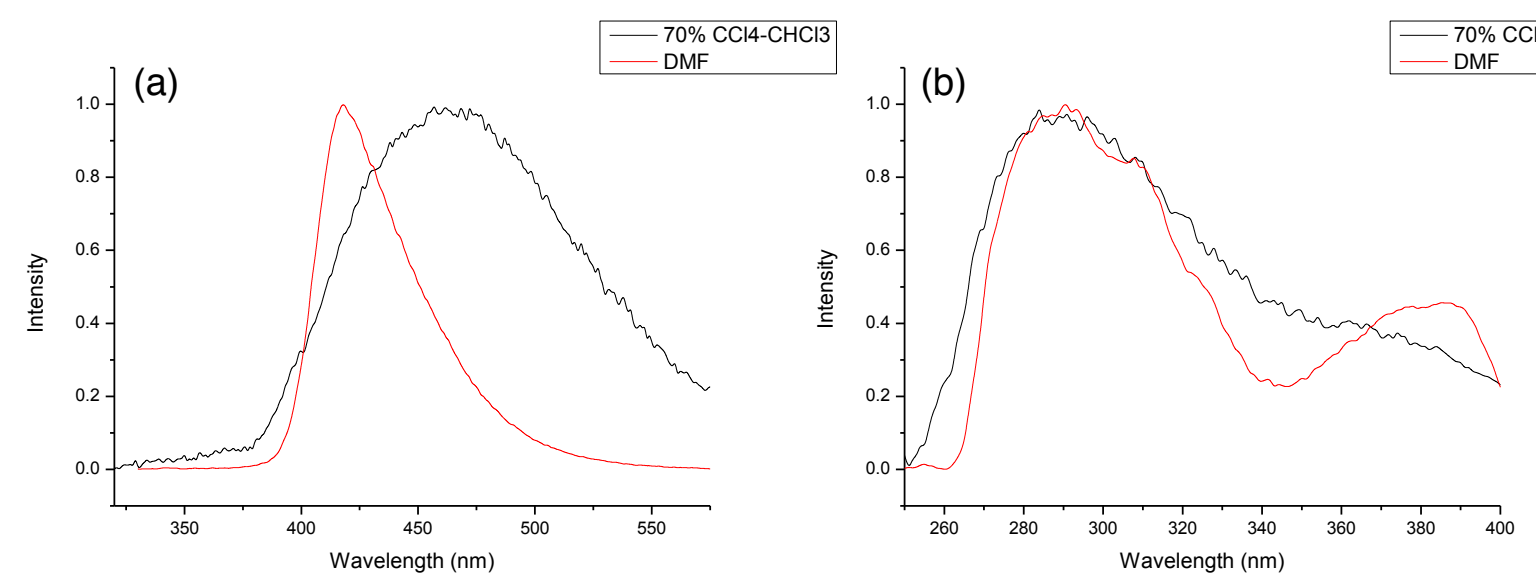

Figure S34. (a) Normalized emission spectra of $\mathbf{2}-\mathbf{N H}_{2}(5 \mu \mathrm{M})$ in $\mathrm{DMF}$ (red) and $\mathrm{CCl}_{4} / \mathrm{CHCl}_{3}(7 / 3, \mathrm{v} / \mathrm{v})$ (black). In DMF: excited at $295 \mathrm{~nm}\left(\right.$ slit $_{\mathrm{ex}}=2.5 \mathrm{~nm}$, slit $\left.\mathrm{em}=5 \mathrm{~nm}\right)$; in $\mathrm{CCl}_{4} / \mathrm{CHCl}_{3}(7 / 3)$ : excited at $295 \mathrm{~nm}\left(\right.$ slit $_{\mathrm{ex}}$ $=5 \mathrm{~nm}$, slit $\mathrm{em}_{\mathrm{m}}=10 \mathrm{~nm}$ ). Emission $\lambda_{\max }=418 \mathrm{~nm}$ (in DMF) and $464 \mathrm{~nm}$ (in $\mathrm{CCl}_{4} / \mathrm{CHCl}_{3}$ ). (b) Normalized excitation spectra of $\mathbf{2}-\mathbf{N H}_{2}(5 \mu \mathrm{M})$ in DMF (red) and $\mathrm{CCl}_{4} / \mathrm{CHCl}_{3}(7 / 3, \mathrm{v} / \mathrm{v})$ (black) monitored at $420 \mathrm{~nm}$ (red) and $480 \mathrm{~nm}$ (black) with background subtraction (in DMF: slit $\mathrm{ex}=2.5 \mathrm{~nm}$, slit $\mathrm{em}=5 \mathrm{~nm}$; in $\mathrm{CCl}_{4} / \mathrm{CHCl}_{3}(7 / 3$, $\mathrm{v} / \mathrm{v})$ : slit $_{\mathrm{ex}}=5 \mathrm{~nm}$, slit $\left.{ }_{\mathrm{em}}=10 \mathrm{~nm}\right)$. Excitation $\lambda_{\max }=291 \mathrm{~nm}(\mathrm{DMF})$ and $291 \mathrm{~nm}\left(\mathrm{in} \mathrm{CCl}_{4} / \mathrm{CHCl}_{3}\right)$. 

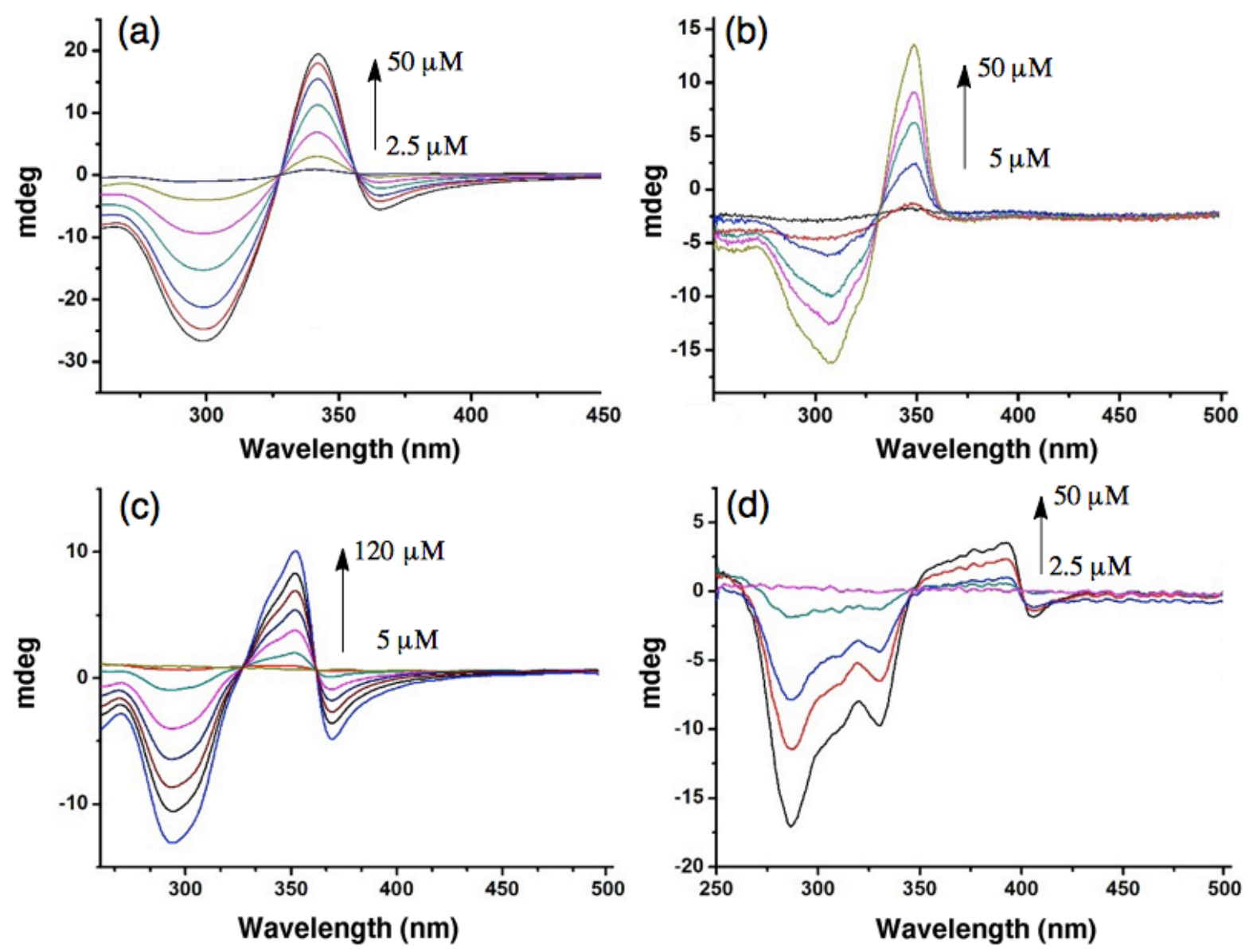

Figure S35. Concentration-dependent $\mathrm{CD}$ spectra of (a) $\mathbf{2}-\mathbf{H}$ in $\mathrm{CCl}_{4} / \mathrm{CHCl}_{3}(7 / 3, \mathrm{v} / \mathrm{v})$, (b) $\mathbf{2}-\mathbf{M e}$ in $\mathrm{CCl}_{4} / \mathrm{CHCl}_{3}(9 / 1, \mathrm{v} / \mathrm{v})$, (c) 2-F in $\mathrm{CCl}_{4} / \mathrm{CHCl}_{3}(7 / 3, \mathrm{v} / \mathrm{v})$, and (d) $2-\mathbf{N H}_{2}$ in $\mathrm{CCl}_{4} / \mathrm{CHCl}_{3}(8 / 2, \mathrm{v} / \mathrm{v})$ recorded at room temperature. 


\section{Atomic Force Microscopy}

\section{Sample Preparation}

The compounds were dissolved in $\mathrm{CHCl}_{3}$ to a final concentration of $10 \mu \mathrm{M}$. Each of the sample solution $(10 \mu \mathrm{L})$ was deposited on a freshly cleaved mica surface and was then placed in saturated $\mathrm{CCl}_{4}$ vapor overnight. The saturated $\mathrm{CCl}_{4}$ vapor was created by placing a beaker containing $\sim 30 \mathrm{~mL}$ of $\mathrm{CCl}_{4}$ in a desiccator that was pre-evacuated. AFM imaging experiments were carried out with a Nanoscope 3D multimode SPM (Bruker, Santa Barbara, CA) in air in the tapping mode with RTESP probes $(40 \mathrm{~N} / \mathrm{m}, 300 \mathrm{kHz}$, Veeco Probes, Camarillo, CA). Typical scan speed was between $1 \mu \mathrm{m} / \mathrm{s}$ to $15 \mu \mathrm{m} / \mathrm{s}$, depending on the scan size. The typical cantilever oscillation amplitude was $35 \mathrm{~nm}$.

\section{AFM images}

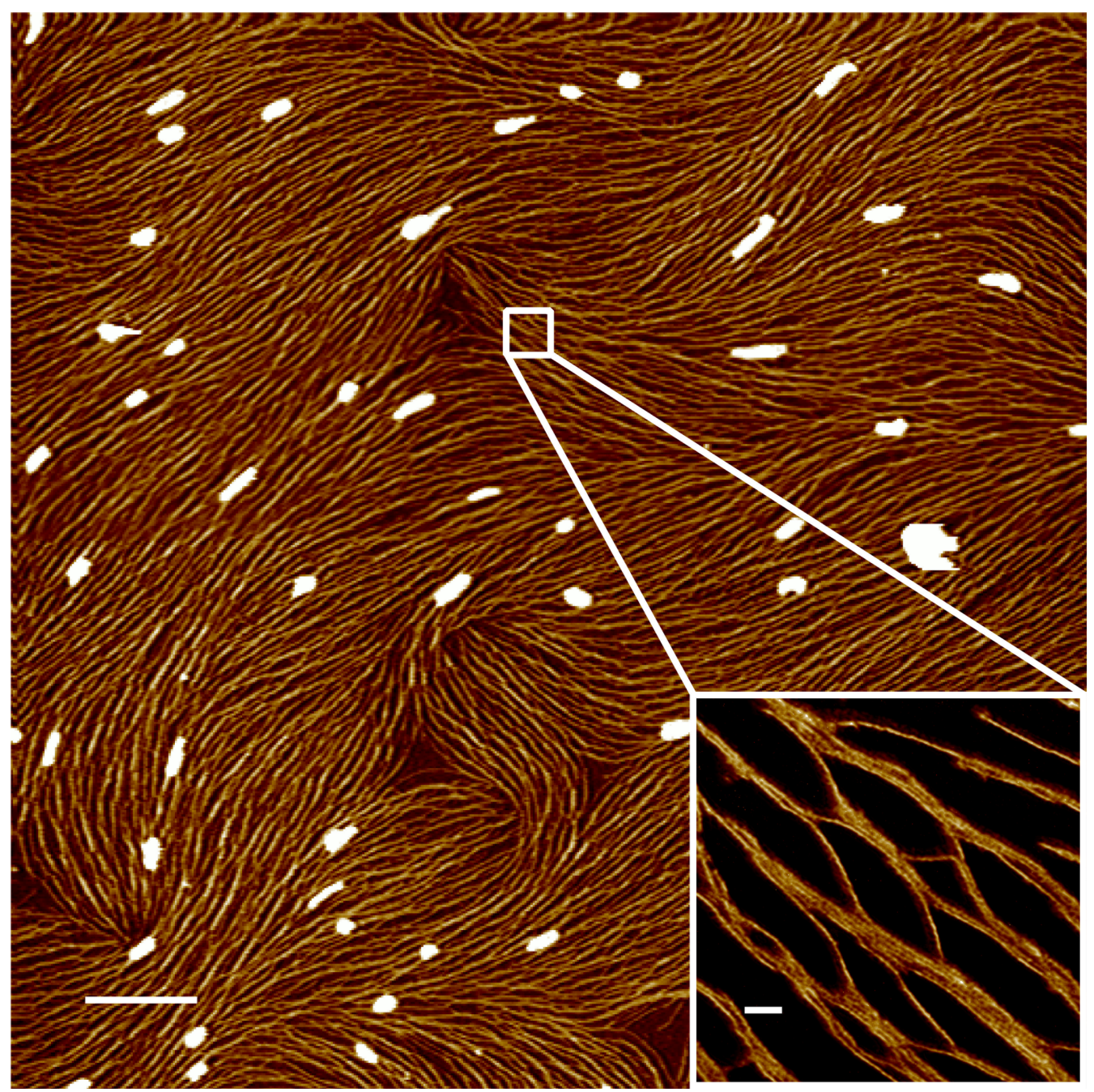

Figure S36. AFM images of nanotubes of 2-H pre-assembled in $\mathrm{CHCl}_{3}$ at a concentration of 10 $\mu \mathrm{M}$, deposited on freshly cleaved mica surface. At large scale, these assembled long nanotubes are seen to remain stable after the $\mathrm{CCl}_{4}$ was removed, and have aggregated into large fibers (Scale bar $=500 \mathrm{~nm}$ ). Inset: At increased magnification, individual nanotube filaments are clearly resolved. The filaments have variable length and are not precisely registered in arrangement. The average distance between the nanotube filaments is around $2.8 \pm 0.2 \mathrm{~nm}(\mathrm{n}=10)$ and the height of the nanotube filaments is $2.1 \pm 0.2 \mathrm{~nm}(\mathrm{n}=10)($ Scale bar $=20 \mathrm{~nm})$. 


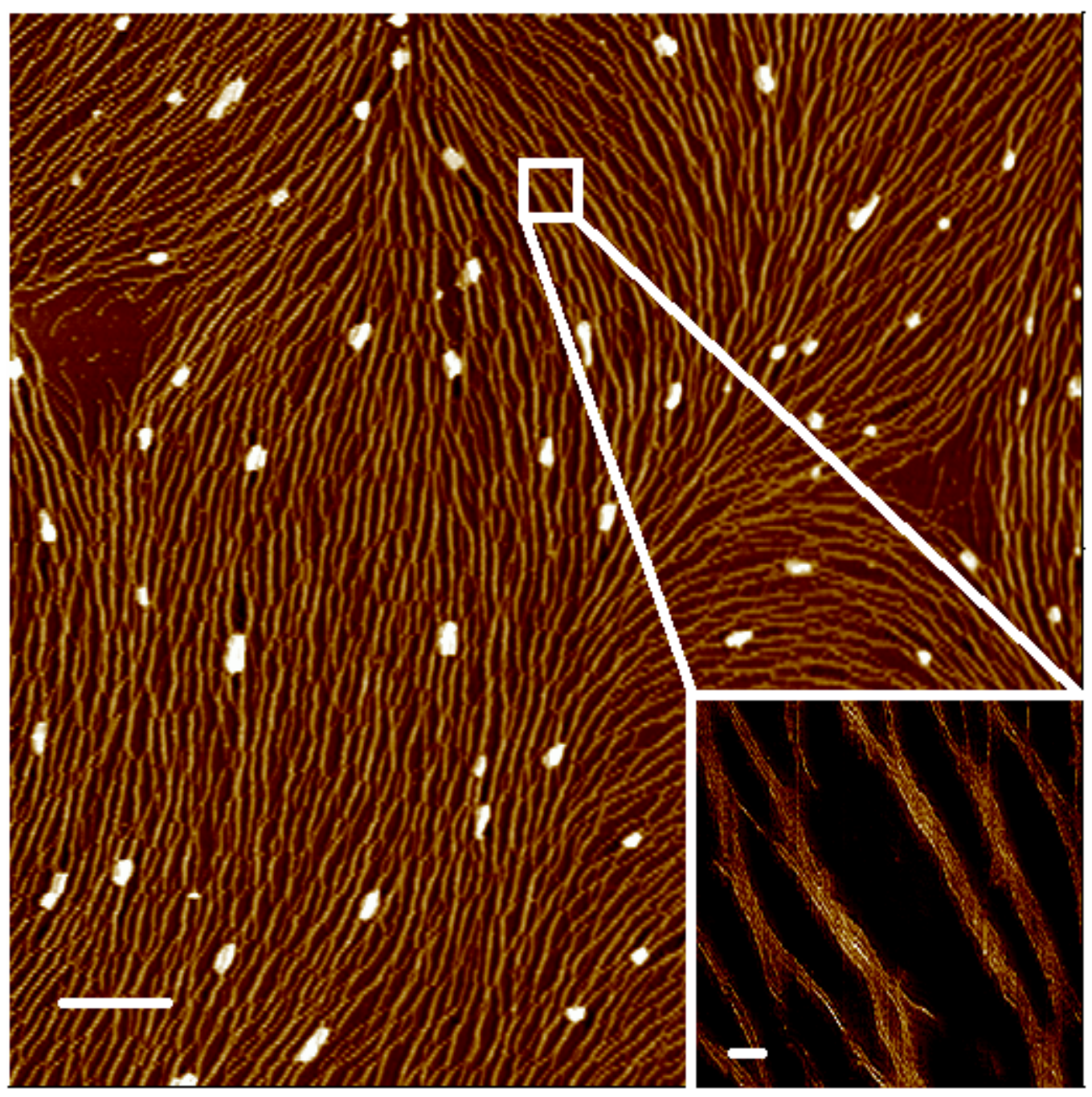

Figure S37. AFM images of nanotubes of 2-Me pre-assembled in $\mathrm{CHCl}_{3}$ at a concentration of 10 $\mu \mathrm{M}$, deposited on freshly cleaved mica surface. At large scale, these assembled long nanotubes are seen to remain stable after the $\mathrm{CCl}_{4}$ was removed, and have aggregated into large fibers (Scale bar $=500 \mathrm{~nm})$. Inset: At increased magnification, individual nanotube filaments are clearly resolved. The filaments have variable length and are not precisely registered in arrangement. The average distance between the nanotube filaments is around $2.8 \pm 0.2 \mathrm{~nm}(\mathrm{n}=$ 10) and the height of the nanotube filaments is $2.0 \pm 0.3 \mathrm{~nm}(\mathrm{n}=10)($ Scale bar $=20 \mathrm{~nm})$. 


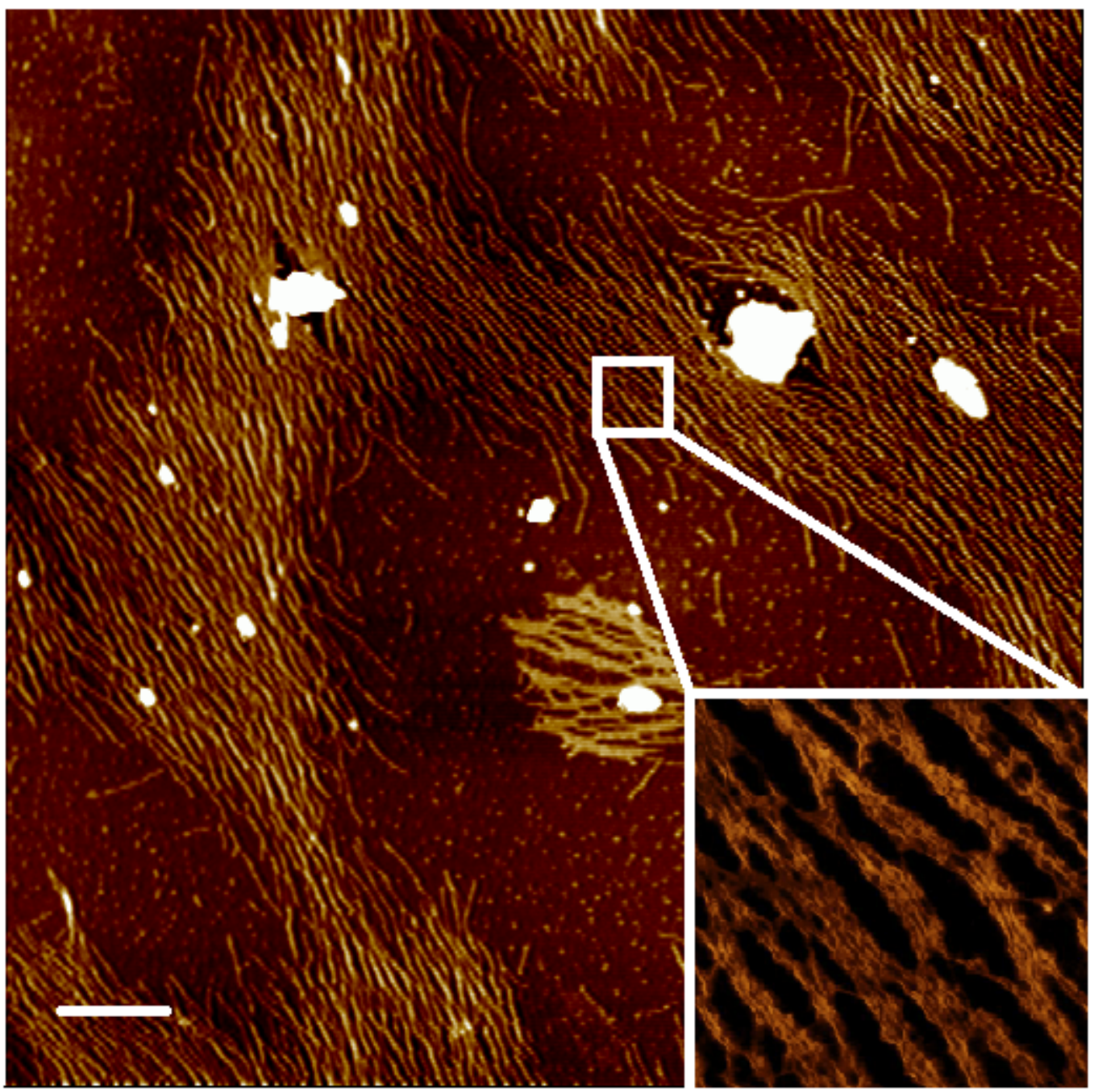

Figure S38. AFM images of nanotubes of 2-F pre-assembled in $\mathrm{CHCl}_{3}$ at a concentration of 10 $\mu \mathrm{M}$, deposited on freshly cleaved mica surface. At large scale, these assembled long nanotubes are seen to remain stable after the $\mathrm{CCl}_{4}$ was removed, and have aggregated into large fibers (Scale bar $=500 \mathrm{~nm})$. Inset: At increased magnification, individual nanotube filaments are clearly resolved. The filaments have variable length and are not precisely registered in arrangement. The average distance between the nanotube filaments is around $2.8 \pm 0.3 \mathrm{~nm}(\mathrm{n}=$ 10) and the height of the nanotube filaments is $2.1 \pm 0.1 \mathrm{~nm}(\mathrm{n}=10)($ Scale bar $=20 \mathrm{~nm})$. 


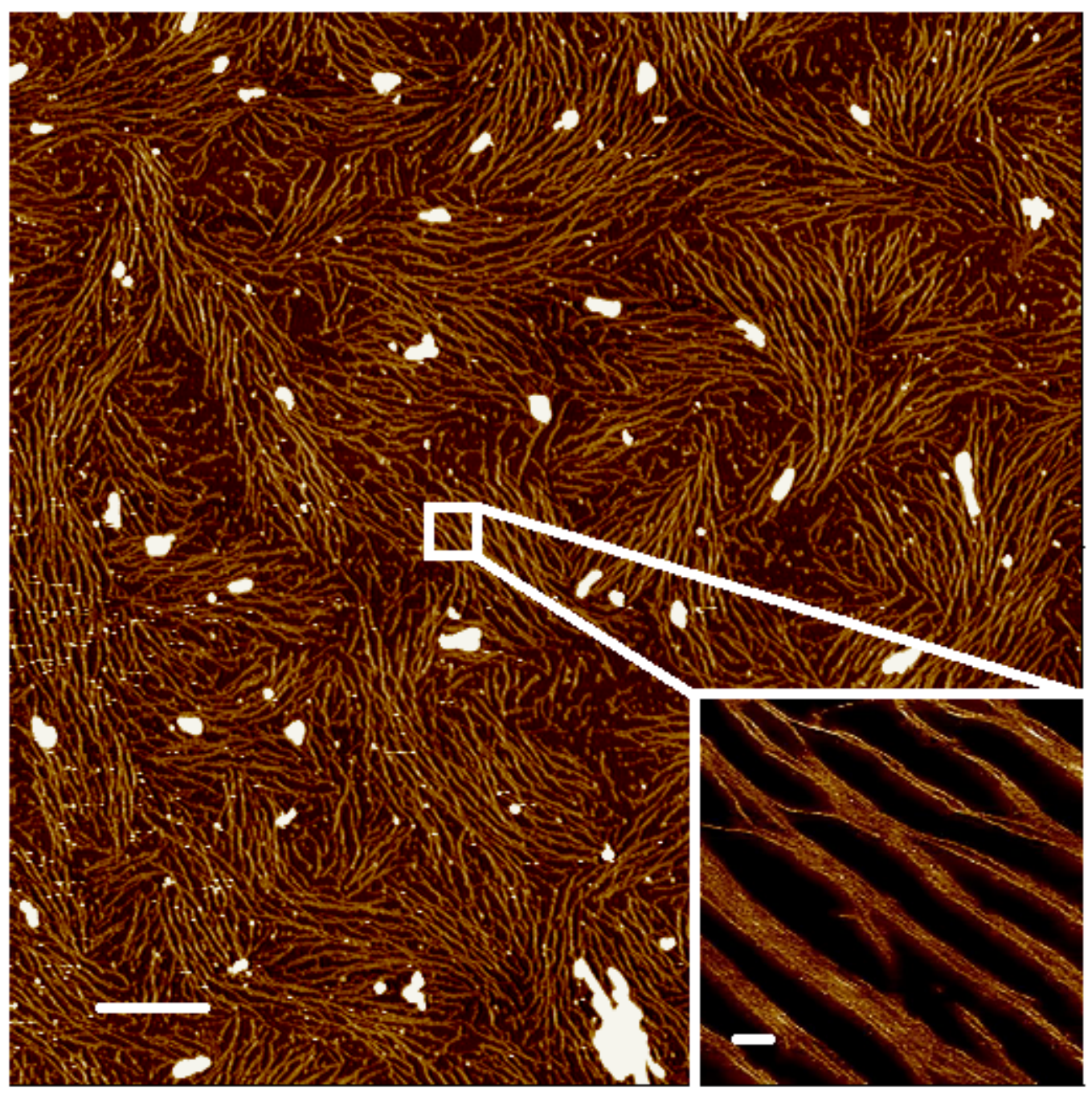

Figure S39. AFM images of nanotubes of $\mathbf{2}-\mathbf{N H}_{2}$ pre-assembled in $\mathrm{CHCl}_{3}$ at a concentration of $10 \mu \mathrm{M}$, deposited on freshly cleaved mica surface. At large scale, these assembled long nanotubes are seen to remain stable after the $\mathrm{CCl}_{4}$ was removed, and have aggregated into large fibers $($ Scale bar $=500 \mathrm{~nm})$. Inset: At increased magnification, individual nanotube filaments are clearly resolved. The filaments have variable length and are not precisely registered in arrangement. The average distance between the nanotube filaments is around $2.7 \pm 0.2 \mathrm{~nm}(\mathrm{n}=$ $10)$ and the height of the nanotube filaments is $2.0 \pm 0.1 \mathrm{~nm}(\mathrm{n}=10)($ Scale bar $=20 \mathrm{~nm})$. 


\section{Stopped-Flow Kinetic Assays}

Phospholipid POPC (1-palmitoyl-2-oleoyl-sn-glycero-3-phosphocholine) (from Avanti Polar Lipids, US) was first dissolved in chloroform with or without compounds 2 . The solvent was evaporated in a rotary evaporator under vacuum for one hour, after which the dried lipids were placed in a buffer (100 mM HEPES, $145 \mathrm{mM} \mathrm{KCl,} 0.1 \mathrm{mM}$ HPTS (8-hydroxypyrene-1, 3, 6-trisulfonate, from Thermo Fisher Scientific Inc., USA), pH 7.0); final concentration of lipids = $2 \mathrm{mg} / \mathrm{mL}$, final concentration of compounds $=10 \mu \mathrm{M}$, lipid $/$ compound $(\mathrm{mol} / \mathrm{mol})=263)$. The solution was incubated at $37{ }^{\circ} \mathrm{C}$ in a water bath for one hour, followed by extrusion through a $0.1-\mu \mathrm{m}$ polycarbonate membrane (Avanti Polar Lipids, USA) to produce a homogeneous solution of large unilamellar vesicles (LUVs). The dyes not entrapped in the LUVs were then removed by gel filtration using Sephadex G-50 (GE Healthcare, US), pre-equilibrated with HEPES buffer. The average size of the LUVs was measured with a dynamic light scattering (DLS) particle analyzer (Nano ZS90, Malvern, UK). The measured average size of LUVs with/without added compounds 2 was around $100 \mathrm{~nm}$. Before each the fluorescence measurement, the vesicles were pre-incubated with valinomycin $(5 \mu \mathrm{M})$ for 5 min.

Proton transport was measured by mixing vesicles containing the compounds or control vesicles without added compounds with the lower-pH solution (100 mM HEPES, $145 \mathrm{mM} \mathrm{KCl}$, $80 \mathrm{mM} \mathrm{HCl}$ ) at an equal volume in a stopped-flow spectrometer (SX-20, Applied Photophysics, UK) at $12{ }^{\circ} \mathrm{C}$. The excitation wavelength was set at $450 \mathrm{~nm}$ using a $150-\mathrm{W}$ xenon arc lamp and monochromator, and the emission wavelength was 510-550 $\mathrm{nm}$ using a band pass filter.

As reported before [Clement, N. R. \& Gould J. M. Biochemistry 1981, 20, 1534], the emission intensity of HPTS is dependent on the $\mathrm{pH}$ of the solution. In this case, since HTPS is only present in the lumen of the vesicles, the signal change will be a direct indicator for the $\mathrm{pH}$ value inside these vesicles. When the extravesicular proton concentration is higher than that inside the vesicles, proton conductance will lead to an increase of the proton concentration in the vesicles, leading to quenching of HPTS emission. The presence of valinomycin, a potassium carrier, counters the charge buildup owing to the influx of protons in this case. Thus, the presence of valinomycin eliminates the intrinsic potassium permeability of the membrane as a limiting factor in kinetic measurements. [Nichols, J. W. \& Deamer, D. W. Proc. Natl. Acad. Sci. USA 1980, 77, 2038; Weiss, L. A.; Sakai, N.; Ghebremariam, B.; Ni, C.; Matile, S. J. Am. Chem. Soc. 1997, 119, 12142]. 


\section{Liposome-Based Assays on Chloride Transport}

Chloride transport across lipid bilayer was monitored by following the normalized emission intensity of $\mathrm{N}$-(ethoxycarbonylmethyl)-6-methoxyquinolinium bromide (MQAE) encapsulated inside POPC LUVs. Solutions of $\mathrm{Cl}^{-}$free LUVs (10 mM MQAE, potassium gluconate $100 \mathrm{mM}$, HEPES $20 \mathrm{mM}, \mathrm{pH}$ 7.4) were first incubated with $\mathrm{KCl}(100 \mathrm{mM})$ in HEPES (100 mM, pH 7.4) buffer for $1 \mathrm{~min}$, to which aliquots of stock solutions $(1 \mathrm{mM})$ of $\mathbf{4 - H}$ and $\mathbf{4 - \mathbf { N H } _ { 2 }}$ in THF, and THF alone, were then added (final concentration of $\mathbf{4 - H}$ or $\mathbf{4}-\mathbf{N H}_{2}=10 \mu \mathrm{M}$ ). The change of emission intensity at $460 \mathrm{~nm}$ (excited at $354 \mathrm{~nm}$ ) were monitored for 5 min. Triton X-100 (200 $\mu \mathrm{L}, 3.1 \mathrm{mM}$ in $\mathrm{H}_{2} \mathrm{O}$ ) was then added to achieve total rupture of LUVs. 


\section{Single Channel Electrophysiology}

Preparation of Salt Bridge. An agar salt bridge provides an electrical connection to the bath solution while minimizing the transfer of ions or solute from the electrical environment. The procedure to create salt bridges can be found online from Warner Instruments [Warner Instruments; Vol. 2014] and involves three steps: 1) formation of bridges using glass capillary tubes; 2) preparing the agar; 3) loading the bridges with agar and 4) storing the bridges for later use. The agar salt bridges were disposed of after single usage for each BLM experiment performed to avoid contamination. Agar $(2 \%, 20 \mathrm{mg} / \mathrm{mL}$ in $1 \mathrm{M} \mathrm{KCl})$ salt bridges were used to transfer the signal.

Formation of Planar Lipid Bilayer. DOPE (1, 2-di-(9Z-octadecenoyl)-sn-glycero3-phosphoethanolamine), PS (L- $\alpha$-phosphatidylserine), and POPC (1-hexadecanoyl-2-(9Zoctadecenoyl)-sn-glycero-3-phosphocholine) lipids at a concentration of $10 \mathrm{mg} / \mathrm{mL}$ were prepared in chloroform from Avanti Polar Lipids (Alabaster, Al) and were combined in 5:3:2 $(\mathrm{w} / \mathrm{w})$ mixture and then dispersed in $4 \mathrm{ml}$ glass vials. All the vials containing the lipid solution were wrapped with parafilm and stored in a freezer at $-20^{\circ} \mathrm{C}$.

Before each experiment, a single vial containing the prepared lipid solution was continuously air dried under a stream of argon for 30 minutes to remove chloroform and then dispersed in decane to reach the a final concentration of $50 \mathrm{mg} / \mathrm{mL}$. The planar lipid bilayer (BLM) was prepared by the "painting method" by applying the lipid solution in decane over an aperture with a diameter of $\sim 200 \mu \mathrm{m}$ in a Delrin cup (Warner Instruments) while the cis and trans chambers are filled symmetrically with various electrolyte solutions depending on the fluorescence probe. Before bilayer formation, it is an option to pretreat these apertures dry, without buffer solution present, with a droplet of $50 \mathrm{mg} / \mathrm{mL}$ lipids in decane.

Membrane formation is easier and more consistent without pretreating except for the reversal potential probe. Electrodes of $\mathrm{Ag} / \mathrm{AgCl}$ were used to impose voltages and measure currents across the membrane. Membrane formation was monitored by measuring membrane capacitance. For each experiment, a membrane capacitance over $110 \mathrm{pF}$ can ensure good stability of the bilayer membrane for an aperture size of $200 \mu \mathrm{m}$. The buffer solution was allowed to continuously stir for 5 minutes using a stir plate (SPIN-2, Warner Instruments) before the addition of a solution containing channel forming compound in the cis chamber. A moderate 
voltage from $-100 \mathrm{mV}$ to $100 \mathrm{mV}$ was applied for the BLM single channel studies. A higher voltage could lead to higher possibility of membrane rupture. BLM single channel studies do not require high concentration of channel forming compounds. For macrocycles 2, a final concentration between $0.5 \mu \mathrm{M}$ was sufficient to obtain well-defined single channel signal.

Potassium $\left(\mathrm{K}^{+}\right)$Conductance of Macrocycles 2 via BLM Recording. The transmembrane conductivity of the $\mathrm{K}^{+}$ion in the presence of macrocycle $\mathbf{2}-\mathbf{H}$ and $\mathbf{2}-\mathbf{N H}_{2}$ was investigated with BLM methods. Solutions of $0.5 \mathrm{M} \mathrm{KCl}$ were present in both the cis and trans chambers. The strength of the applied electric field across the membrane was varied (-75 mV to $75 \mathrm{mV})$ and the current fluctuation was monitored in the presence of $\mathbf{2}-\mathbf{H}$ and $\mathbf{2}-\mathbf{N H}_{2}$ at $0.5 \mu \mathrm{M}$. Data were amplified (BC-525D Bilayer Amplifier; Warner Instruments, Hamden, CT), digitized (DigiData 1322A; Molecular Devices, Sunnyvale, CA), Data acquisition and process was carried via pCLAMP 9.2 (Molecular Devices, Sunnyvale, CA)

Reversal Potential Experiment of Macrocycle 2-H \& 2-NH2. An ion gradient is applied across the membrane by doubling the $\mathrm{KCl}$ concentration on the cis chamber (cis: $1 \mathrm{M} \mathrm{KCl}$; trans: $0.5 \mathrm{M} \mathrm{KCl}$ ). At zero potential, cation species can pass through the membrane driven by the ion gradient, resulting in a positive current shown on the I/V diagram on the right. Reversal potential represents the critical potential needed to cancel the cation flow driven by the ion gradient, resulting in a negative value of the $\mathrm{x}$ intercept of the $\mathrm{I} / \mathrm{V}$ plot on the right. I/V diagram obtained by reversal potential experiment with a variety of potentials $(-50 \mathrm{mV}$ to $50 \mathrm{mV})$ applied for a cation selective channel. Data were amplified (BC-525D Bilayer Amplifier; Warner Instruments, Hamden, CT), digitized (DigiData 1322A; Molecular Devices, Sunnyvale, CA), Data acquisition and process was carried via pCLAMP 9.2 (Molecular Devices, Sunnyvale, CA) 